\title{
PACIFIC OCEAN AND CENOZOIC EVOLUTION OF CLIMATE
}

\author{
Mitchell Lyle, ${ }^{1}$ John Barron, ${ }^{2}$ Timothy J. Bralower, ${ }^{3}$ Matthew Huber, ${ }^{4}$ Annette Olivarez Lyle, ${ }^{1}$ \\ A. Christina Ravelo, ${ }^{5}$ David K. Rea, ${ }^{6}$ and Paul A. Wilson ${ }^{7}$ \\ Received 2 November 2005; revised 17 April 2006; accepted 10 August 2006; published 19 April 2008.
}

[1] The Pacific Ocean has played a major role in climate evolution throughout the Cenozoic $(65-0 \mathrm{Ma})$. It is a fundamental component of global heat transport and circulation, the dominant locus of primary productivity, and, consequently, the largest reservoir for carbon exchange between the oceans and the atmosphere. A satisfactory understanding of the Cenozoic evolutionary history of the Pacific and its impact on global climate is currently datalimited. Nevertheless, the large dynamic range of Cenozoic conditions sets the stage to greatly expand our understanding of global climate and biogeochemical cycles. Past Earth "experiments" are particularly useful to understand interactions between climate and geosystems under different greenhouse gas loads. We highlight in this review four important problems in which the Pacific played a major role: the effect of changing geographic boundary conditions on ocean circulation; interactions between the carbon cycle and climate; the Pacific Ocean's influence on North American climate and its water cycle; and the gradual evolution of climate systems.

Citation: Lyle, M., J. Barron, T. J. Bralower, M. Huber, A. Olivarez Lyle, A. C. Ravelo, D. K. Rea, and P. A. Wilson (2008), Pacific Ocean and Cenozoic evolution of climate, Rev. Geophys., 46, RG2002, doi:10.1029/2005RG000190.

\section{INTRODUCTION}

[2] Understanding Earth's climate history requires an understanding of the modern and ancient Pacific Ocean. The modern Pacific Ocean is the largest ocean basin, occupying slightly more than $50 \%$ of global ocean surface area and a third of the Earth's surface. The Pacific has shrunk in size by plate tectonic movement of the continents since the beginning of the Cenozoic, $65 \mathrm{Ma}$ (million years ago), when it accounted for almost $65 \%$ of total ocean area. Pacific Ocean circulation, temperature, primary productivity, and chemistry have changed radically over the course of the Cenozoic. During that same period of time the Earth cooled from the extreme warmth of the early Cenozoic to the glacial conditions of the modern world. Studies of the Cenozoic Pacific provide an excellent opportunity to under-

\footnotetext{
${ }^{1}$ Department of Oceanography, Texas A \& M University, College Station, Texas, USA.

${ }^{2}$ U.S. Geological Survey, Menlo Park, California, USA.

${ }^{3}$ Department of Geosciences, Pennsylvania State University, College Park, Pennsylvania, USA.

${ }^{4}$ Department of Earth and Atmospheric Sciences, Purdue University, West Lafayette, Indiana, USA.

${ }^{5}$ Department of Ocean Sciences, University of California, Santa Cruz, California, USA.

${ }^{6}$ Department of Geological Sciences, University of Michigan, Ann Arbor, Michigan, USA.

${ }^{7}$ Southampton Oceanography Centre, Southampton, UK.
}

stand how different Earth systems interact and respond to changing boundary conditions of global temperature and geography.

[3] To study the ancient Pacific Ocean, we must use its sediments, which are the only existing record of the physical, biological, and chemical processes that either caused or responded to the climate changes at the Earth's surface. Sedimentary records spanning major parts of the Cenozoic allow researchers to study the long-term components of important biogeochemical cycles that can be accessed in no other way. For example, from these records we now know that the major element composition of the oceans has changed significantly over the Cenozoic, indicating that strong changes occurred in the relative proportion of continental weathering versus subseafloor alteration [Delaney and Boyle, 1988; Wilkinson and Algeo, 1989; Hardie, 1996; Lowenstein et al., 2001; Horita et al., 2002; Lowenstein et al., 2003]. Climate conditions that were markedly different from each other were stable for periods exceeding 10 million years, some under much higher atmospheric $\mathrm{CO}_{2}$ levels. That these conditions lasted for so long argues that geosystems can be organized in more than one stable configuration to maintain a climate state; in other words, Pleistocene and Holocene climate are but a small part of Earth's climate spectrum.

[4] In this article we explore several major changes within and around the Pacific in order to highlight the role 
of paleoceanography in understanding major Earth system processes. For example, significant changes in carbon fluxes have been hypothesized to result in major changes in heat storage in the Earth's atmosphere and oceans. Similarly, temperature should be an important factor in organic carbon degradation and should regulate the burial of reduced carbon. Elucidating accurate descriptions of previous climate states throughout the Cenozoic can help us to understand and perhaps to forecast the consequences of the current anthropogenic greenhouse gas transient and to better quantify other feedbacks among different Earth systems. The Pacific Ocean is especially important for understanding global biogeochemical cycles because of its major role in ocean primary productivity and its large capacity for nutrient storage.

[5] The Pacific is also the world's largest reservoir of heat and water, such that shifts in Pacific temperature and rainfall patterns can be expected to drive regional climate shifts around the globe through a variety of teleconnections, the phenomenon where one area's climate influences the climate and weather patterns in a distant region. The best modern example of a teleconnection is the El NiñoSouthern Oscillation (ENSO) pattern, which originates in the Pacific but has global influence. Documenting the changes in the temperature and rainfall in the Pacific is especially important for understanding climate change in the Americas because the climate regimes of the Americas are associated with circulation and temperature distribution in the Pacific Ocean.

[6] We also highlight the lack of regional paleoceanographic data, even though such data are potentially available and in many cases merely require a systematic study of existing sediment cores already archived by the Integrated Ocean Drilling Program (IODP). Because regional data are often missing, paleoceanographers have emphasized the dominant global signal. Global manifestations of the evolution of Earth's climate and biogeochemical cycles are critical because they show the magnitude of the integrated response of Earth systems compared to relatively small changes in boundary conditions. However, both climate and geosystems that affect climate are fundamentally geographic in nature. Regional data are critical to understand how and why both terrestrial and marine systems change.

[7] The changing tectonic configuration of ocean basins and landmasses also impacts global climate. The Pacific Ocean during the Paleogene (between 65 and $23 \mathrm{Ma}$ ) was physiographically connected to the other oceans differently than the modern Pacific. These tectonic changes that constrict or augment the flow rate and direction of water masses between basins provide natural experiments that may help us to understand the effect of changing physiographic boundary conditions upon the climate state. Before $25 \mathrm{Ma}$ the major water passages from the Pacific to the Indian and Atlantic oceans were found within the tropics rather than in the high latitudes of the Southern Ocean. The tropical ocean gateway between the Atlantic and Pacific persisted throughout the Cenozoic and did not disappear completely until circa 3 Ma [Duque-Caro, 1990; Coates and Obando, 1996].
The tropical Indonesian Passage between the Indian and Pacific oceans is today severely restricted but not yet closed. As tropical passages were closing, the Southern Ocean passages began opening in the middle Eocene (circa $50 \mathrm{Ma}$ ) and opened deeply at the end of the Eocene and within the Oligocene (34-23 Ma) to effect a net change in the flow of surface and deep waters of the oceans.

[8] Tectonic forces also created and moved mountains that interact directly with the atmosphere and the prevailing winds. Mountain belts around the Pacific, which steer winds and define important loci of air-sea interactions, were markedly different in height and position at the beginning of the Cenozoic [Harrison et al., 1998; Chase et al., 1998]. Tectonic reorganizations by themselves were not the dominant cause of the warm climates of the Cenozoic, but they affected climate by controlling the processes that control ocean circulation, transport or trap solar heat, and maintain greenhouse gas levels in the atmosphere.

[9] We will highlight three periods within the Cenozoic that represent examples of unique climate states of the Earth: the warm Eocene greenhouse world, which is associated with elevated atmospheric $\mathrm{CO}_{2}$; the Miocene, when globally warm temperatures persisted but without the aid of high atmospheric $\mathrm{CO}_{2}$ concentrations; and the Pliocene, a warm period that gradually cooled to become the Pleistocene ice ages. The climate of the early Cenozoic (Paleocene and Eocene, 65-33.7 Ma) was warm, atmospheric $\mathrm{CO}_{2}$ was high, and burial of both carbonate and organic carbon were minimal in the pelagic Pacific. Although there was substantial climate variability during the early Cenozoic, the climate system was stable in the sense that when it was perturbed either toward warmer or cooler conditions, negative feedbacks brought conditions back to a warm mean. New work in the Pacific implies that the carbon cycle was strongly involved in these feedbacks: High rates of carbonate sediment burial coincided with cool events, and carbonate dissolution accompanied warming conditions. The feedbacks that operated to maintain a warm Earth apparently failed during the Eocene-Oligocene transition (34-33 Ma). This time marks an abrupt transition from a warm, greenhouse Earth to a time when permanent ice first covered Antarctica. Synchronous with the ice buildup, the largest global Cenozoic shift in the carbonate compensation depth (CCD) within the Cenozoic era is recorded. The CCD is defined as the depth of the seafloor where the depth-dependent change in solubility causes all particulate carbonate produced in ocean waters to be dissolved before burial. New data show that the CCD plummeted $1200 \mathrm{~m}$ in the Pacific Ocean in only 300,000 years [Coxall et al., 2005].

[10] The warm climate of the early and middle Miocene ( $\sim 23$ to $12 \mathrm{Ma}$ ) apparently was achieved without the aid of high atmospheric $\mathrm{CO}_{2}$ concentrations [Pagani et al., 1999a]. The cooling that occurred through the middle and late Miocene involved both the permanent development of the Antarctic ice cap and a global weakening of the water cycle. For example, global aridification caused replacement of forests by grasslands in much of the temperate regions between 8 and $6 \mathrm{Ma}$ [Cerling et al., 1997; Pagani et al., 


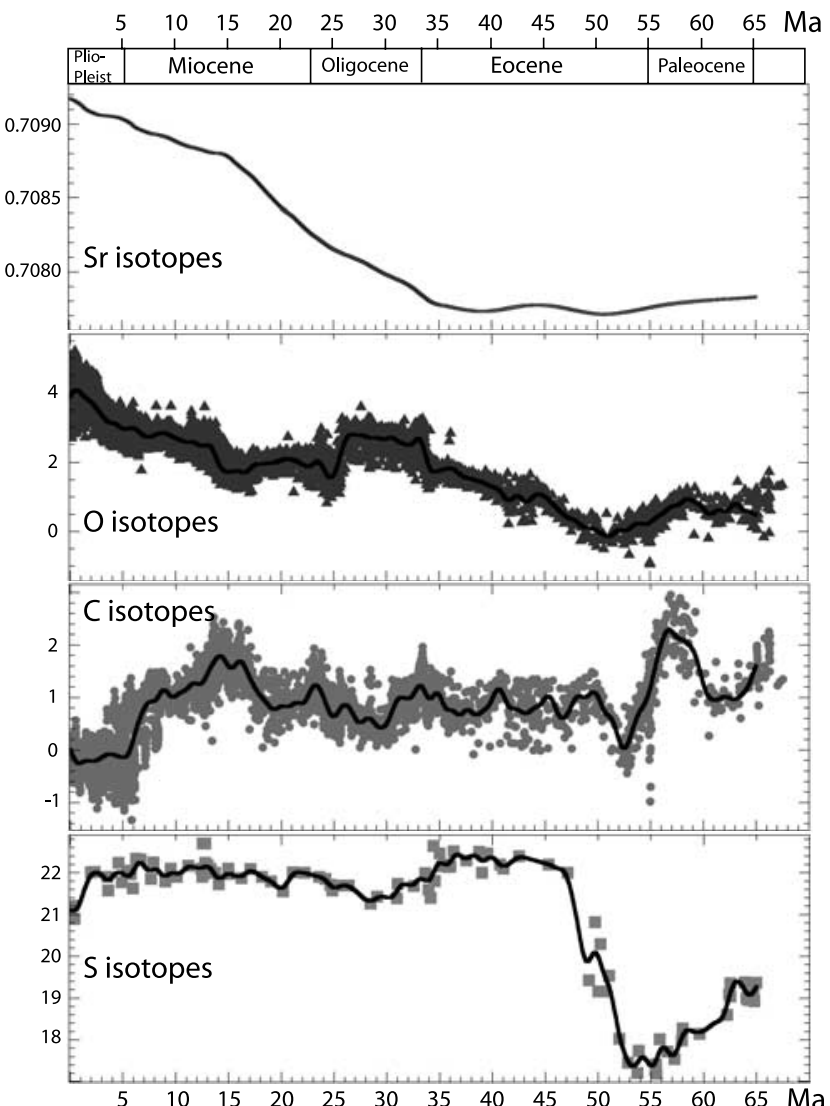

Figure 1. Cenozoic time series of important isotope systems and major elements in the oceans, also shown are the ages of the Cenozoic epochs. Oxygen and carbon isotopes are from Zachos et al. [2001a], sulfur isotopes are from Paytan et al. [1998], and strontium isotopes are from McArthur et al. [2001].

1999a], and the Pacific played an important role in the spectacular changes in the global water cycle characteristic of the late Miocene ( $\sim 11$ to $5 \mathrm{Ma}$ ), as shown by the drying of the North American West and the loss of western North American deciduous forests. The Miocene provides an opportunity to study how the water cycle contributes to, and is affected by, global warming.

[11] The Pliocene $(5.3-1.8 \mathrm{Ma})$ is the best documented warm interval of Earth's history, but it is not a time of extreme warmth, compared to the rest of the Cenozoic. Climate change during the Pliocene exhibits both gradual trends and periods of rapid change. Gradual change occurred until 2.5 Ma, when Northern Hemisphere glaciers abruptly appeared and the Alaska Gyre water masses abruptly cooled. The Pliocene exhibited modest changes in greenhouse gases as well as modest changes in mountain height and ocean water exchange through gateways. Fundamental questions remain unanswered despite numerous relatively detailed studies of the Pliocene. What were the nonlinear regional interactions that fed back into global climate? What thresholds caused the shift to the glacial conditions that have persisted for the last 2 million years of Earth history?
[12] We begin this survey with a brief discussion of the changes in Earth climate over the last 65 million years, and we provide a summary of what is known about the configuration of mountains and oceans at the critical times that we discuss. Unfortunately, we cannot conduct controlled "Earth experiments" as we would conduct laboratory experiments. Multiple variables likely changed at the same time such that cause and effect cannot be readily discerned. nor can the "experiment" be repeated. The best approach for conducting such hypothetical experiments is through the use of modeling techniques. As modeling becomes more sophisticated, researchers can separate with greater confidence the direct changes caused by different ocean and mountain configurations from feedbacks caused by other Earth system processes.

[13] Figure 1 provides a summary of the ages of the different geologic epochs. Geologists also divide the Cenozoic era into two periods, the Paleogene (Paleocene, Eocene, and Oligocene epochs) and the Neogene (Miocene, Pliocene, Pleistocene, and Holocene epochs). Ages for the earlier part of the timescale, prior to $20 \mathrm{Ma}$, are still being revised [e.g., Pälike et al., 2006]. Nevertheless, the different age models are becoming consistent, and we expect that the ages of important events for all the Cenozoic should be well constrained over the next few years.

\section{SUMMARY OF CENOZOIC PACIFIC HISTORY, 65 TO 0 MILLION YEARS AGO}

[14] The range of behavior exhibited by almost any Earth system process typically increases toward greater extremes as the time frame is expanded. For example, the temperature range at any location on any given day (time frame $24 \mathrm{~h}$ ) is universally smaller than the annual temperature range. Therefore we can never know the natural temperature variation by limiting observations to relatively short time periods (e.g., days). Conversely, expanding observations over larger time frames can be used to study processes under extreme conditions relative to the present. Our challenge as paleoceanographers is to learn about the range, excursion, or natural boundary of all of the key physical variables and processes intimately linked with climate over the course of Earth's history. Large excursions accessible in deep time can thus provide end-members to study linkages between geosystems.

[15] For example, throughout the Cenozoic at least, Earth's energy budget was probably within a few percent of today's value in terms of the amount of solar energy entering the top of the atmosphere [e.g., Laskar et al., 2004; Pälike et al., 2004], and so we can treat this variable as fixed within certain limits for the Cenozoic. Yet the Earth was able to maintain a global temperature more than $10^{\circ} \mathrm{C}$ warmer than today for millions of years during the Paleogene. Thus we conclude that the capacity of the Earth to absorb and trap energy has varied significantly over this time frame.

[16] Unfortunately, our studies of the deep past as relevant to climate change are strongly hampered by the lack of 
clear description of the boundary conditions, e.g., the height and location of major mountains, the depth and extent of major ocean gateways, and location and size of ice caps. Other geographic features, like seafloor topography, also need to be understood, at least at a statistical level, in order to hindcast important processes such as thermohaline mixing [Munk and Wunsch, 1998; Egbert and Ray, 2000].

[17] Studies of deep time are also hampered by a general lack of data. Appropriate sedimentary sections must first be preserved. Then they must be located and sampled. A proper timescale must be established for the sedimentary sections so that the geographic fingerprint of events can be studied. Finally, large numbers of samples need to be analyzed to obtain high-resolution records in order to resolve climatic variability caused by orbitally forced changes in insolation.

[18] Our summary of Cenozoic history focuses on basic patterns and events that affected the Earth's heat balance rather than on all the changes that are thought to have occurred. A good outline of Cenozoic history is given by Zachos et al. [2001a] and should be a primary reference for anyone interested in Cenozoic paleoclimate. Hay et al. [2002] provide an excellent examination of the drift in Cenozoic climate from warm to cool conditions, and Crowley and Burke [1998] examine the role of changing tectonic boundary conditions.

[19] Earth experienced a generally warm climate, termed the "greenhouse world" [e.g., Miller et al., 1987], which lasted from the beginning of the Cenozoic until just after the end of the Eocene (Eocene-Oligocene boundary, now dated at $33.7 \mathrm{Ma}$ ). Abyssal water temperatures were about $10^{\circ}$ warmer than modern bottom water in the early Eocene [Zachos et al., 2001a], while mean annual temperatures in northern Greenland were above freezing [Fricke and Wing, 2004].

[20] At the Eocene-Oligocene boundary (33.7 Ma), seawater became significantly enriched in the oxygen isotope ${ }^{18} \mathrm{O}$ relative to ${ }^{16} \mathrm{O}$. This "heavy" marine oxygen isotope excursion, known as Oi-1, coincides with major expansion of the Antarctic ice cap and the beginning of the "icehouse world" that has characterized much of the rest of the Cenozoic [Miller et al., 1987; Zachos et al., 2001a; Coxall et al., 2005]. Ice caps preferentially trap the light stable isotope of oxygen, so these events mark major changes in the cryosphere mass. The Oi-1 glacial interval reached its maximum at 33.6 Ma [Coxall et al., 2005; Pälike et al., 2005] as global climate cooled abruptly and rapidly. Following roughly 10 million years of generally cool conditions, the climate gradually warmed and reached another warm maximum at circa $15 \mathrm{Ma}$ (beginning of the middle Miocene). Cooling that eventually led to the Pleistocene ice ages began with another major Antarctic cooling event at $14 \mathrm{Ma}$, marked by another abrupt change in marine oxygen isotopes [Flower and Kennett, 1993, 1994].

[21] Between the onset of large continental ice sheets on Antarctica at $33.6 \mathrm{Ma}$ and the development of Northern Hemisphere ice sheets at $2.5 \mathrm{Ma}$, global temperatures were generally warm compared to the Holocene but less warm than the early Cenozoic. By $25 \mathrm{Ma}$, atmospheric $\mathrm{CO}_{2}$ levels declined to reach near-modern levels [Pagani et al., 2005; Royer, 2006], yet warm conditions relative to the Pleistocene persisted.

[22] The lack of high atmospheric $\mathrm{CO}_{2}$ concentration since about $25 \mathrm{Ma}$, despite warm global temperatures during much of the Miocene, is a surprising result of recent paleoclimate proxy studies and is supported by results of studies that have utilized three different methods to estimate atmospheric $\mathrm{CO}_{2}$. The first method is based on estimates of ocean $\mathrm{pH}$ derived from the boron isotope composition of planktic foraminferal calcite and assumes other aspects of carbon chemistry are known [Pearson and Palmer, 2000]. Atmospheric $\mathrm{CO}_{2}$ concentrations are also estimated by terrestrial plant leaf stomatal indices [Royer, 2002]. Finally, $\mathrm{CO}_{2}$ can be estimated by carbon isotope shifts of a phytoplankton biomarker provided that a number of conditions are met, including that it grows in water that experiences complete nutrient utilization [Pagani et al., 1999a, 1999b].

[23] It is important to bear in mind that the range of atmospheric $\mathrm{CO}_{2}$ levels reconstructed for the Cenozoic is large in comparison with the range exhibited over the Holocene or Pleistocene. The beginning of the Cenozoic was marked by atmospheric $\mathrm{CO}_{2}$ concentrations estimated at 4-5 times higher than modern levels, contributing to early Cenozoic greenhouse conditions [Pearson and Palmer, 2000; Demicco et al., 2003; Royer et al., 2004; Royer, 2006]. Sometime near the end of the Eocene or beginning of the Oligocene the atmospheric $\mathrm{CO}_{2}$ content began to drop to near-modern levels [Pagani et al., 2005], which may have been a major driver for the greenhouse-icehouse transition during the Eocene-Oligocene transition.

[24] High- $\mathrm{CO}_{2}$ conditions lasted for millions of years and represent a different organization of Earth system processes than those that have existed in the Pleistocene. Because evidence suggests that atmospheric $\mathrm{CO}_{2}$ and methane concentrations have varied by large factors over the Cenozoic, we can view the time periods, each with different levels of greenhouse gases and different global temperatures, as natural experiments to study the relationships between greenhouse gases and climate. Important transient events, such as the relatively brief but extreme warming event known as the Paleocene-Eocene thermal maximum (PETM) at 55 Ma [Kennett and Stott, 1991; Dickens et al., 1995; Norris and Röhl, 1999; Thomas et al., 2002; Thomas, 2003; Zachos et al., 2003], provide opportunities to study how the Earth responds to very large but temporary changes in greenhouse gas concentrations. Finally, carbon cycle and climate responses to the periodic changes in insolation caused by orbital variations [Laskar et al., 2004; Pälike et al., 2006] provide a way to monitor climate sensitivity under altered base conditions.

\section{EVOLUTION OF CENOZOIC GEOSYSTEMS}

\subsection{Tools of the Trade}

[25] Interacting Earth systems that affect climate have clearly evolved over the Cenozoic, as revealed by a variety 
of geochemical records (Figure 1) (O and $\mathrm{C}$ isotopes [Zachos et al., 2001a], S isotopes [Paytan et al., 1998; Kurtz et al., 2003], and Sr isotopes [McArthur et al., 2001]). Basic geochemical records of Cenozoic global changes have now been compiled, but they lack unambiguous interpretations because all isotopic and major element data that record the paleocomposition of seawater are affected by more than one process or physical state. For example, oxygen isotopes record both temperature and ice volume. Strontium isotopes record both the rate of weathering and the provenance of the weathered material, and sulfur isotopes change because of continental weathering, marine pyrite burial, and submarine hydrothermal activity.

\subsection{Oxygen Isotopes: Climate and Cryosphere}

[26] A perfect example of a mixed signal recorded by isotopes in the sedimentary record is the global oxygen isotope signal of marine carbonates [Zachos et al., 2001a; Miller et al., 2005], because oxygen isotopes in carbonates record both the local temperature of seawater where the carbonate was formed and the mean isotopic composition of seawater, a measure of the amount of water that is removed from the oceans and stored as ice [Emiliani and Shackleton, 1974]. The greatest challenge in interpreting the variations in the marine oxygen isotope signal arises because the magnitude of variation caused by ice formation/continental storage of evaporated seawater is similar to that caused by typical temperature changes in seawater where organisms live $\left(\sim 0.3 \%\right.$ o change in $\delta^{18} \mathrm{O}$ per degree centigrade change of temperature versus $\sim 0.1 \%$ change for every $10 \mathrm{~m}$ of global ocean water locked in ice caps).

\subsection{Paleotemperature Estimates}

[27] This ambiguity in interpreting the oxygen isotope signal has required independent estimates of both ocean temperatures [e.g., Lear et al., 2000] and ice volume, primarily via sea level changes [Miller et al., 1998; Pekar et al., 2002; Miller et al., 2005]. A useful paleothermometer is the $\mathrm{Mg} / \mathrm{Ca}$ ratio of foraminiferal shells [e.g., Lea et al., 2000; Lear et al., 2000]. When calibrated for the vital effects of the organism, the difference in the $\mathrm{Mg} / \mathrm{Ca}$ ratio from a baseline value (defined by the global ocean $\mathrm{Mg}$ and $\mathrm{Ca}$ concentration) is a function of temperature. Inferring the baseline composition of seawater is relatively straightforward because both $\mathrm{Mg}$ and $\mathrm{Ca}$ are major components of ocean salts and both have long residence times in the oceans ( $>1$ million years).

[28] For the Pleistocene the baseline oceanic $\mathrm{Mg} / \mathrm{Ca}$ has not changed. However, over the course of the Cenozoic the ratio has changed from near 1 at the base of the Cenozoic to about 5 today [Wilkinson and Algeo, 1989; Hardie, 1996; Lowenstein et al., 2001; Horita et al., 2002; Lowenstein et al., 2003; Demicco et al., 2005]. The $\mathrm{Mg} / \mathrm{Ca}$ thermometer thus needs to be corrected to account for changes in the weathering cycle in particular the relative rates of weathering from continental areas versus seafloor alteration at midocean ridges [Hardie, 1996]. The correction for the secular evolution of seawater composition is not trivial. Since both
$\mathrm{Mg}$ and $\mathrm{Ca}$ have long residence times in seawater, however, relative temperature changes over million-year time periods can be assessed assuming that the exponential form of the temperature calibration remains constant [Zachos et al., 2003].

[29] Other methods of temperature estimation exist, like alkenone biomarker thermometers [Brassell et al., 1986; Prahl and Wakeham, 1987; Marlowe et al., 1990; Prahl et al., 2000; Rosell-Melé et al., 2001], but some of these methods are not yet calibrated for older strata of the Cenozoic. A novel biomarker thermometer, $\mathrm{TEX}_{86}$, is based on structural changes in crenarcheote membrane lipids preserved in sediments. The $\mathrm{TEX}_{86}$ thermometer has recently been used for Cretaceous sediments [Schouten et al., 2002; Jenkyns et al., 2004] and is being applied with promising results in the early Cenozoic [Sluijs et al., 2006; Brinkhuis et al., 2006] and is likely to produce major insights in the future when combined with other methods.

\subsection{Sr Isotopes and the Weathering Cycle}

[30] The Sr cycle convolves continental weathering and seafloor hydrothermal alteration [DePaolo and Ingram, 1985; Palmer and Elderfield, 1985; Hess et al., 1986] as well as the type of continental crust being weathered. The ocean crust is characterized by low ${ }^{87} \mathrm{Sr} /{ }^{86} \mathrm{Sr}(0.7035$ [Palmer and Edmond, 1989; Derry and France-Lanord, 1996a; Blum, 1998]), while continental ratios vary depending upon age. Old continental terranes have high ${ }^{87} \mathrm{Sr} /{ }^{86} \mathrm{Sr}$ relative to younger rocks. In addition, sedimentary carbonates are easily eroded and have ratios that reflect seawater at the time they were deposited, while metamorphosed carbonates can have ratios reset by mobilization of $\mathrm{Sr}$ during the metamorphic process [Quade et al., 1997]. Groundwater can also be a significant source of $\mathrm{Sr}$ to the oceans, with a distinctive ${ }^{87} \mathrm{Sr} /{ }^{86} \mathrm{Sr}$ ratio [Basu et al., 2001]. The $\mathrm{Sr}$ cycle is also linked to the production rate of carbonates, because $\mathrm{Sr}^{+2}$ readily substitutes for $\mathrm{Ca}^{+2}$ in the production of marine carbonates, which is a primary sink for the element from seawater. Changes in ${ }^{87} \mathrm{Sr} /{ }^{86} \mathrm{Sr}$ ratio of seawater thus measure a mixed signal of continental versus ocean weathering rates as well as a regional signal relying on the extent and rates that different terranes were weathered. The distinctive shape of the seawater ${ }^{87} \mathrm{Sr} /{ }^{86} \mathrm{Sr}$ curve is recorded by all marine carbonates and has been used as a coarse chronostratigraphy for the Phanerozoic [McArthur et al., 2001]. For an excellent review of $\mathrm{Sr}$ isotopes in seawater the reader is referred to Veizer [1989].

\subsection{Carbon and Sulfur Isotopes: Reservoirs Versus Changes in Carbon Cycling}

[31] Carbon and sulfur isotopes relate organic carbon burial, the redox state of the burial region, and the geochemistry of pore fluids [Shackleton, 1985; Derry and France-Lanord, 1996b; Paytan et al., 1998; Kurtz et al., 2003]. Biological fixation of carbon favors the light isotope ${ }^{12} \mathrm{C}$, so enhanced burial of organic carbon relative to its exhumation and weathering tends to make the surface carbon reservoir enriched in ${ }^{13} \mathrm{C}$ relative to ${ }^{12} \mathrm{C}$ (Figure 1). 
Carbonates exhibit only a small carbon isotope fractionation relative to the reservoir during their formation, so changes in carbonate exhumation and burial affect the size of the carbon reservoir (as well as the $\mathrm{Ca}$ content of the oceans) but have little effect on carbon isotopic ratio. Similarly, sulfur isotope fractionation occurs during reduction of $\mathrm{S}^{+6}$ (as $\mathrm{SO}_{4}$ ) to $\mathrm{S}^{2-}$ and fixation as pyrite. The oceans (and the pore waters of marine sediments) have high-sulfate contents, and microbes in the sediment utilize sulfate as an energy source under anoxic conditions. Consequently, the sulfur and carbon isotope systems are coupled where there is high biological productivity and burial of organic carbon, primarily along ocean margins, especially shelf-delta regions. Decoupling of the two systems occurs in the oceans where productivity is low or the burial rate of organic matter does not trigger sulfate reduction or when high rates of carbon fixation and burial occur in terrestrial swamps where waters have little or no sulfate [Kurtz et al., 2003]. Finally, sulfate reduction by microbial chemosynthesis at mid-ocean ridges will cause some dependence of sulfur isotopes upon the rate of ridge formation. On the basis of estimates of sulfate reduction at ridge crests [Alt, 1995] the mid-ocean ridges exchange about as much sulfur to the oceans from crustal alteration as is reduced from seawater flowing into the crust. Ocean ridge-derived sulfur is about $20 \%$ depleted with respect to seawater $\delta^{34} \mathrm{~S}$, and the modern exchange is about $15 \%$ of the global river flux. Significant changes in mid-ocean ridge production could thus also have some effect upon the sulfur isotope composition.

\section{PACIFIC OCEAN CIRCULATION IN THE CENOZOIC ERA}

[32] For the last 65 million years of Earth history, unlike earlier in the past, there exist marine sediments representative of the major oceanic provinces. It is therefore possible to study the oceans at a regional scale even near the base of the Cenozoic. Prior to $65 \mathrm{Ma}$ the preserved record is incomplete because subduction of ocean plates has recycled the sediments into the Earth. Prior to $150 \mathrm{Ma}$ all existing marine sediment records are on land, either buried within continental margins or exhumed by mountain building.

\subsection{Plate Tectonics and Ocean Reconstructions}

[33] Plate tectonic processes cause the ocean floor to move and continuously offset the sediment sections deposited upon them away from the surface oceanographic features they once were associated with. A classic example is the northward offset of the equatorial Pacific sediment bulge, originally formed at the equatorial divergence zone. The thick sediment pile is formed because most equatorial Pacific sediment is made of the remains of plankton and because there is a higher than average sedimentation of plankton tests within the equatorial upwelling zone (Figure 2) [Ewing et al., 1968; Hays et al., 1969; van Andel et al., 1975; Leinen, 1979; Mitchell, 1998; Mitchell et al., 2003; Moore et al., 2004].
[34] The northward offset of the locus of deposition was a major piece of evidence for plate tectonics [van Andel, 1974], and the rate of displacement of the central Pacific northward (about $0.25^{\circ}$ of latitude per million years) has prevented Paleogene equatorial sediments from becoming deeply buried. Because they have not suffered diagenesis associated with deep burial, it is possible to sample unconsolidated sediments of early Paleogene age and perform analyses similar to those performed on Pleistocene sediments in the equatorial Pacific.

[35] Errors associated with estimating the Pacific plate's movement during the Cenozoic creates uncertainty in the paleogeographic position where sediments were originally deposited [e.g., Pares and Moore, 2005]. Because the errors are cumulative, the paleogeographic location of older sediments is more poorly constrained than younger sediments, and continued refinement of plate tectonic movements is key to a better understanding of the evolution of the geosystems.

\subsection{Overview of Pacific Surface Circulation}

[36] Paleoceanographic changes in the Pacific were first identified in pioneering studies of sediments recovered by the Deep Sea Drilling Project (DSDP) [van Andel et al., 1975; Berger et al., 1981; Berger, 1982; Kennett, 1982] (see http://www.deepseadrilling.org/). Further understanding of Cenozoic ocean circulation and geosystem evolution is the direct result of continued drilling in the follow-up Ocean Drilling Program (ODP) (see http://www.odplegacy.org) and the new Integrated Ocean Drilling Program (see http:/iodp.tamu.edu/publications/) as well as continued study on archived sediment cores.

[37] Studying Cenozoic atmospheric circulation is more problematic because of the difficulty in finding evidence of paleowinds. Basic information on wind patterns and wind velocities can be derived from the deposition patterns of wind-blown dust that falls out in the oceans to become marine sediments [Rea, 1994]. Climate models have grown increasingly sophisticated over the last 20 years and allow a quantitative examination of possible atmospheric and ocean circulation, information that can be extracted from the same ocean sediments that are being studied to reconstruct ocean circulation history. These observations, combined with modeling based on reasonable geographic boundary conditions, help to flesh out how different geosystems affected global climate.

[38] Modeling studies indicate that the basic structure of Cenozoic ocean circulation, i.e., the geographic distribution of circulation gyres and upwelling systems, is similar to the modern structure (Figure 3) [Huber and Caballero, 2003; Huber et al., 2003, 2004]. One major change was the disappearance of Antarctic subpolar gyres once the South Pacific was joined to the Indian Ocean (Tasman Gateway) near the end of the Eocene and then to the Atlantic Ocean (Drake Passage) somewhat later [Huber et al., 2004]. Between 34 and $12 \mathrm{Ma}$, there was also a stronger interaction of the South Pacific subtropical gyre with that of the Indian Ocean. Northward movement of Australia opened a deep 


\section{Sediment Intervals}

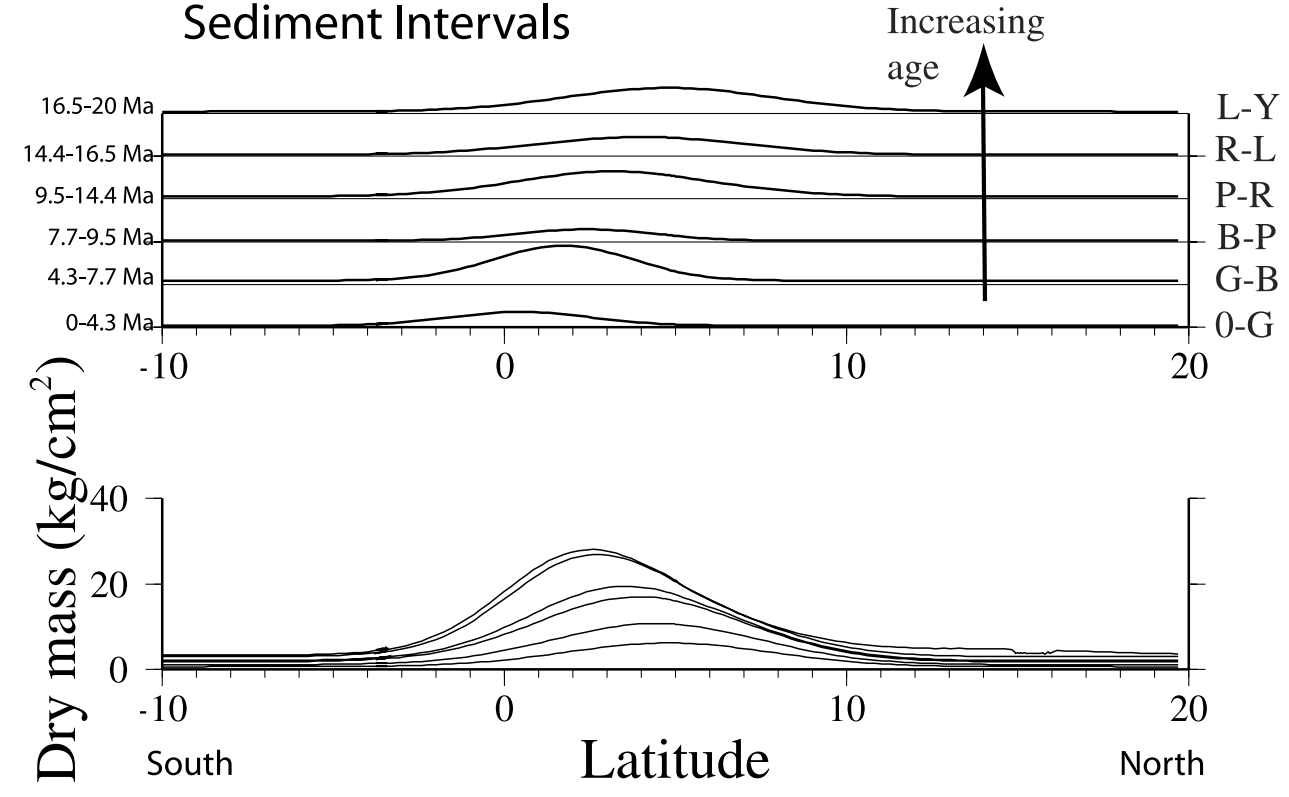

Figure 2. Northward movement of the equatorial sediment bulge in the Cenozoic [from Mitchell et al., 2003]. The latitudinal component of Pacific Plate movement is roughly $0.25^{\circ} \mathrm{C}$ per million years. This movement carries sediments originally deposited at the equator to the north and outside the regime of highest biogenic sediment deposition.

southern passage into the Pacific and eventually closed the tropical connection through Indonesia. When both passages were well open, the equatorward side of the South Pacific Gyre extended from South America to Africa, and return flow developed to the south of Australia [Stickley et al., 2004]. As the Indonesian Gateway has slowly closed, the tropical part of the gyre circulation has become more restricted.

[39] While the general circulation features of the Pacific Ocean are relatively predictable, the position of fronts and other boundaries of circulation regimes may have varied by more than $5^{\circ}$ in latitude over the Cenozoic [Huber and Sloan, 2001]. In addition, the average temperature of individual gyres has changed as the Earth has cooled [Huber et al., 2004; Huber and Nof, 2006]. Such changes in sea surface temperature (SST) and position of these ocean heat reservoirs are important to the atmospheric redistribution of heat and precipitation [Huber and Sloan, 1999; Sloan and Huber, 2001].

\subsection{Evolution of Thermohaline Circulation}

[40] The pathways of thermohaline circulation are dependent upon the geography of ocean basins and have changed over the Cenozoic. However, the changes in deepwater circulation are probably less drastic than some authors have speculated. Low SST gradients from equator to pole and warm high-latitude conditions [Zachos et al., 1994] had been interpreted as requiring sluggish deep circulation or the development of novel deep flow paths such as Warm Saline Deep Water (a low-latitude deepwater source similar to Mediterranean water [Brass et al., 1982]). However, the basic physics of thermohaline circulation does not require the rate of circulation to be dependent upon sea surface temperatures; instead, it depends upon the rate that buoyancy is added to the dense deep water through mixing [Munk and Wunsch, 1998]. In fact, Lyle [1997] and Nilsson et al. [2003] proposed that significantly higher than modern rates of thermohaline circulation may be achieved if mixing rates are correlated to the density gradients in the ocean [Lyle, 1997; Nilsson et al., 2003].

[41] Since a low-latitude source of high-salinity deep water was hypothesized as possible under conditions of extreme warmth, other researchers have tried to model it using realistic Eocene geography but found that low-latitude formation of deep water is difficult to reproduce [O'Connell et al., 1996; Bice and Marotzke, 2001; Huber and Sloan, 2001]. Nevertheless, oxygen isotope evidence for the existence of deep high-salinity water in the Southern Ocean on Maude Rise has been reported [Kennett and Stott, 1991]. While the modeling could not absolutely rule out large flows of warm saline deep water, it is clear that such flows occur under only special conditions, and deepwater formation in high latitudes is favored.

[42] In the modern oceans, deep waters are formed only in the highest latitudes of the North Atlantic (known as North Atlantic Deep Water) and in the Southern Ocean (Antarctic Bottom Water). The Greenland-Iceland-Norwegian (GIN) seas region is a favored source of Northern Hemisphere deepwater formation because the Atlantic is more saline than the Pacific and there is no equivalent high-latitude region in the Pacific $\left(\sim 70^{\circ} \mathrm{N}\right)$. The GIN seas did not exist in the early Cenozoic because the area was part of a subsiding continental rift system. The locus of deepwater formation in the Atlantic was found southward in the Eocene at around $50^{\circ} \mathrm{N}$. The Pacific, in contrast, still had regions north of $60^{\circ} \mathrm{N}$ where deep water could be formed. 


\section{eo4fc Annual Average in 3 layer}

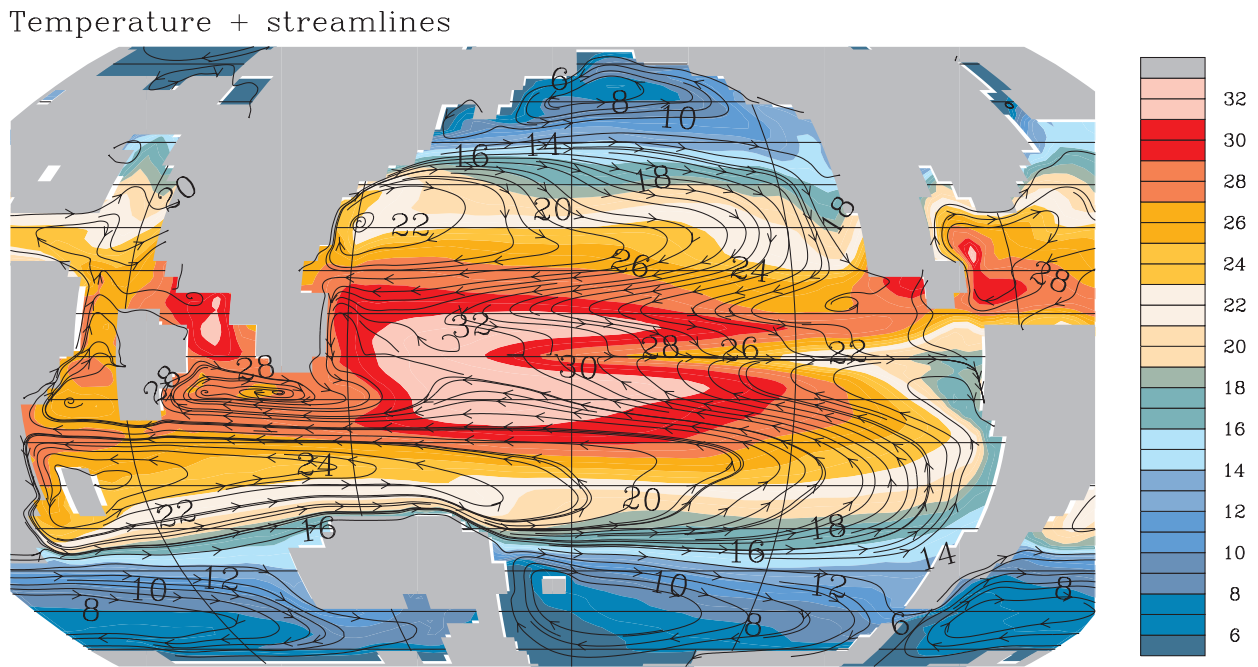

Estimated D180 of carbonate

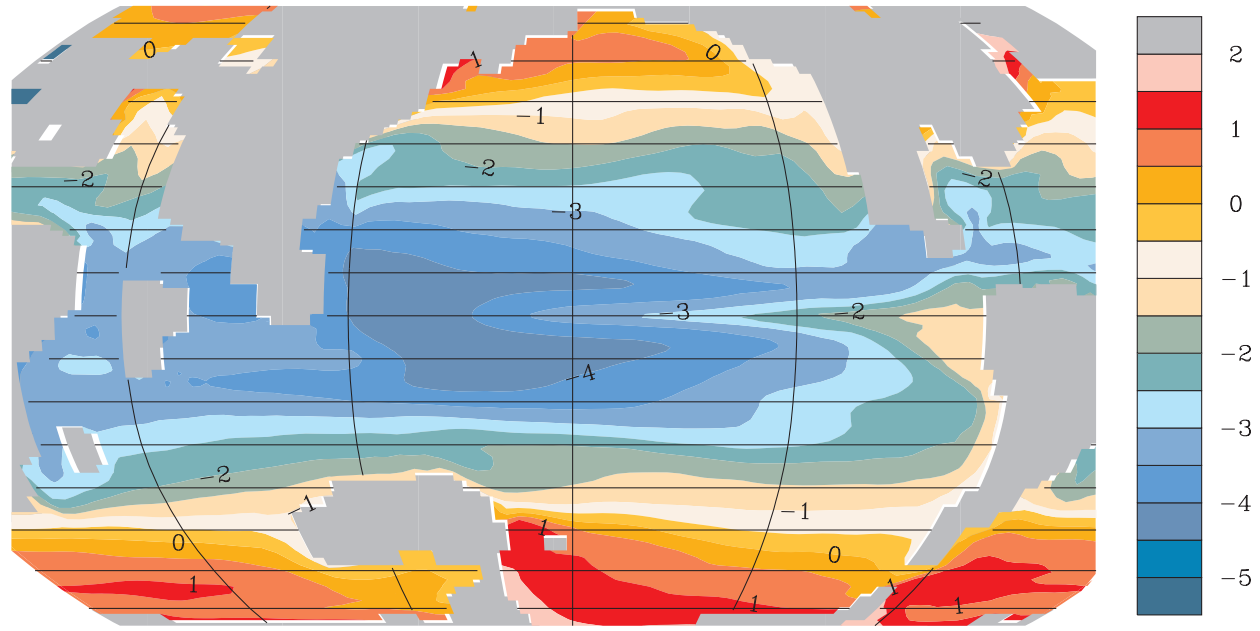

Figure 3. (top) Pacific Ocean circulation in early Eocene from a coupled atmosphere-ocean model described by Huber [2002]. Primary differences in the Pacific Ocean from the modern ocean are the existence of Southern Ocean high-latitude gyres and a stronger coupling between the Indian Ocean subtropical gyre and that of the South Pacific. (bottom) Estimated oxygen isotope composition of planktic foraminiferal calcite based upon sea surface temperature (SST) and precipitation minus evaporation (assumes zero continental ice volume).

[43] Modeling can suggest where deep waters might form, but the dependence of deepwater formation on local conditions [Bice et al., 1997; von der Heydt and Dijkstra, 2006] means that verification is necessary through comparisons between models and paleoceanographic tracers. Two such tracers now being used are the distribution of carbon isotopes [Kroopnick, 1985; Duplessy et al., 1988; Nuñes and Norris, 2006] and Nd isotopes [Thomas, 2004, 2005]. $\mathrm{Nd}$ weathered from the continents to different oceans has a different isotopic signature depending on age and $\mathrm{Sm}$ content of crustal rocks that are being weathered [Thomas, 2005]. These source signatures can be tracked by measuring $\mathrm{Nd}$ in ferromanganese oxides or fish teeth. For carbon isotopes, waters that form new deep water are relatively enriched in ${ }^{13} \mathrm{C}$ because they have a large component of nutrient-depleted surface water, where ${ }^{12} \mathrm{C}$ has already been preferentially extracted from the water mass to form the bodies of plankton [Kroopnick, 1985]. Different deepwater sources have different initial $\delta^{13} \mathrm{C}$ values, with modern North Atlantic deep waters being most enriched in ${ }^{13} \mathrm{C}$ [Kroopnick, 1985]. The rain of organic matter and degradation within deep waters slowly enriches the waters with ${ }^{12} \mathrm{C}$, so that older deep waters far from their source regions have a low $\delta^{13} \mathrm{C}$ value relative to the source region.

[44] The study of Cenozoic thermohaline circulation is relatively new. Information about sources depends to a certain extent on analogies to modern circulation paths and source regions. Within the Neogene, there is a growth in importance of a North Atlantic source region [Wright and Miller, 1996; Thomas and Via, 2007], partly regulated by the sill depth between the North Atlantic and the GreenlandIceland-Norwegian seas. Evidence exists for a North Pacific source region for much of the Paleocene and Eocene [Thomas, 2004] based on $\mathrm{Nd}$ isotopes in deep Pacific 
waters. In contrast, Nuñes and Norris [2006] use carbon isotopes to define a southern source for Paleocene and Eocene deep waters spreading into the Atlantic and Pacific, with a flow reversal occurring at the Paleocene-Eocene boundary. Van de Flierdt et al. [2004] note a decrease toward nonradiogenic Atlantic source Nd isotopes during the period 40-20 Ma in the Pacific, consistent with increased mixing of Atlantic source deep water into the Pacific via the opening of a Southern Ocean passageway. The Pacific Nd isotope data are also consistent with the proposed development of the North Atlantic thermohaline source in the early Oligocene [Via and Thomas, 2006] and increased flow of North Atlantic-sourced deep waters into the Pacific via other routes.

\section{BOUNDARIES: CENOZOIC MOUNTAIN CONFIGURATIONS}

\subsection{How has Geography Affected Climate?}

[45] Changes in continental position and height have frequently been invoked as causes of large-scale climate change in the Cenozoic, but the only real evidence has been a coincidence between a climate event and a tectonic event whose timing is poorly known. Furthermore, the linkage between tectonics and climate is driven by paleoelevation in the case of mountains and the cross-sectional area and depth in the case of ocean gateways, parameters that cannot be estimated from tectonic studies alone.

[46] Numerical modeling of the climate's response to tectonic changes in ocean or mountain configuration is beginning to produce physically realistic consequences [Ruddiman and Kutzbach, 1989; Mikolajewicz and Crowley, 1997; Toggweiler and Bjornsson, 2000; Hay et al., 2002; Sijp and England, 2004; Cane and Molnar, 2001]. Unfortunately, the timing of the tectonic events is poorly constrained relative to the timing of climate changes [e.g., Gupta et al., 2004], and understanding the coupling is complicated by the fact that tectonic change occurs over millions of years to exert a gradual change in atmospheric or oceanic circulation, while important climate thresholds happen within $10^{5}$ years, at least an order of magnitude faster.

[47] Circularities exist in some estimates of the climatic effects of mountain rise; that is, a change in climate has been used as evidence for the development of mountains (see discussion of Chase et al. [1998]). Furthermore, several potentially important tectonic events overlapped in time, such as mountain building and ocean gateway change (Figure 4). As we understand more about tectonic changes, we find that the interactions with other geosystems are more complex than originally envisioned [Hay et al., 2002]. The complexity underscores the need to better define the geographic boundary conditions to understand geosystems processes and how they interact.

[48] Mountain building can change air flow in the atmosphere, but tectonics can also affect the net atmospheric water balance by changing the proportion of oceans located within the tropics and subtropics versus higher latitudes
[Fawcett and Barron, 1998]. Reorganizations of ocean gateways change the geographic flow of heat, water, and salt to reorganize ocean heat transport and air-sea interactions. Increases in silicate weathering cycles caused by tectonic uplift change the alkalinity and major element content of the oceans to affect atmospheric $\mathrm{CO}_{2}$ levels, presumably on longer timescales [Raymo et al., 1988; Raymo and Ruddiman, 1992]. However, evidence for relatively stable greenhouse gas concentrations since the late Oligocene (circa $25 \mathrm{Ma}$ [Pagani et al., 2005]) suggest that some sort of chemostat for atmospheric $\mathrm{CO}_{2}$ must exist, as suggested by a set of geochemical models [Berner et al., 1983; Berner and Caldeira, 1997; Broecker and Sanyal, 1998]. The decline of atmospheric $\mathrm{CO}_{2}$ near the EoceneOligocene boundary [Pagani et al., 2005] implies that there are at least two stable set points for the chemostat over the Cenozoic.

\subsection{Mountain Building Around the Pacific Rim}

[49] The Cenozoic is characterized by the widespread development of young mountain ranges [Ruddiman and Kutzbach, 1989; Hay et al., 2002]. The mountain ranges that most affect the Pacific are the Himalaya, the Rocky Mountains in North America, and the Andes. Of these, the Andes are thought to play a minor role because of their geographic position, longitudinal narrowness, and relative stability [Jordan et al., 1997]. Even so, changes in convergence vectors between the Nazca plate and the South American plate have meant that the Andes have evolved significantly since the late Oligocene [Isacks, 1988; Hoorn et al., 1995; Hartley et al., 2000].

[50] Orogenies are complex, and estimating mountain height is difficult even when the age of the event is relatively well understood. The definitive Cenozoic history of topographic change in every one of the mountain belts mentioned above has yet to be written, and revisions of height estimates are likely to continue for some time. Many methods for estimating paleoelevation are, in turn, dependent on knowledge of the climate state, e.g., the isotopic and enthalpic methods [Forest et al., 1999; Garzione et al., 2000; Poage and Chamberlain, 2001], and hence the problems are interwoven, and solutions will be iterative.

\subsubsection{Himalaya Mountains}

[51] Modeling studies [e.g., Ruddiman and Kutzbach, 1989; Prell and Kutzbach, 1992; Rind et al., 1997] have clearly shown that the development of the Himalayan mountain range, and the associated Tibetan Plateau, should have strongly affected Pacific circulation and global climate. Uplift of the Himalayas should have intensified the North Pacific subtropical high-pressure and the Aleutian low-pressure cells. Important teleconnections are also found between the Himalayas and the Atlantic and Indian oceans circulation systems: strengthening of the North Atlantic high and warming of the North Atlantic region at the expense of the Pacific as the Himalaya rise [Rind et al., 1997]. Most attention has been paid to the strengthening of the Indian monsoon with Himalayan uplift [Prell and Kutzbach, 1997]. 


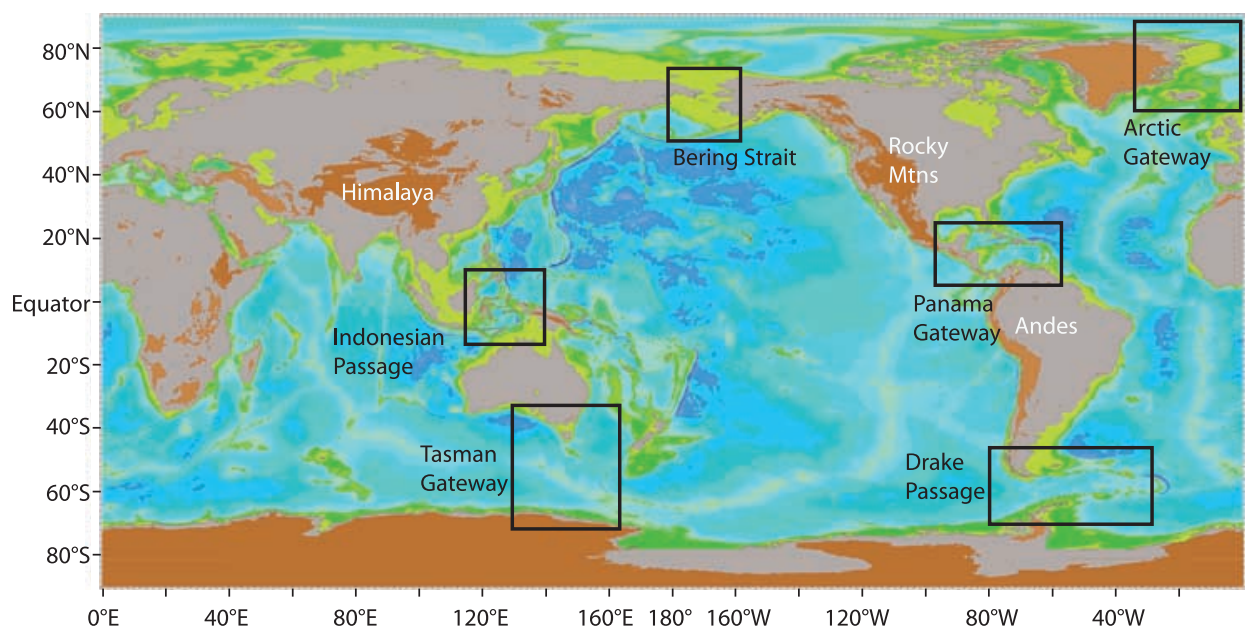

Figure 4. Mountain ranges and ocean gateways active in the Cenozoic on the modern Earth. The Himalayas reached modern elevation by about $15 \mathrm{Ma}$, while the Rockies have had high elevation since at least $50 \mathrm{Ma}$. The Tasman Gateway opened between 36 and $30 \mathrm{Ma}$, while the Drake Passage opened either at $30 \mathrm{Ma}$ or around $20 \mathrm{Ma}$. The Indonesian Passage is still open, but significant restrictions occurred at about $11 \mathrm{Ma}$. The Panama Gateway completed closure around $3 \mathrm{Ma}$. The Arctic Gateway (between the North Atlantic and the Arctic oceans) began opening about $55 \mathrm{Ma}$ but is still a restricted passage. Bering Strait began its existence about 5.3 Ma.

[52] The Himalayan uplift and climate change connection is the classic example of the linkage between mountains and climate, yet despite significant attention and study a consensus history of the growth of the Himalayas (and associated Tibetan Plateau) has been elusive [Molnar et al., 1993; Copeland, 1997; Harrison et al., 1998]. The tectonic collisions that produce mountains leave complex physical evidence of their timing and horizontal shortening, and the altitude of ancient mountains is hard to estimate because altitude is a balance between the crustal uplift rate versus the erosion rate. If erosion balances uplift, altitude remains constant even though a piece of crust below the erosion zone may be elevated by kilometers [Molnar et al., 1993; Harrison et al., 1998; Hay et al., 2002]. Mountain-building events are complex and long-lived, and revisions of the tectonic history often occur. Constraining the uplift history depends upon indirect methods and can lead to opposing conclusions. For example, the inferred uplift of the Himalaya between 10 and $8 \mathrm{Ma}$ is based upon a well-known global drying at this time [Cerling et al., 1997] and strengthening of the Indian monsoon [Prell et al., 1992]. Uplift of the magnitude of the Himalayas should produce a climate effect similar to what has been observed [Ruddiman and Prell, 1997]. However, without independent evidence, Ruddiman and Prell [1997] also noted that it is impossible to disprove the alternate hypothesis that climate change was caused by other factors but amplified by an already highstanding Himalayas [e.g., Gupta et al., 2004]. It is also possible that unroofing of the Tibetan Plateau was partially a response to climatic change [Molnar and England, 1990], leading to the intriguing conclusion that climate change can affect mountain height.
[53] The Himalayas have a long and active tectonic history. Collision and uplift began to the west, around Pakistan, as early as the Paleocene or early Eocene and progressed eastward as India rotated toward its modern position [Copeland, 1997; Uddin and Lundberg, 1998] (Figure 5). Prior to the collision of India with Asia, there is evidence that the Asian margin had a significant mountain range along the subduction zone between the two plates [Murphy et al., 1997; Harrison et al., 1998].

[54] Methods to estimate the altitude of the Himalayas have relied on indirect evidence such as paleobotany [Forest et al., 1999; Spicer et al., 2003], change in the oxygen isotope composition of environmental precipitates [Garzione et al., 2000; Rowley et al., 2001, Currie et al., 2005], and sedimentation rates in the foreland basins of the Indus, to the south of the Himalayas [Copeland, 1997], and Bengal Fans [Uddin and Lundberg, 1998]. Estimates of paleoaltitude are thus likely to be revised further as we better understand how the climate has changed, independent of the changes in mountain height.

[55] Our preferred model for Himalayan uplift is that a subduction-related mountain range existed at the present position of the Himalaya in the Cretaceous and Paleocene, possibly being more than $3 \mathrm{~km}$ high but relatively narrow. Collisional mountains began to form in the west part of the Himalayas in the early Eocene, but much of the crustal shortening was taken up by crustal escape mechanisms [Copeland, 1997; Harrison et al., 1998]. By about $30 \mathrm{Ma}$ the average elevation of the Himalayas was roughly $3 \mathrm{~km}$ [Harrison et al., 1998]. A period of rapid elevation gain appears to have occurred in the early Miocene between 24 and $17 \mathrm{Ma}$ [Harrison et al., 1998], and estimated elevation based upon oxygen isotopes and paleobotany suggests 


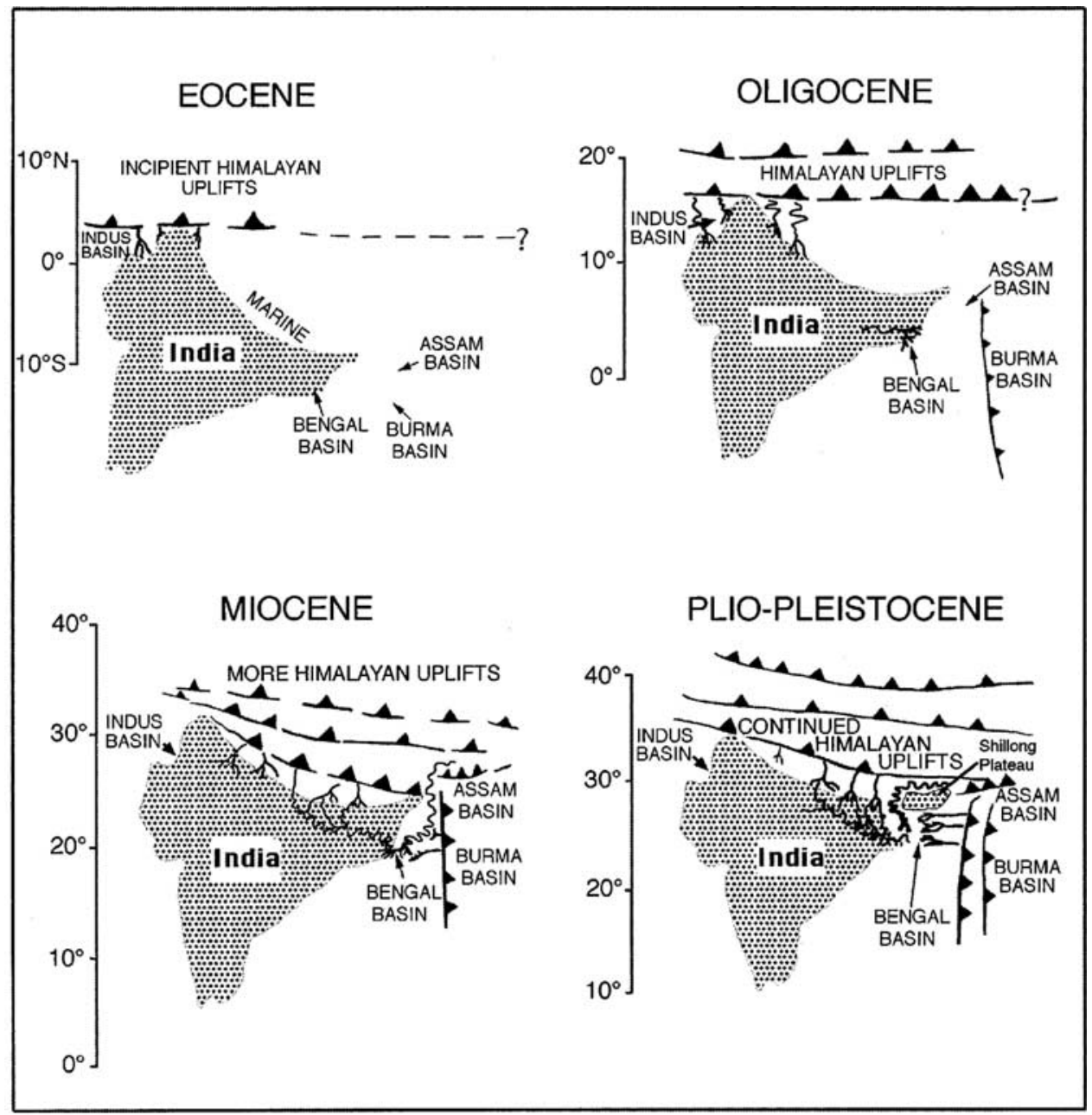

Figure 5. Collision of India with Asia and Cenozoic evolution of the Himalaya Mountains [from Uddin and Lundberg, 1998]. The collision between India and Asia began in the west and progressed to the east. The best current information suggests that the Himalaya were a high and broad mountain range by around $15 \mathrm{Ma}$.

mountains near $5 \mathrm{~km}$ high by $15 \mathrm{Ma}$ [Spicer et al., 2003; Currie et al., 2005] or at least by >10 Ma [Garzione et al., 2000; Rowley et al., 2001].

[56] It is also clear that uplift did not stop at this time. Clark et al. [2005a] note accelerated erosion into the southeastern Tibetan Plateau and propose that uplift of the southeastern Tibetan Plateau occurred primarily in the late Miocene between 13 and $9 \mathrm{Ma}$. Similar uplift along the northern edge of the plateau occurred between 13.7 and 9 Ma [Sun et al., 2005], although paleobotanical evidence [Spicer et al., 2003] suggests that the central plateau was already near $5 \mathrm{~km}$ at $\sim 15 \mathrm{Ma}$. The best way to reconcile this evidence is to suggest early Miocene uplift but with a significant broadening of the elevated region in the late Miocene, perhaps associated with normal faulting, which actually might have lowered the average regional height [Molnar et al., 1993]. We note that it is not the peak elevations but large expanses of high-elevation terrain that are likely to generate the kind of planetary-scale atmospheric waves responsible for large-scale climate effects.

\subsubsection{Rocky Mountains and Coastal Mountains of Western North America}

[57] The Rocky Mountains of North America also influence wind patterns over the Pacific and precipitation in western North America. Rocky Mountain orography may also fix stationary atmospheric waves and enhance atmospheric heat transport into the North Atlantic [Seager et al., 2002]. The history of the western U.S. topography, which includes the Rocky Mountains, Sierra Nevada, and Cascade Mountains, is as controversial as the elevation history of the Himalayas [Huber, 1981; Ruddiman and Kutzbach, 1989; Norris et al., 1996; Wolfe et al., 1997, 1998; Chase et al., 1998; Forest et al., 1999; Dettmann and Lohmann, 2000; Horton et al., 2004], particularly the history of the Sierra Nevada Mountains of California and the Great Basin. The development of the Sierra Nevada caused the formation of the western North American rain shadow that has helped to dry the Great Basin since the Miocene. As discussed in section 9, we hypothesize that the development of the Sierra/Cascade rain shadow is a secondary effect in the Miocene drying of the west. The majority of the loss of 
summer rainfall that occurred between 13 and $5 \mathrm{Ma}$ should be associated with changes in SST distribution in either the Pacific or Gulf of Mexico.

[58] The Rocky Mountain region around the present-day locations of Utah and Wyoming already formed a broad plateau in the Paleocene ( $>55 \mathrm{Ma})$ and was elevated as much as $3 \mathrm{~km}$ in the southern Utah region and over $1.5 \mathrm{~km}$ in Wyoming before the end of the Eocene (circa $34 \mathrm{Ma}$ [Chase et al., 1998]). A pattern of north to south elevation development of the Rocky Mountains also is evident according to Horton et al. [2004], who argue for high topography of $2.5-3 \mathrm{~km}$ in the early middle Eocene near the present Canada-U.S. border in Washington and high topography migrating southwestward into Nevada from the middle Eocene to Oligocene. Mountains in British Columbia may have reached a height of $4 \mathrm{~km}$ around $48 \mathrm{Ma}$ [Mulch et al., 2004].

[59] The Basin and Range region (mostly Nevada and western Utah) was higher than modern regional elevation around $15 \mathrm{Ma}$, approximately $3 \mathrm{~km}$ high versus an elevation of $2 \mathrm{~km}$ today [Wolfe et al., 1997; Chase et al., 1998; Horton et al., 2004]. The elevation history of the Sierra Nevada is problematic, but elucidating its development is important for understanding the formation of the rain shadow effect on the Great Basin. The Sierra Nevada were at first thought to have achieved some elevation in the early Miocene but had reached their present height of about $3 \mathrm{~km}$ by 3.6 Ma [Christensen, 1966]. Huber [1981] suggested that the Sierra Nevada were already relatively tall by $10 \mathrm{Ma}$ (900-m base with mountains to $2 \mathrm{~km}$ ). By 3 Ma they reached a base height of over $2 \mathrm{~km}$ and rose another kilometer in the last 3 million years. Similarly, stream incision of the Sierra range would suggest uplift relative to the Great Basin beginning around $5 \mathrm{Ma}$ [Wakabayashi and Sawyer, 2001; Stock et al., 2004]. Incision at this time may mean the relative uplift of a Sierra block rather than the beginning of high topography. Nonequilibrium stream topography [Clark et al., 2005b] provides evidence that $1.5-\mathrm{km}$-high mountains have probably been in existence since the end of the Cretaceous. New thermochronology data show that the northern Sierra Nevada had slow exhumation rates from the early Paleogene onward and, by inference, slow Cenozoic uplift rates after high uplift rates in the Cretaceous [Cecil et al., 2006]. Paleobotanical evidence suggests that Nevada may have dropped by about a kilometer since $20 \mathrm{Ma}$ to its present elevation [Wolfe et al., 1997], whereas oxygen isotope data suggest a near-present altitude for the Sierra Nevada since $16 \mathrm{Ma}$ [Chamberlain and Poage, 2000].

[60] The Cascades of Oregon and Washington were also uplifted in the Miocene, but there is less information than for the Sierra Nevada and Great Basin. The eastern part of the Pacific Northwest near the Idaho-Oregon border should have been elevated around $15 \mathrm{Ma}$ associated with the thermal event that caused the eruption of the Columbia River Basalts [Hooper, 1997; Hooper et al., 2002] as well as the passage of the Yellowstone hot spot through the general region [Colgan et al., 2004]. Since that time, there should have been subsidence in the intermountain region relative to the coast. Evidence for such subsidence was found by Takeuchi and Larson [2005], who showed a development of approximately 4\% shift in the oxygen isotopic composition of meteoric water between about 12 and $8 \mathrm{Ma}$ for the Washington Cascades and attributed it to the development of a Cascades rain shadow. Similarly, Kohn et al. [2002] showed an isotopic shift after 7.2 Ma that they attributed to uplift of the Oregon Cascades. Care must be taken in this interpretation, however, because of the sensitivity of the argument to climate teleconnections. The time period in question is one of global drying and cooling, which could have caused a significant part of the isotope shift. Furthermore, by $5 \mathrm{Ma}$, precipitation patterns in middle Miocene western North America changed from year-round to primarily winter precipitation. Such a shift to precipitation that is confined to the winter months should have produced an oxygen isotope signal similar to an altitude change without invoking a tectonic rain shadow effect. It would be surprising if there were no mountains in the Pacific Northwest prior to the late Miocene, since it has been an active margin for most of the Cenozoic [Engebretson et al., 1985; Verplanck and Duncan, 1987] and it is likely that there was a continental expression of this subduction, i.e., mountains, as well.

[61] Our preferred elevation history for western North America is one of relatively high elevations in the Rocky Mountains and Nevada since the Eocene, such that mountain building on North America is not a major factor causing climate change. The present evidence suggests that the average elevation of the Great Basin dropped by about $1 \mathrm{~km}$ since the beginning of the middle Miocene. Some uplift of the Sierra Nevada was likely associated with this event, although much of the uplift probably occurred in the late Miocene or early Pliocene between 10 and 4 Ma.

\section{BOUNDARIES: CENOZOIC OCEAN GATEWAYS}

[62] Ocean gateways are directly linked to changes in ocean circulation because they control the flow of water between basins. By allowing mixing (or restricting it during closure), gateways regulate the flow of heat, salt, and fresh water between the oceans. Once sufficiently open, however, flow through ocean gateways is usually a function of climate state [De Boer and Nof, 2004a, 2004b] and not a function of the bathymetric details of the gateway itself. This is encouraging because it suggests that paleobathymetric knowledge need not be perfect to understand paleoceanographic flows but also hints at the circularity of inferring gateway opening from paleoceanographic changes.

\subsection{Cenozoic Closing of the Tethys Sea and Tropical Isolation Between Oceans}

[63] At the beginning of the Cenozoic, there was a welldeveloped circumglobal seaway, the Tethys Sea, which provided deepwater connections between the major ocean basins. Connections to the Arctic were through shallow 


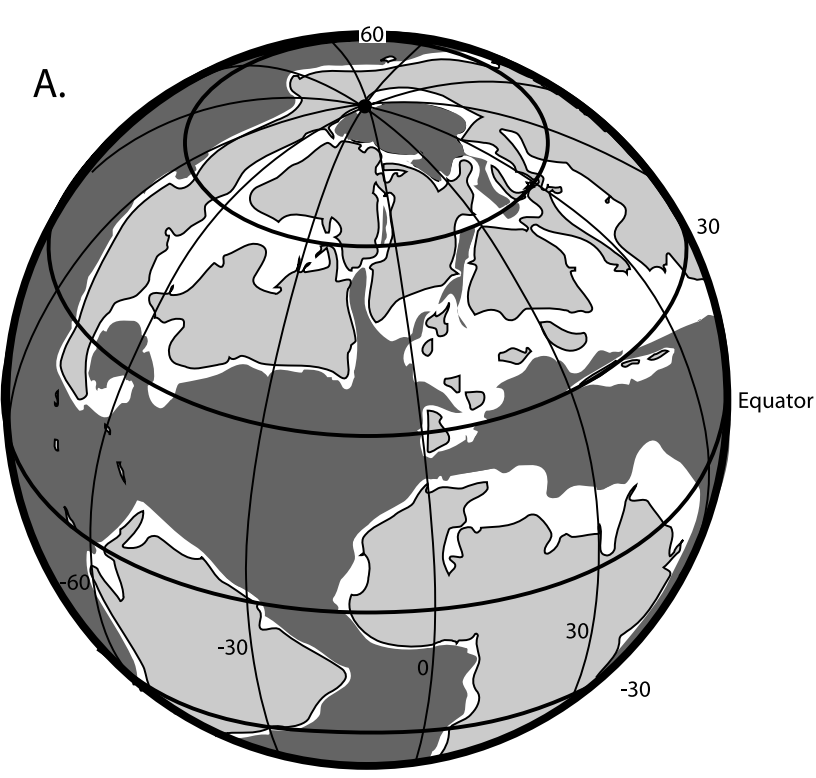

Tethys Seaway, Atlantic view $70 \mathrm{Ma}$

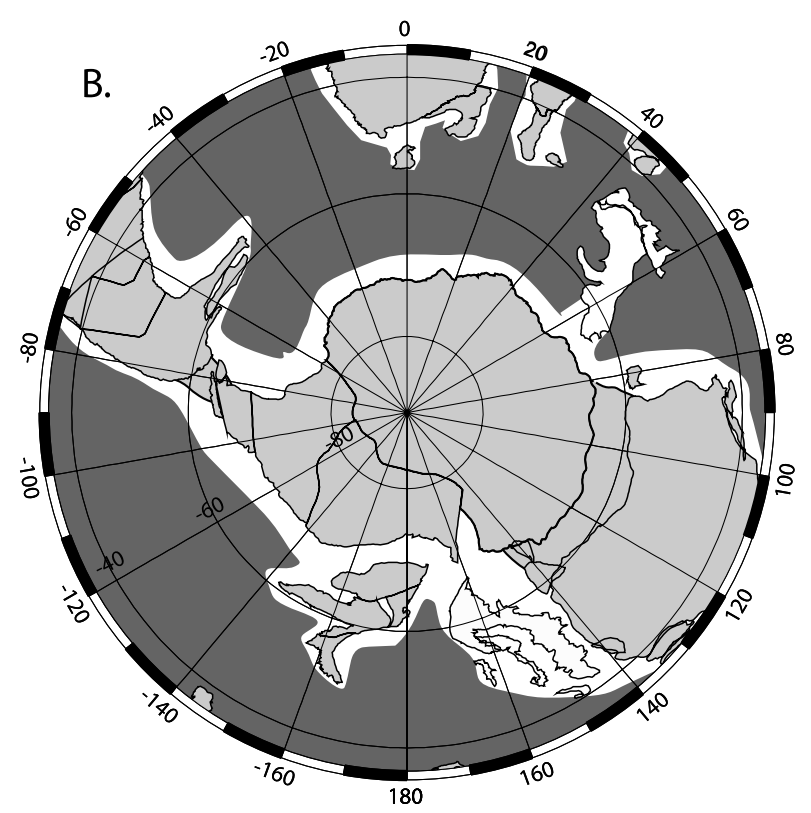

Southern Ocean $70 \mathrm{Ma}$

Figure 6. Ocean configuration in the early Maastrichtian (circa $70 \mathrm{Ma}$ ) just before the beginning of the Cenozoic. Dark shading delineates deep ocean, while white areas indicate shallow seas. (a) View of the tropics and Northern Hemisphere, showing the Tethys Ocean and the shallow sea connections between the Tethys and the Arctic [after Ziegler and Rowley, 1998], reproduced by permission of Oxford University Press, www.oup.com. (b) Polar view of the Maastrichtian Southern Ocean showing how the Atlantic and Pacific were blocked by connections of Antarctica to Australia and to South America. Figure $6 \mathrm{~b}$ was produced using Ocean Drilling Stratigraphic Network (see http://www.odsn.de/) paleomagnetic reconstruction.

water epeiric seaways across continents (Figure 6). The Southern Ocean was divided into two separate domains, the Atlantic-Indian and Pacific. The high-latitude South Pacific was blocked from the Indian Ocean by the joined AustraliaAntarctica and was blocked from the Atlantic by the Scotia Arc joining South America to Antarctica.

[64] Significant closure of the Tethyan Seaway began in the Paleocene with the collision of India with Asia. Collisions and closure have continued ever since, driven by the Africa-Asia and Europe-Africa collisions. The convergence of North America and South America cut off a connection between the tropical Atlantic and Pacific, and the northward migration of Australia is cutting off the tropical connection between the Indian and Pacific oceans.

[65] The Panama Gateway illustrates the complications of a gateway closure [Duque-Caro, 1990; Coates and Obando, 1996; Droxler et al., 1998]. Continent-continent collisions typically contort and deform the ocean floor caught between the two continents, including true ocean floor as well as continental margins. The result from such deformation is a series of basins, islands, and serpentine deepwater connections during the "mature" phase of closure (e.g., modern Indonesian Passage, Figure 7). In the Caribbean-Gulf of Mexico region, serious restrictions on flow between the Atlantic and Pacific probably existed since the migration of the Greater Antillean Arc into the region from the Pacific at about 80 Ma [Droxler et al., 1998]. Comparisons of planktonic oxygen isotopes from the Atlantic and Pacific sides of the Isthmus of Panama have shown that significant restriction of surface water exchange occurred around $4 \mathrm{Ma}$ [Keigwin, 1982; Haug et al., 2001]. Development of a shallow CCD in the eastern Pacific around $10 \mathrm{Ma}$ [Lyle et $a l ., 1995]$ has been related to the disappearance of deepwater passages between the Atlantic and Pacific through northern South America [Duque-Caro, 1990; Coates and Obando, 1996]. Furthermore, final closure of the isthmus is correlated with a shift in the locus of highest equatorial Pacific biogenic sedimentation $25^{\circ}$ of longitude eastward from about $110^{\circ} \mathrm{W}$ in the late Miocene to about $85^{\circ} \mathrm{W}$ around $3 \mathrm{Ma}$ [Farrell et al., 1995; Lyle, 2003].

[66] The Indonesian Passage is the last of the Tethyan ocean gateways, through which there is still significant flow from the Pacific to the Indian Ocean (10-15 sverdrups (Sv) or $10^{6} \mathrm{~m}^{3} / \mathrm{s}$ [Murray and Arief, 1988; Gordon and Fine, 1996; Rodgers et al., 1999; Ganachaud and Wunsch, 2000; Lee et al., 2002, Gordon et al., 2003]). Tectonic reconstructions clearly show that deepwater passages through the Indonesian Archipelago became severely restricted in the middle Miocene [Nishimura and Suparka, 1997; Linthout et al., 1997]. Subduction jumped in the early middle Miocene to the western edge of Indonesia [Nishimura and Suparka, 1997], and late Miocene obduction of the Banda Arc has further restricted water flow north of Australia [Linthout et al., 1997]. Radiolarian faunas became differentiated between the Indian Ocean and western Pacific at about $11 \mathrm{Ma}$, suggesting sufficient restriction of water exchange 


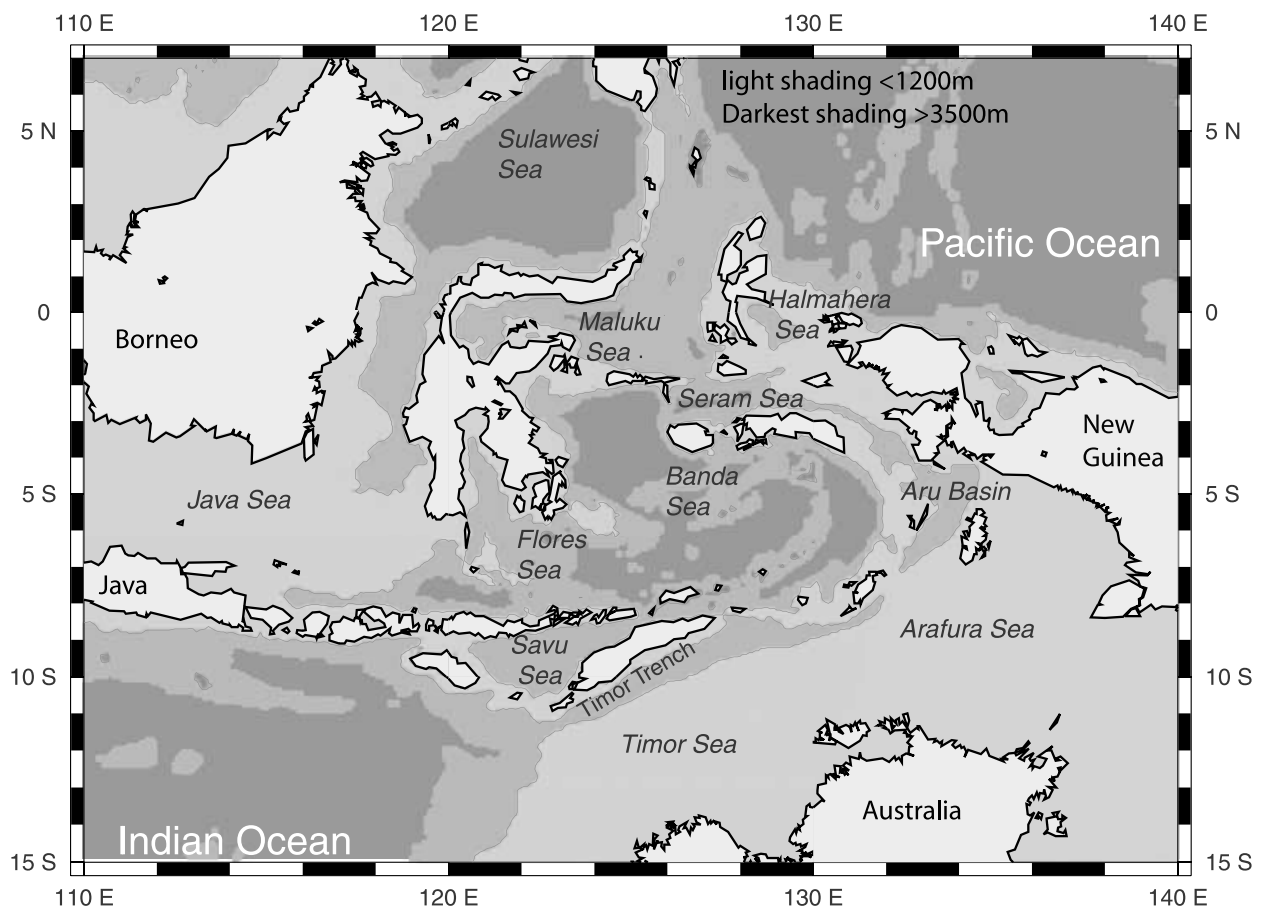

Figure 7. Modern Indonesian Passage, illustrating the mature phase of a gateway closure. Light shading indicates water depths shallower than $1200 \mathrm{~m}$, medium shades are water depths greater than 1200 but less than $3500 \mathrm{~m}$, and dark shading marks water depths greater than $3500 \mathrm{~m}$.

through the Indonesian Passage to develop different water masses on either side of the Indonesian Gateway [Romine and Lombari, 1985]. Similarly, Leinen [1979] and Keller [1985] propose that the Equatorial Undercurrent was initiated by circa $11 \mathrm{Ma}$ in the equatorial Pacific because of partial closing of the Indonesian Seaway.

[67] It is important to note that deepwater passages still exist today, although they were all wider in the Miocene. Water exchange between the Pacific and Indian oceans has probably slowly decreased to approximately $10-15 \mathrm{~Sv}$ since the middle Miocene. Overall, the Cenozoic history of the Indonesian Passage is poorly understood and deserves more attention.

[68] Small changes in the source and strength of Indonesian Gateway waters, or "throughflow," can strongly affect global climate [Rodgers et al., 1999]. Wells et al. [1999] also showed that changes in past Pacific Ocean productivity may have been caused by shifts in currents and nutrient supply as the Indonesian Throughflow evolved. Cane and Molnar [2001] suggested that the northward displacement of New Guinea caused Pacific source regions for Indonesian Throughflow to change from the South Pacific to the North Pacific. Such a hemispheric change would have cooled the Indian Ocean and helped to aridify Africa in the Pliocene. Variations in the exchange of heat and salt between the Indian and Pacific oceans must have occurred all through the Miocene and may have directed some of the slow evolution of global climate over this period.

\subsection{Cenozoic Opening of the Bering Strait, North Pacific}

[69] Three high-latitude Pacific gateways have opened since the start of the Cenozoic: two in the Southern Hemisphere, the Tasman Gateway between Antarctica and Australia and the Drake Passage between South America and Antarctica, and in the Northern Hemisphere the Bering Strait into the Arctic. Of these the Bering Strait is the youngest (5.3 Ma [Marincovich and Gladenkov, 1999]), shallowest, and most immature. The Bering Strait now allows a minor flow of water from the Pacific into the Arctic basin (0.8 Sv [Ganachaud and Wunsch, 2000]). While this flow is important to sea ice development and its movement in the Holocene, it has a minor impact on Pacific water flow. Since about 3.6 Ma, net flow generally has been from the Pacific to the Arctic [Marincovich and Gladenkov, 1999]. This export of relatively fresh water from the Pacific is extremely important for North Atlantic salinity and deepwater formation [Shaffer and Bendtsen, 1994]. The opening of the Bering Strait fundamentally changed the stability of modes of the meridional overturning circulation in the Atlantic [De Boer and Nof, 2004a, 2004b] but did not strongly affect the Pacific except through teleconnections. The Pacific-Arctic-Atlantic connections depended not only on the Bering Strait but also on the evolution of the Fram Strait between Greenland and Svalbard [Myhre and Thiede, 1995; Myhre et al., 1995; Thiede et al., 1996]. Recently completed drilling in the Arctic (IODP Leg 302 [Expedition 302 Scientists, 2006; Moran et al., 2006]) will help to better reconstruct the Pacific-Arctic-Atlantic connection. 


\subsection{Southern Ocean Gateways}

[70] Kennett [1977] and Berggren and Hollister [1977] first proposed that the opening of Southern Ocean gateways thermally isolated Antarctica through the creation of the Antarctic Circumpolar Current (ACC) to cause a major climate cooling at the Eocene-Oligocene boundary. In contrast to this theory, modeling studies suggest that it was the gradual decrease in atmospheric $\mathrm{CO}_{2}$ between the Eocene and Oligocene that had a more important effect [DeConto and Pollard, 2003a, 2003b; Huber and Nof, 2006].

[71] Clearly, the controversy is partly addressed by information about the timing of the opening of the Southern Ocean gateways relative to the Eocene-Oligocene cooling and relative to the formation of the ACC. A true ACC could not have developed prior to the opening of both the Tasman Gateway and the Drake Passage, so the tectonic evolution of both gateways must be known to understand surface and deep circulation in the high-latitude South Pacific. The relationship between tectonics and cooling is discussed in more detail in the section 8.2.

\subsubsection{Tasman Gateway}

[72] The opening history of the Tasman Gateway is relatively well constrained [Exon et al., 2003; Stickley et al., 2004]. Australia began breaking away from Antarctica in the Late Cretaceous, but final separation did not take place until the latest part of the Eocene [Exon et al., 2003]. The Tasman Gateway opened a shallow ( $\sim 50 \mathrm{~m}$ deep) connection about $35.5 \mathrm{Ma}$ into the northward flowing limb of an Eocene Antarctic subpolar gyre [Huber et al., 2004; Stickley et al., 2004], and Lawver and Gahagan [2003] suggest that the gateway passage was deeper than $2000 \mathrm{~m}$ by $32 \mathrm{Ma}$. A tectonic reconstruction of the Tasman Gateway at the end of the Eocene ( $\sim 34 \mathrm{Ma}$ [from Stickley et al., 2004, Figure 8]) shows restricted deep flow through the gateway even after significant rifting had occurred between Australia and Antarctica. Because the final part of the opening occurred by transform motion between the west coast of Tasmania and Antarctica, the development of a deep passage was relatively slow. This style of rifting is analogous to that at Fram Strait in the modern Arctic. At Fram Strait, rifting began around $55 \mathrm{Ma}$, but significant deep passages did not form prior to the early Miocene ( $\sim 20 \mathrm{Ma}$ [Myhre and Thiede, 1995]). Rifting did not change the cross-sectional area of the passage significantly until the two ends of the transform slid past each other. Australia thus experienced roughly $10^{\circ}$ of northward motion relative to Antarctica before a significant Tasman Gateway was formed.

[73] When a deepwater connection through the Tasman Gateway was established, initial flow of cold polar water appears to have been westward from the Pacific to the Indian Ocean not eastward in a proto-Antarctic Circumpolar Current. Distribution of faunal assemblages and modeling [Huber et al., 2004] suggest that the first flows established through the gateway were a relatively warm surface current through the north part of the gateway derived from west of Australia in a wind-driven proto-Leeuwin Current and a minor cold "Antarctic countercurrent" from the high-latitude Pacific into the Indian Ocean (Figure 8).

\subsubsection{Drake Passage}

[74] An Antarctic Circumpolar Current could not have developed until both the Tasman Gateway and the Drake Passage opened. Two very different dates have been suggested for the opening of the Drake Passage: an early Oligocene opening that is older than $30.5 \mathrm{Ma}$ [Lawver and Gahagan, 1998, 2003; Livermore et al., 2005] and an early Miocene opening between 22 and $17 \mathrm{Ma}$ [Barker and Burrell, 1977; Barker, 2001]. The discrepancy is caused by the complex nature of the Drake Passage opening. Unlike the Tasman Gateway, which was a relatively simple rifting of continental masses, the Drake Passage opening involves the splitting of an active subduction zone (the Scotia Arc) and the development of the Scotia microplate. Clearly, the opening involved multiple passageways, and the controversy centers around the size of the opening needed to make a true ocean connection. Some extension between Antarctica and South America occurred between 50 and $33 \mathrm{Ma}$, and a shallow passage between the Pacific and Atlantic may have formed then [Livermore et al., 2005]. However, continental fragments may have obstructed deepwater passages until the early Miocene [Barker, 2001].

[75] Further evidence for the opening of the Drake Passage is based upon inferences about the strength of the $\mathrm{ACC}$ and $\mathrm{Nd}$ isotope tracing of water around Antarctica, as discussed in section 7. While such evidence is useful, using the development of the ACC to define the opening of the Drake Passage leads to another circular proof of the climatetectonics link [Barker and Thomas, 2004]. Clearly, better constraints on the history of the Drake Passage independent of the development of the ACC are needed to better understand the evolution of global climate.

\section{EOCENE-OLIGOCENE BOUNDARY COOLING: THERMAL ISOLATION OF ANTARCTICA?}

[76] The transition from the late Eocene to early Oligocene epoch represents a major cooling step for the planet and arguably the most important switch in the climate and carbon cycle in the Cenozoic. This boundary, also sometimes referred to as the greenhouse to icehouse transition, is marked by the development of a continent-wide Antarctic ice cap, the Oi-1 glaciation [Miller et al., 1987; Zachos et al., 2001a], and the beginning of permanent Southern Hemisphere polar glaciers. Recent work in the Norwegian-Greenland Sea indicates that glacial ice existed on Greenland during the late Eocene and early Oligocene [Eldrett et al., 2007], but there is no evidence for the existence of a substantial ice sheet at this time. Thus, after the Oi-1 glaciation the Earth transformed from the "no-ice cap" condition to a southern cryosphere condition, which lasted from 33.6 to $2.7 \mathrm{Ma}$. Only after circa $2.7 \mathrm{Ma}$ did the permanent northern cryosphere develop.

[77] The Eocene-Oligocene (E-O) boundary also marks an important controversy: Was the thermal isolation of Antarctica the primary cause of the development of the 

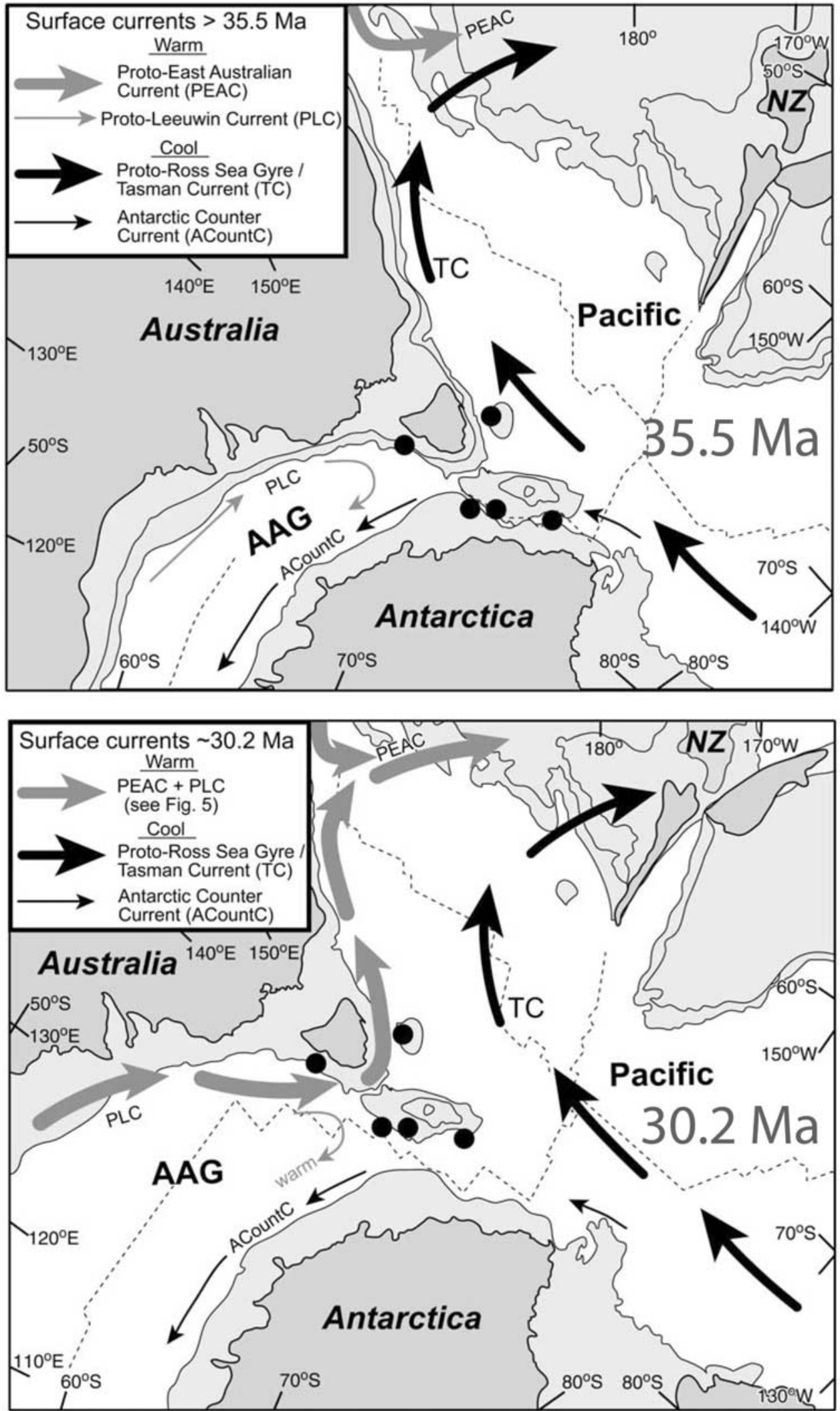

Figure 8. Tasman Gateway at the late Eocene (35.5 Ma) and in the early Oligocene (30.2 Ma) [from Stickley et al., 2004]. Note that modeling suggests that the major flow through the gateway was of temperate waters in a proto-Leeuwin current. Cold currents near Antarctica flowed eastward. 


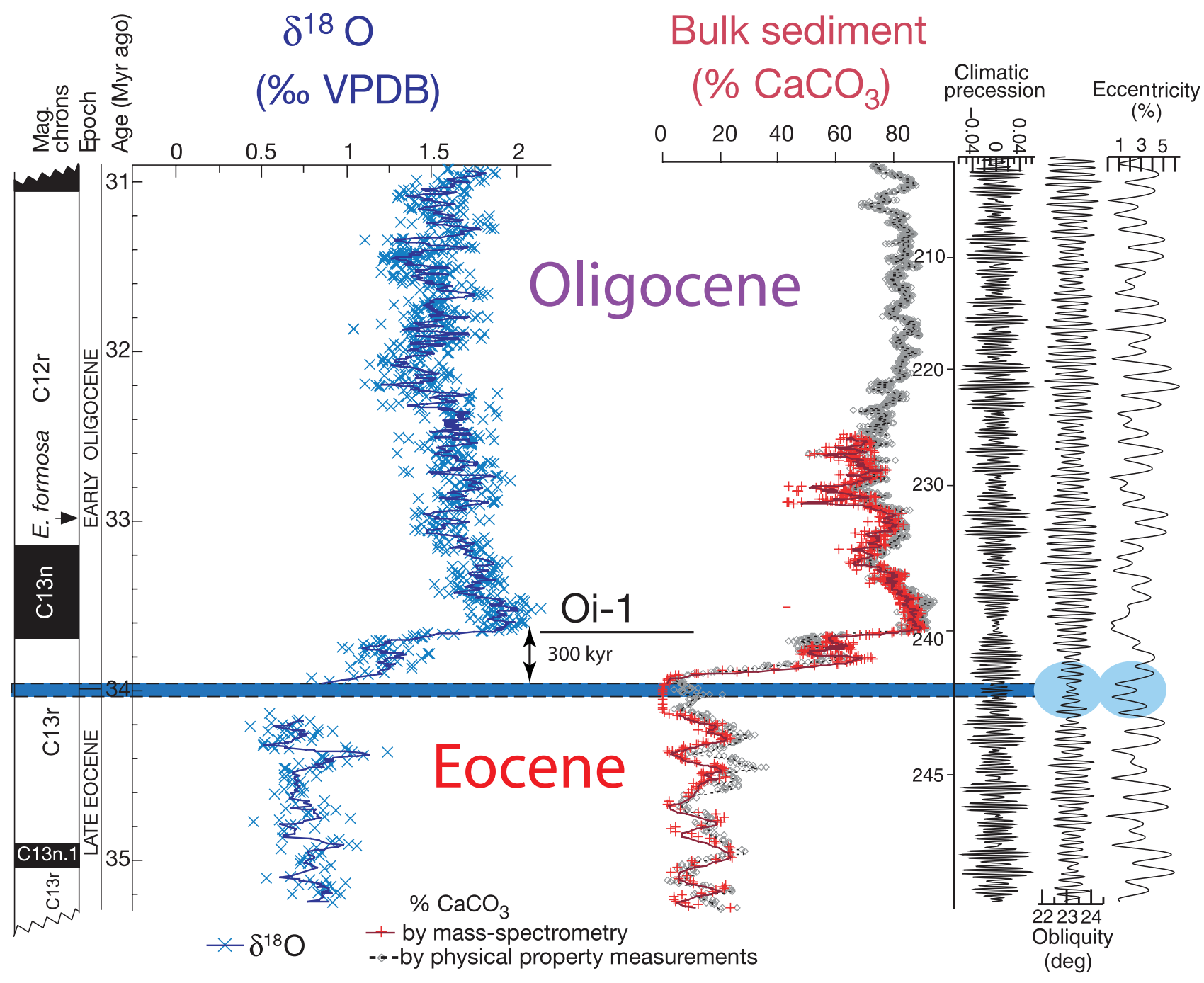

Figure 9. Chronology and stratigraphy of the Eocene-Oligocene boundary [after Coxall et al., 2005], reprinted by permission from Macmillan Publishers Ltd, copyright 2005, http://www.nature.com/nature/ index.html. Oi-1 marks the first continent-wide glaciation of Antarctica. The transition to high-carbonate sediments took $300 \mathrm{ka}$ in two steps that lasted less than $40 \mathrm{ka}$.

Antarctic cryosphere? Since the hypothesis was formulated that the development of the ACC thermally isolated and cooled Antarctica [Kennett, 1977; Berggren and Hollister, 1977], other researchers have investigated the amount of cooling that might be caused by the formation of the ACC and also whether that level of cooling could cause the development of an Antarctic ice cap. These investigations led to an alternative hypothesis that the cooling at the E-O boundary was caused by a crossed threshold in atmospheric $\mathrm{CO}_{2}$ [DeConto and Pollard, 2003a, 2003b]. In this section we review the controversy by first discussing the timing of the E-O boundary event and then examining the evidence for the time when the ACC was established before examining the model results. This will lead us into the subsequent discussion of the early Cenozoic carbon cycle.

\subsection{Time Span of the Eocene-Oligocene Boundary Event}

[78] Coxall et al. [2005] have produced a detailed chronostratigraphy of the Eocene-Oligocene boundary from a study of equatorial Pacific sediments from Ocean Drilling Program Site 1218 (Figure 9). By using cyclostratigraphy, biostratigraphy, and detailed correlations between Sites 1218 and 1219 from the Eocene equatorial Pacific they have revealed that the transition from the "warm" Eocene to the "cool" Oligocene took less than $300 \mathrm{ka}$ to complete. The rapidity of the change, relative to a tectonic forcing, is strong evidence that feedbacks from other components that influence climate were very important to the abrupt cooling.

[79] Both the carbonate content of the equatorial Pacific sediments and the oxygen isotope composition of seawater increased abruptly and in synchrony during the E-O boundary event. The transition took place in two steps each that are roughly $40 \mathrm{ka}$ long, separated by a plateau that lasted $\sim 200 \mathrm{ka}$, and occurred during a period of minimum obliquity orbital insolation forcing. Such a condition suggests that the cool high-latitude summers associated with a "low-amplitude modulation of tilt" condition interacted synergistically with a gradual cooling condition to produce a step in climate [Coxall et al., 2005]. A similar association 
of Paleogene glaciations with Earth's obliquity modulation nodes has been noted for most of the Oligocene [Pälike et al., 2006].

[80] As the first record of its type available from the Pacific, the data from Site 1218 provide the best measure of the global signals for the E-O transition. The amplitude of $\delta^{18} \mathrm{O}$ increase recorded in these data is large $(\sim 1.5 \%$ Vienna Peedee belemnite, Figure 9). In fact, this signal is impossibly large to be explained by ice growth on Antarctica alone and must therefore also indicate contemporaneous global cooling or possibly ice growth in the Northern Hemisphere [Coxall et al., 2005]. The discovery of dropstones discovered in the Norwegian-Greenland Sea indicates that glacial ice existed on Greenland around this time. These data cannot be used to determine ice extent, and arguably, the simplest explanation is that these sediments originated from isolated upland valley glaciers [Eldrett et al., 2007].

[81] Miller et al. [1998, 2005] estimated the magnitude of ice buildup through Cenozoic changes in sea level as recorded along the New Jersey passive margin. Kominz and Pekar [2001] focused on the Oligocene part of the sequence and found that the initial change in sea level associated with Oi-1 at the E-O boundary was about $55 \mathrm{~m}$, and a permanent drop in sea level of about $30-40 \mathrm{~m}$ was sustained after the waning of the Oi-1 glaciation. For comparison, modern glaciation of Antarctica locks ice on the continent equivalent to about a 70-m drop in sea level. The E-O glaciation event must have covered Antarctica with substantial ice. Much of the ice remained through subsequent warm periods throughout the rest of the Cenozoic.

[82] Lear et al. [2000, 2004] used $\mathrm{Mg} / \mathrm{Ca}$ ratios to estimate the magnitude of cooling versus ice buildup across the E-O boundary and reported a larger ice buildup even when oxygen isotope records are corrected for temperature change. An estimate of ice mass depends upon an estimate of an average oxygen isotope composition of the ice, which is dependent on the average polar water temperature and distance from the source waters. However, Lear et al. [2004] also note a slight warming of deep waters at this time as well based on $\mathrm{Mg} / \mathrm{Ca}$. Because changes in ocean $\mathrm{pH}$ affect the $\mathrm{Mg} / \mathrm{Ca}$ ratio, the extent of the temperature change at the E-O boundary is still in question. Nevertheless, there is no evidence for significant cooling of deepwater temperatures despite the Antarctic buildup of ice.

\subsection{ACC and the Development of the Cenozoic Icehouse}

[83] Antarctic Circumpolar Current flow depended upon the opening of the Drake Passage once the Tasman Gateway had opened sufficiently at the E-O boundary. Although they did not explicitly discuss the strength of the current, Sijp and England [2004] explored how ACC flow should have changed with the opening of the Drake Passage. In their set of models, which had a modern geometry except for changes in Drake Passage depth, they found that the ACC strength is roughly linear with respect to the depth of the
Drake Passage. Omta and Dijkstra [2003] achieved a similar result but also pointed out that the ACC flow out of the Pacific was related to the strength of ocean transport from the North Atlantic to the Pacific through the Panama Gateway.

[84] Model results suggest that the development of the ACC could produce significant cooling in the Antarctic. The first experiments [Mikolajewicz et al., 1993] suggested that the opening only had a small sea surface temperature effect around Antarctica $\left(-0.8^{\circ} \mathrm{C}\right)$ but a large effect on thermohaline circulation derived from the Southern Ocean. Antarctic overturning strength is higher with a closed Drake Passage and is closer to the continent in their model. More recent studies [Nong et al., 2000; Toggweiler and Bjornsson, 2000] have pointed out that restoring boundary conditions within the Mikolajewicz et al. [1993] model minimized temperature changes, and they suggest that $1.5^{\circ}$ to $3^{\circ} \mathrm{C}$ of cooling is associated with the development of the Antarctic circulation.

[85] Paleoceanographic constraints on the timing and strength of ACC flow could remove ambiguities in the modeling by constraining the timing of changes in Southern Ocean currents relative to the timing of ice growth and cooling. However, such studies need to disentangle changes in sediment deposition caused by a developing ACC from those changes primarily associated with the E-O climate change itself. The paleoceanographic literature sometimes treats as equivalent the formation of the ACC, growth of glaciation on Antarctica, and development of sedimentary biofacies in the Southern Ocean [Barker and Thomas, 2004], leading to circular logic instead of clarification.

[86] On the basis of the existing evidence, relatively small and gradual cooling associated with the developing ACC might have been sufficient to cause the E-O boundary event, provided that the circulation gradually grew in strength at that time (circa 34-33 Ma). There are three main age groupings of geologic evidence related to the ACC. First, Scher and Martin [2006] investigated Nd isotopes in the Atlantic sector of the Southern Ocean over the middle Eocene to early Oligocene. They note that radiogenic Nd, a Pacific source signature, appeared in the Atlantic between 41 and $37 \mathrm{Ma}$. They argue that significant flow through the Drake Passage occurred prior to the Tasman Gateway opening. Under their scenario the Tasman Gateway was the bottleneck that controlled the development of the ACC. Because Atlantic and Pacific waters have very distinct $\mathrm{Nd}$ isotope compositions and because of the short residence time of $\mathrm{Nd}$ in ocean waters, there probably was a flow of water from the Pacific to the Atlantic at this time. However, it is not clear whether the Drake Passage was open sufficiently in the late Eocene to allow the flow of a climatically significant amount of water. Further work is needed to constrain the opening of the Drake Passage.

[87] A second group of events clusters in the early Oligocene. The Marshall paraconformity is a hiatus in sediment deposition in the SE New Zealand continental margin sediments [Fulthorpe et al., 1996; Carter et al., 2004] that is correlated to a series of gaps in sedimentation 
offshore [Carter et al., 2004] and is indicative of scour by strong currents, as might be evidenced by the ACC. However, the timing of the paraconformity in the onshore section [Fulthorpe et al., 1996] is younger than the Oi-1 glaciation event and is, in fact, correlated to Oi-2 by Fulthorpe et al. [1996]. The Oi-2 oxygen isotope excursion is now dated between 30.1 and $30.4 \mathrm{Ma}$ [Wade and Pälike, 2004] using the same timescale that places the Oi-1 glacial maximum at $33.6 \mathrm{Ma}$. The Marshall paraconformity was thus formed at least 3 million years after the climate change at the E-O boundary, and the Oi-1 glaciation either was not caused by development of the ACC or the Marshall paraconformity does not mark the earliest evidence of a strong ACC.

[88] Latimer and Fillipelli [2002] also note rapid changes in the sediment source region and increases in productivity near the E-O boundary based on a study of Site 1090 from the South Atlantic. They attribute the change to new circulation through the South Atlantic associated with the opening of the Drake Passage. The changes occur near $32.8 \mathrm{Ma}$, about 0.8 million years after the boundary events. Both the rapidity and the timing suggest that what they observe may actually be caused by the climate change that brought continent-wide ice to Antarctica rather than by a fractional increase in the size of flow through the Drake Passage.

[89] There are several indicators of development of high ACC flow near the Oligocene-Miocene boundary (circa $23 \mathrm{Ma})$. Pfuhl and McCave [2005] compared Site 1170, east of the Tasman Gateway, to Sites 1171 (west of gateway) and 1172 (NW of gateway). They noted an increase in grain size in sediments at the time of the Mi-1 glaciation at the Oligocene-Miocene boundary (23.0 Ma in the most recent age models [Pälike et al., 2006]) indicative of significantly higher current speeds on both sides of this restricted passageway. They did not observe a change in grain size in sediments of Site 1172 to the north. The inferred current speed changed as a step, supporting the development of higher flow. Unfortunately, Pfuhl and McCave [2005] have grain size records for only the period 28-21 Ma and none that span the E-O boundary.

[90] Pfuhl and McCave [2005] pointed out that the Oligocene-Miocene development of the first strong ACC flow coincides with the only major Cenozoic hiatus on the Kerguelen Plateau, located in the path of ACC flow in the South Indian Ocean [Leg 119 Shipboard Scientific Party, 1989]. In addition, Lyle et al. [2007] have produced evidence from the deep SW Pacific that the ACC increased its strength only in the late Oligocene after circa $25 \mathrm{Ma}$. Between 40 and $26 \mathrm{Ma}$ they observe typical pelagic drape indicative of low current speeds at the bottom. Evidence of asymmetric sedimentation and current erosion were found only in sediments dated younger than 24-26 Ma. At both the Kerguelen Rise and the SW Pacific location, pelagic sedimentation resumed only when plate tectonics moved the site locations northward and out of the influence of ACC flow.

[91] All of these studies can be linked in a chronology that suggests important exchange of water from the Pacific to the Atlantic began around $41 \mathrm{Ma}$, followed by important current reorganizations during and soon after the E-O climate change. Deep bottom currents into the Pacific, i.e., thermohaline flow at abyssal depths, produced a hiatus at the E-O boundary [Carter et al., 2004]. The Marshall paraconformity [Fulthorpe et al., 1996; Carter et al., 2004] indicates that there were major reorganizations of shallow currents around $30 \mathrm{Ma}$, involving perhaps surface currents like the proposed northward flowing Ross Sea Gyre/Tasman Current of Stickley et al. [2004]. The modern ACC probably ramped up in strength in the period between about 26 and $23 \mathrm{Ma}$, associated with the Oligocene-Miocene epoch boundary.

[92] These studies imply that a strong ACC did not develop until after the emplacement of an Antarctic ice cap at the E-O boundary. The gradual increase in speed of the current indicates a climate drift associated with the slow development of both the Tasman Gateway and Drake Passage. The drift might have set threshold conditions at the E-O boundary but begs the question of what was the trigger for the Oi-1 event, as well as the change in conditions that prevented climate after the E-O boundary from returning to warm Eocene conditions. Section 8 explores the carbon cycle as a contributing factor to the changes between the Eocene and Oligocene.

\section{EOCENE PACIFIC: ALTERED BIOGEOCHEMICAL CYCLES}

[93] The development of the ACC was a long process that culminated long after the E-O boundary climate change. The development of circum-Antarctic ocean circulation provided a gradual drift toward a cooler Earth but could not have provided the climate trigger at the E-O boundary. Here we explore alterations in the carbon cycle from the Eocene to the Oligocene as a possible contributor to this climate step. The Pacific Ocean is a major repository of carbon cycle records as well as an important reservoir of carbon itself. Continued study of the geologic history of the Pacific is addressing many of the important problems in the global carbon cycle.

[94] In a modeling study, DeConto and Pollard [2003a, 2003b] compared the effect of cooling associated with the opening of the Drake Passage with that associated with decreasing atmospheric greenhouse gases to show that $\mathrm{CO}_{2}$ is a much more effective initiator of glaciation than Southern Ocean circulation changes. They simulated a closed Drake Passage by increasing ocean heat transport in this case by $25 \%$ to roughly match closed-open results from ocean circulation models. When atmospheric $\mathrm{CO}_{2}$ is above 3 times modern values $(840 \mathrm{ppm})$, no glaciers form in Antarctica in either the "open" or "closed" Drake Passage scenario despite natural climate variations imposed by orbital variation of insolation. As $\mathrm{CO}_{2}$ was gradually reduced from 4 times modern levels to twice modern levels over a 10-million-year run, ice caps formed in both the open and closed Drake Passage configurations, although somewhat lower levels of $\mathrm{CO}_{2}$ were required in the closed Drake Passage case. Huber and Nof [2006] also reiterated the 


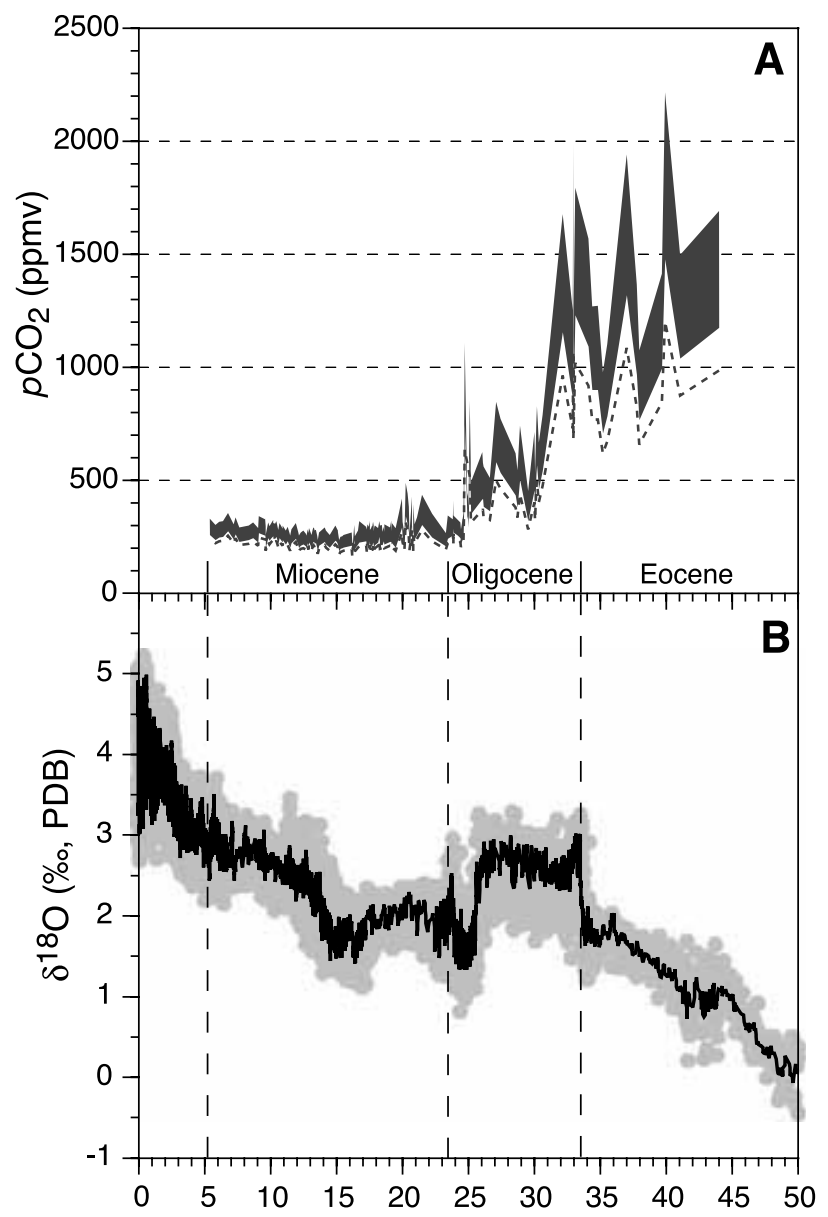

Figure 10. Cenozoic changes in $\mathrm{CO}_{2}$ content, based upon changes of carbon isotope composition of specific biomarkers preserved in sediments compared to the composite benthic oxygen isotope curve of Zachos et al. [2001a] that responds to deep ocean temperature and cryosphere volume [from Pagani et al., 2005]. The Cenozoic is subdivided into the Paleocene and Eocene region of elevated $\mathrm{CO}_{2}$ and the Miocene-Holocene regions where atmospheric $\mathrm{CO}_{2}$ is at near-modern levels. From Pagani et al. [2005]. Reprinted with permission from AAAS.

sensitivity of the poles to greenhouse gases. The reduction in greenhouse gases from 4 to 2 times modern values has a similar temperature effect as lowering ocean heat transport to the Antarctic from 3 times modern heat transport values to modern values. It is unlikely that ocean heat transport changed by this magnitude at the E-O boundary.

[95] Unfortunately, no proxy $\mathrm{CO}_{2}$ records exist for the E-O transition itself, but where data exist, they suggest a drop in levels from the Eocene to the Oligocene (Figure 10) [Pearson and Palmer, 2000; Pagani et al., 2005]. For example, Pagani et al. [2005] estimate that atmospheric $\mathrm{CO}_{2}$ dropped from greater than 4 times modern to 2 times modern levels between 35 and $30 \mathrm{Ma}$. Atmospheric $\mathrm{CO}_{2}$ then decreased to modern values by the end of the Oligocene, $\sim 23 \mathrm{Ma}$, and remained near modern values since then.

[96] We do not yet know why atmospheric $\mathrm{CO}_{2}$ declined, but it is certain to involve processes in the Pacific, and the effects of the decline are shown by changes in Pacific sediment composition. For instance, significant changes in ocean carbon chemistry can be inferred from the change in CCD, defined as the depth (below sea level) within a sedimentary regime where carbonate disappears from the sediment column. This depth coincides with the depth in seawater below which carbonate is sufficiently undersaturated that all carbonate dissolves before it can be buried as sediment. The solubility products of carbonates are pressuredependent and increase significantly in the pressure range found in the oceans. At the depth of the CCD the rate of dissolution of carbonates equals the rate of solid carbonate raining to the sediments, and all carbonates are dissolved before burial.

[97] Changes in the CCD mark significant changes in ocean alkalinity or dissolved inorganic carbon content, as will be discussed further in section 8.4. Since deep ocean flow integrates carbon burial and dissolution throughout an ocean basin, regional differences in the CCD result from different regional levels of carbonate production [van Andel and Moore, 1974]. Changes in relative production, by increasing or decreasing the particulate carbonate rain to be dissolved, can cause regional rather than global changes in CCD. Thus proxies for primary productivity and plankton carbonate production (not necessarily equivalent) are also being applied to explore changes in ocean carbon fixation and burial. Information about primary productivity and organic carbon burial is also needed to understand how organic carbon fixation affects the carbon cycle. In this section we will explore the carbon cycle first by examining productivity in the Eocene Pacific. Then we will document the major changes in the carbon cycle associated with the E-O boundary and earlier in the Eocene. The E-O boundary event is not the only major cold excursion in the Paleogene. However, all others in the Eocene returned to a relatively warm baseline [Lyle et al., 2005]. We will then explore other changes in production and deposition of organic matter and end by discussing how these might have caused the slow decrease of atmospheric $\mathrm{CO}_{2}$ at the end of the Eocene.

\subsection{Productivity in the Eocene Pacific}

[98] Primary productivity is not well studied before the Pleistocene, and there is little synthesis of information for most of the Cenozoic because of lack of sampling and poor age control. New drilling and studies of the recovered sediments have sharpened our understanding of the equatorial Pacific, a large and important part of total global productivity (20-60\% of total new production [Chavez and Barber, 1987]). Coupled atmosphere-ocean general circulation models provide the best clues to productivity in the rest of the Pacific [Huber, 2002], because they provide a physically consistent estimate of upwelling under the altered boundary conditions. The upwelling flux of nutrients into the euphotic zone ultimately determines productivity in the oceans.

[99] The model results show an upwelling pattern that is broadly similar to upwelling in the modern ocean. There is relatively large upwelling associated with both polar gyres 


\section{Early Miocene (18-22 Ma)}

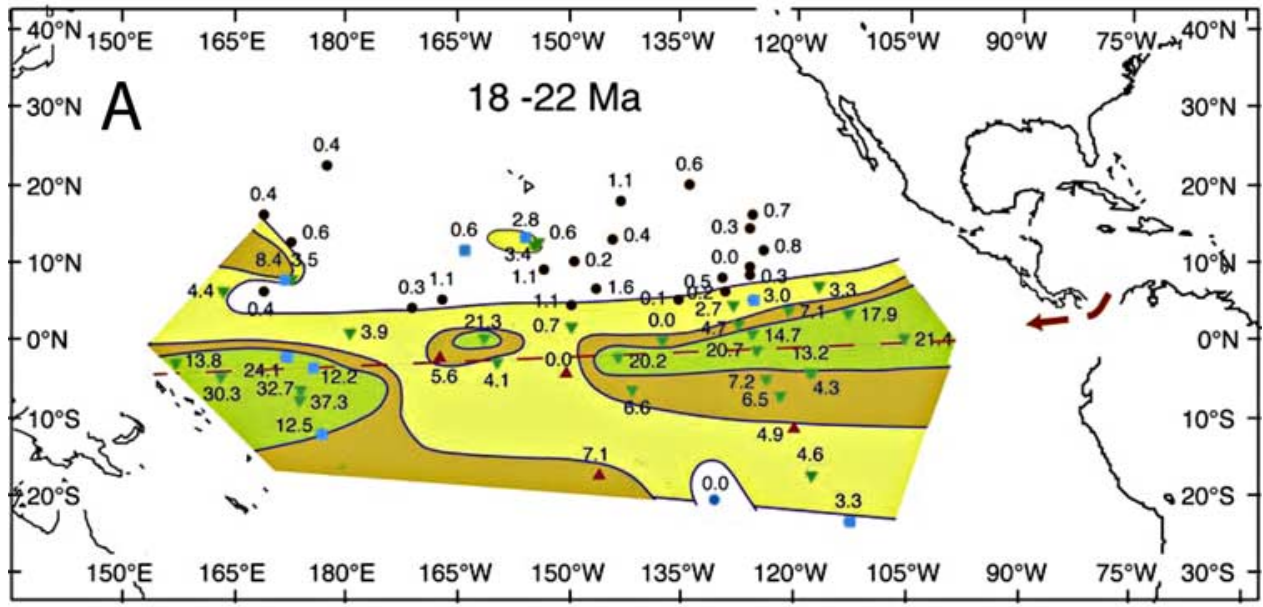

Early Oligocene (30-34 Ma)

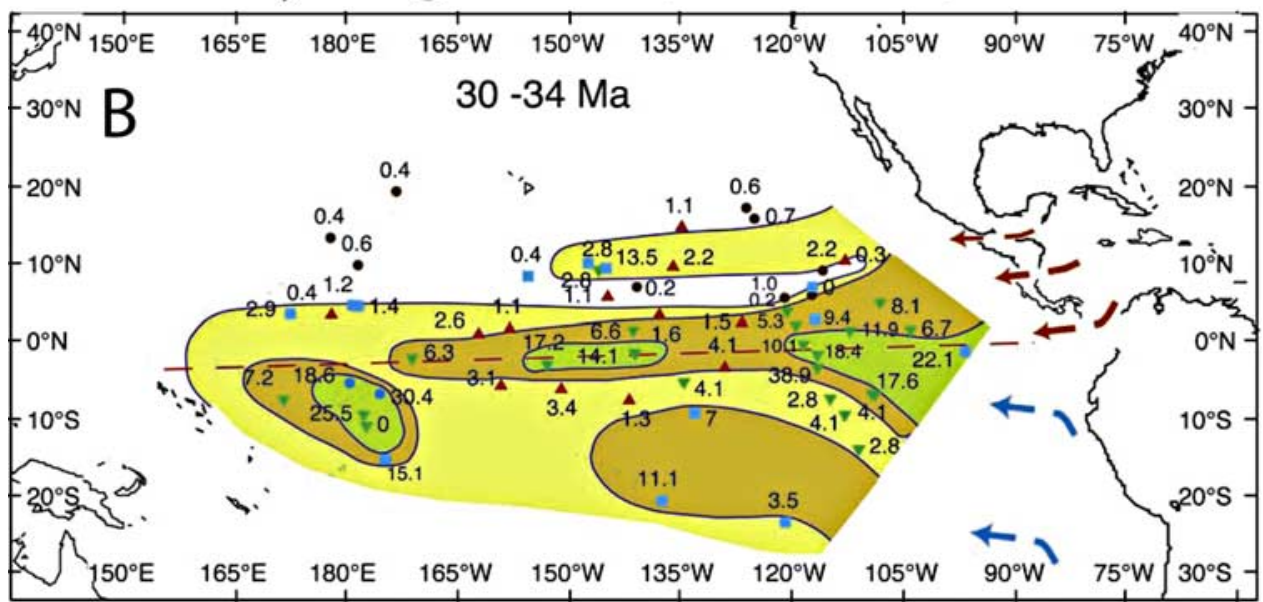

Middle Eocene (40-46 Ma)

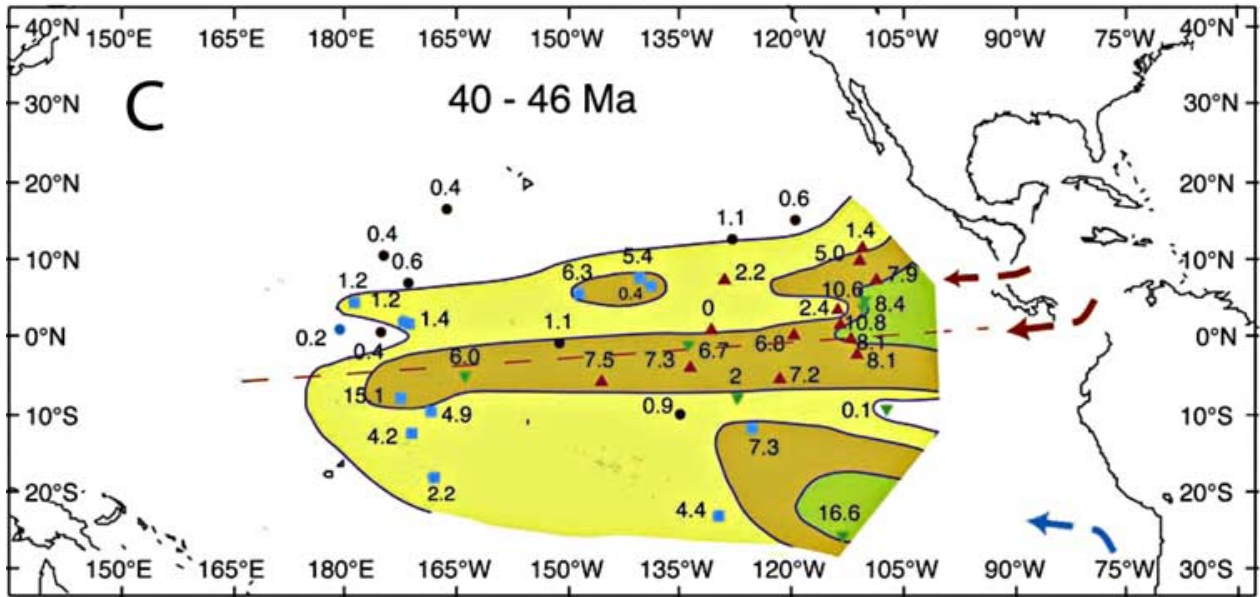

Figure 11. Productivity in the Pacific Ocean, as measured by sedimentation rates, from Moore et al. [2004]: (a) early Miocene, (b) early Oligocene, and (c) middle Eocene. Most of the sediment deposited in the equatorial Pacific is plankton tests. Sedimentation rates thus measure the deposition of these planktonic remains. 


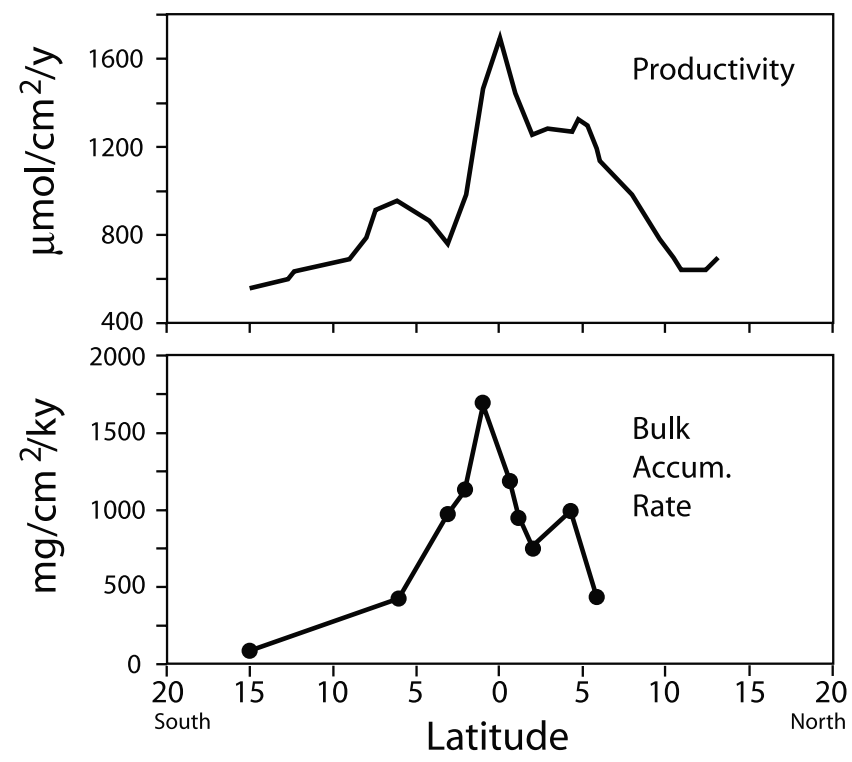

Figure 12. Biogenic sediment accumulation at modern equator [from Murray et al., 1993] showing focused sediment deposition at the equator. Sedimentation rate (increase in thickness of sediments with time) reflects the level of productivity in the surface waters because most of the sediment is plankton tests.

and strong upwelling in the equatorial regions, including the entrance to the Tethys Sea in the Indian Ocean and the equatorial Atlantic. The model also produces a trident-like pattern of upwelling in the eastern Pacific, with two zones at about $10^{\circ} \mathrm{N}$ and $10^{\circ} \mathrm{S}$ of the equator in addition to the equatorial upwelling region. It is unclear whether this represents a real difference from modern conditions or poor parameterization of the physics that controls the Intertropical Convergence Zone [Huber, 2002]. Nevertheless, a new synthesis of scientific drilling data in the equatorial region indicates a broad zone of upwelling in the Eocene eastern Pacific [Moore et al., 2004] with stronger off-equatorial upwelling than the Holocene.

\subsubsection{Observations on Eocene Equatorial Productivity}

[100] General features of the evolution of the Pacific equatorial high-productivity zone were established 30 years ago [van Andel et al., 1975; Leinen, 1979] near the beginning of scientific ocean drilling (DSDP Legs 8 and 16 [Tracey and Leg 8 Shipboard Scientific Party, 1971; van Andel et al., 1973]). However, the primitive state of age models and stratigraphic control, in addition to the limited sediment recovery, restricted the early interpretations. More modern drilling techniques and significantly better age models developed from recent ODP drilling legs have provided the opportunity to better understand Eocene conditions (ODP legs 198 and 199 [Bralower et al., 2002; Lyle et al., 2002)]. Better records for significant parts of the Cenozoic are still needed for the Pacific, especially within the period beginning about $37 \mathrm{Ma}$ and continuing through about $12 \mathrm{Ma}$ as well as the interval between 53 and about
45 Ma. New scientific drilling to cover these defects has been scheduled in IODP for 2008 (http://iodp.tamu.edu/ scienceops/).

[101] Moore et al. [2004] produced a new synthesis of data from equatorial Pacific drilling to explore the evolution of upwelling in the Pacific. They combined new biostratigraphic timescales to synthesize the results of previous scientific drilling in the equatorial Pacific and mapped the areal extent of elevated sedimentation rates for the Cenozoic (Figure 11). Because most of the sediment is composed of the remains of plankton tests, sedimentation rates in the pelagic equatorial Pacific reflect changes in surface water productivity.

[102] Modern process studies show that the shallow nature of equatorial upwelling and the narrow region of divergence act to focus biogenic sediment deposition at the equator [Murray et al., 1993; Honjo et al., 1995] (Figure 12). There is a background of sedimentation from other sources, primarily wind-blown dust from the continents, but the nonbiogenic sediments are deposited at rates near $1 \mathrm{~m}$ per million years in the modern equatorial Pacific, which is less than $10 \%$ of the total sedimentation rate underneath highproductivity zones.

[103] The distribution of biogenic sediments shows clear evidence of a major Eocene upwelling center along the equator throughout the Eocene but also reveals a secondary divergence zone between $6^{\circ} \mathrm{N}$ and $10^{\circ} \mathrm{N}$ that disappeared in the early Oligocene. Moore et al. [2004] suggest that there may be a relationship between the strength of this divergence and a Paleogene northern passage between Costa Rica and Guatemala, i.e., between the Atlantic and Pacific, but it is yet to be determined how such a passageway might affect upwelling. After the E-O boundary, from the beginning of the Oligocene through the beginning of the Miocene, biogenic sedimentation was more tightly focused at the equator, similar to the modern equatorial Pacific upwelling region [Moore et al., 2004; Lyle, 2003]. In the Pliocene the closure of the Isthmus of Panama caused the locus of highest biogenic sediment deposition (and presumably highest productivity and upwelling) to move eastward from about $110^{\circ} \mathrm{W}$ to about $85^{\circ} \mathrm{W}$ [Farrell et al., 1995; Lyle, 2003].

[104] Figure 13 displays the shipboard determination of Si mass accumulation rate (MAR) (or burial flux) along latitudinal transects at about $110^{\circ} \mathrm{W}$ in the Eocene, $120^{\circ} \mathrm{W}$ in the Oligocene, and $110^{\circ} \mathrm{W}$ in the Pleistocene. These determinations provide cross sections across the northern half of the equatorial productivity region at different times in the past. Si MAR is a mixed signal that measures primarily the tests of the silica-fixing plankton (diatoms and radiolaria) but also measures deposition of clay. Clays are a relatively small component at the equator, but they represent most of the Si MAR beyond about $10^{\circ}$ from the equator. The records illustrate the broad zone of plankton deposition in the middle Eocene versus the equatorially focused deposition zone of the Pleistocene. The upwelling region rapidly focused across the Eocene-Oligocene boundary from a broad region to a much narrower zone of 


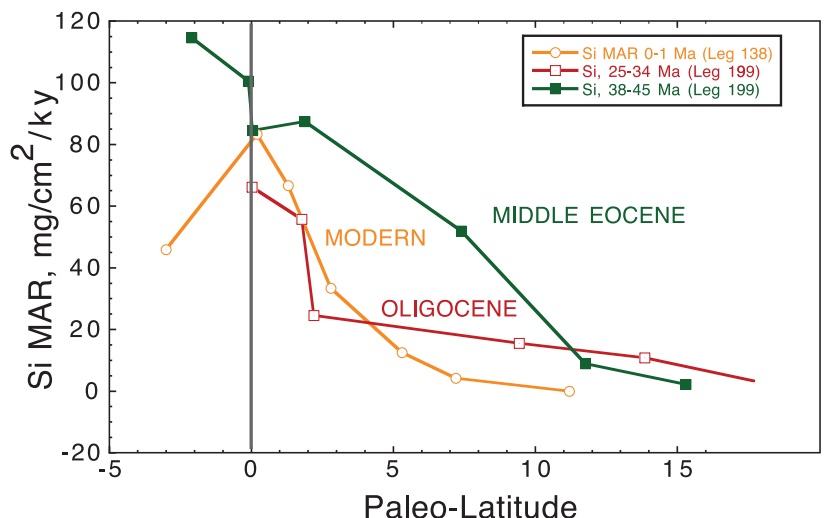

Figure 13. Change in focusing of biogenic $\mathrm{Si}$ mass accumulation rate (MAR) across Eocene-Oligocene boundary, suggesting a narrowing of the width of upwelling zone across the equator at that time. Data are from shipboard analyses on ODP Leg 199 [from Lyle et al., 2002].

biogenic deposition near the equator. There were no significant changes in the tropical gateways to the Pacific at this time, but there was a dynamical change in the upwelling system and, by inference, tropical winds associated with the E-O boundary [Moore et al., 2004; Vanden Berg and Jarrard, 2004].

[105] Observations on the equatorial Pacific thus show the existence of this major productivity region in the Eocene but show that significant differences existed between the greenhouse Earth and the icehouse Earth. Levels of productivity based upon accumulation of biogenic debris seem comparable, i.e., within a factor of 2 . Changes in productivity in the Cenozoic are probably important but do not yet appear to be the driver of the climate event.

8.1.2. Eocene Equatorial Pacific Plankton Community

[106] The Eocene equatorial Pacific plankton community had a much different structure than Pleistocene equatorial plankton. The different structure implies that carbon and nutrient cycles were different. The shallow CCD during the
Eocene makes it difficult to study the carbonate-producing plankton since their tests have been dissolved away at most locations. However, abundant biogenic opal in the sediments allows an assessment of the silica-secreting protists. An assessment of Eocene and Oligocene plankton assemblages is just beginning [e.g., Funakawa et al., 2006], but much can still be learned by comparing the relative abundance of radiolaria and diatoms, i.e., zooplankton versus phytoplankton. The Eocene equatorial Pacific is famous for its radiolarian oozes as evidenced by sediments composed of up to $80 \%$ heavily silicified radiolaria [Moore, 1969; Tracey and Leg 8 Shipboard Scientific Party, 1971]. These oozes are characteristic of the middle and late Eocene (i.e., in the period between 49 and $34 \mathrm{Ma}$ ), while the early Eocene had lower radiolarian numbers [Lyle et al., 2002].

[107] Diatom abundances in the Eocene were low as evidenced by smear slide estimates from Leg 199 sediments [Lyle et al., 2002]. Less than 5\% diatoms are found for most of the Oligocene and Eocene, only one tenth of the abundance of radiolarians. In contrast, Pleistocene eastern equatorial Pacific sediments contain 2-10 times as many diatoms as radiolaria (e.g., Figure 14, Pleistocene smear slide data from ODP Leg 138 [Mayer et al., 1992]). In other words, the relative proportion of diatoms (large primary producers) to radiolarians (consumers) was roughly 2 orders of magnitude lower in the Eocene than in the Pleistocene. Diatoms briefly appeared in relatively high abundance in the early Oligocene but did not become dominant in equatorial Pacific sediments until the end of the early Miocene between 17 and $15 \mathrm{Ma}$ [Barron and Baldauf, 1989] when biogenic Si deposition switched from the North Atlantic to North Pacific.

[108] One interval of high-diatom deposition in Eocene sediments [Lyle et al., 2002] occurred at the end of a major carbonate depositional event and cool interval around $40.5 \mathrm{Ma}$ (carbonate accumulation event 3 (CAE-3), see section 8.3 [Lyle et al., 2005]). In this interval, $50 \%$ of the sediment at Site 1219 was made up of diatoms, and the
Middle Eocene (ca $45 \mathrm{Ma}$ ) radiolarian ooze

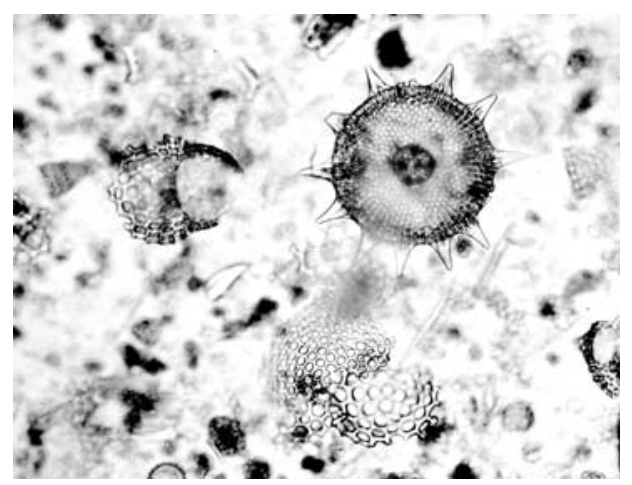

Holocene diatom ooze

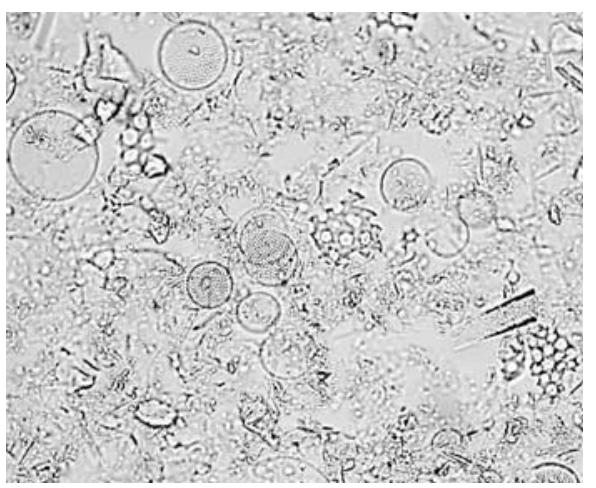

Figure 14. A comparison of acid-treated smear slides to compare the biogenic Si composition of (right) Holocene equatorial Pacific (from core ME0005-24JC) to (left) middle Eocene radiolarian ooze (from core EW9709-3PC). The modern sediments have 2-10 times as many diatoms (circles) as radiolaria. The Eocene sediments are almost completely composed of radiolarian tests. 
$\begin{array}{lllllllllllll}5 & 10 & 15 & 20 & 25 & 30 & 35 & 40 & 45 & 50 & 55 & 60 & 65\end{array}$

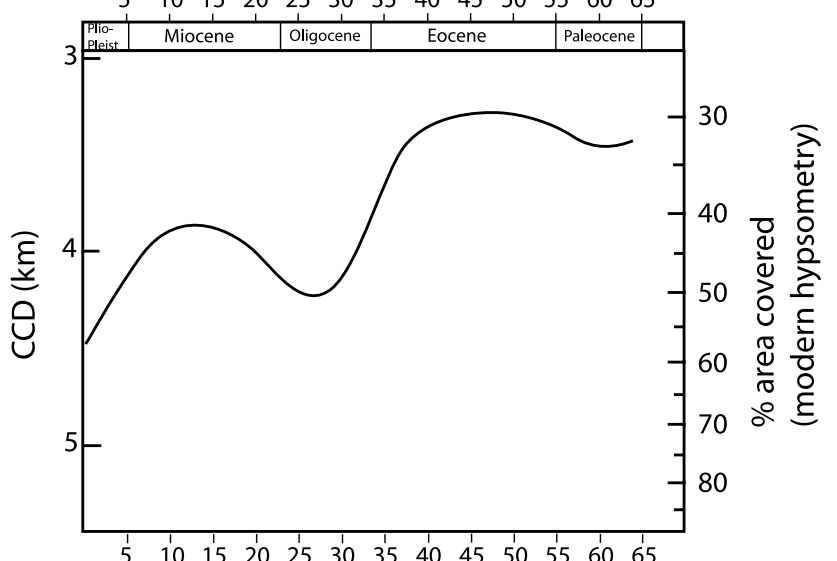

Age (Ma)

Figure 15. Global changes of the carbonate compensation depth (CCD) over the Cenozoic [after Delaney and Boyle, 1988]. CCD has been weighted for the area of the different ocean basins and individual basin CCD estimates. Timescale has been updated to that used in this paper.

event formed a stratigraphic marker at other sites separated by $800 \mathrm{~km}$ [Lyle et al., 2002]. A smaller diatom event was also noted in the early part of the Oligocene, and it correlates with a widespread event in the equatorial Pacific [Baldauf, 1993]. These observations suggest an apparent correlation between diatom numbers in the equatorial Pacific and the timing of peak cold events and warrant further investigation of the temperature dependence of ecological communities.

[109] The Pleistocene distribution and relative abundance of diatoms relative to radiolarians is in concordance with the expectation that zooplankton grazers should be far less abundant than the phytoplankton at the base of the food chain. The lack of diatoms in the Eocene sections cannot be attributed to postdepositional diagenesis, specifically high dissolution rates of diatoms relative to the Pleistocene, because the abundant radiolarian tests should have saturated the pore waters with Si. Furthermore, sedimentation rates were roughly equal for the Eocene and Pleistocene, so sediment layers were buried and removed from the corrosive action of bottom waters at roughly the same rate. If diatoms managed to survive the sediment-water interface in the Pleistocene, there is no clear reason why they should not have survived in the Eocene.

[110] Diatoms are widespread in middle and late Eocene sediments of the middle-latitude North Pacific as well as in the North Atlantic [Barron and Baldauf, 1989], which begs the question of why equatorial Pacific diatom productivity was suppressed in the Eocene. The lack of diatoms suggests that small phytoplankton or bacteria were the primary producers in the equatorial Pacific rather than the larger diatoms. The high flux of particulate organic carbon from the euphotic zone attributed to diatoms [Smetacek, 1985; Dugdale and Wilkerson, 1998, 2001] was probably lacking in the Eocene equatorial Pacific.
[111] Carbonate-producing phytoplankton are typically displaced by the diatoms [e.g., Dymond and Lyle, 1985], so there could have been much higher production rates of carbonate in surface waters and subsequent rain of particulate carbonate to the ocean floor in the Eocene relative to the Pleistocene. Even though the CCD was much shallower in the Eocene, carbonate production may have been greater than modern conditions. The shallow CCD that is typical of the Eocene thus indicates significant differences in ocean carbon chemistry, which also supported the high levels of $\mathrm{CO}_{2}$ in the atmosphere.

\subsection{Eocene-Oligocene Boundary: A Permanent Step in the Cycle}

[112] Two events, at the beginning and end of the Eocene, are evidence of the influence of the carbon cycle upon the maintenance of an equable Earth. The earlier event, known as the "Paleocene-Eocene thermal maximum," marks a significant warming above an already warm Earth at the start of the Eocene. This event may indicate that significant outgassing of methane or $\mathrm{CO}_{2}$ occurred in a relatively brief period of time. However, this perturbation in the carbon cycle, regardless of cause, was relatively short-lived on a geological scale, as conditions decayed back to the background state in about 100-200 ka [Dickens et al., 1997; Norris and Röhl, 1999; Lourens et al., 2005]. The shortterm nature of the PETM indicates that a set of feedbacks were able to return the warm transient to a baseline Eocene level of elevated $\mathrm{CO}_{2}$ and warm climate, thereby preventing a step to even warmer conditions and a more extreme greenhouse.

[113] The Eocene-Oligocene boundary marks a permanent deepening of global CCD by 1200-1500 m (Figure 15) [Berger, 1973; van Andel and Moore, 1974; Delaney and Boyle, 1988; Peterson et al., 1992] that occurs rapidly and in synchrony with the glaciation of Antarctica [Coxall et al., 2005]. In contrast, the equatorial Pacific CCD change associated with Pleistocene glaciations in the last $800 \mathrm{ka}$ has remained within a range of about $100 \mathrm{~m}$ [Farrell and Prell, 1989]. The Oi-1 glaciation at the beginning of the Oligocene [Miller et al., 1991; Zachos et al., 2001a] marks a threshold in the Earth's climate system that resulted in cooler average global conditions and maintenance of lower average atmospheric $\mathrm{CO}_{2}$ concentration (Figure 10). The Eocene-Oligocene transition thus represents a failure of the warm "thermostat" that is very important to understand. The greatest change was the permanent, global deepening of the ocean's CCD of $\sim 1200 \mathrm{~m}$, which has never again risen to the shallow depths of the Eocene.

[114] The increase in sedimentary $\mathrm{CaCO}_{3}$ content is well correlated with the change in oxygen isotopes of benthic foraminifera (a measure of high-latitude temperature and ice volume), indicating an important link between the deepening of the CCD and the Oi-1 glacial period [Coxall et al., 2005]. Both $\mathrm{CaCO}_{3}$ burial rates and oxygen isotopes reached a peak between 33.6 and $33.5 \mathrm{Ma}$ at the beginning of the Oligocene. The peak of the Oi-1 glacial was marked by geographically extensive carbonate burial, with carbonate 
Sites 1218 \& 1219 MAR data

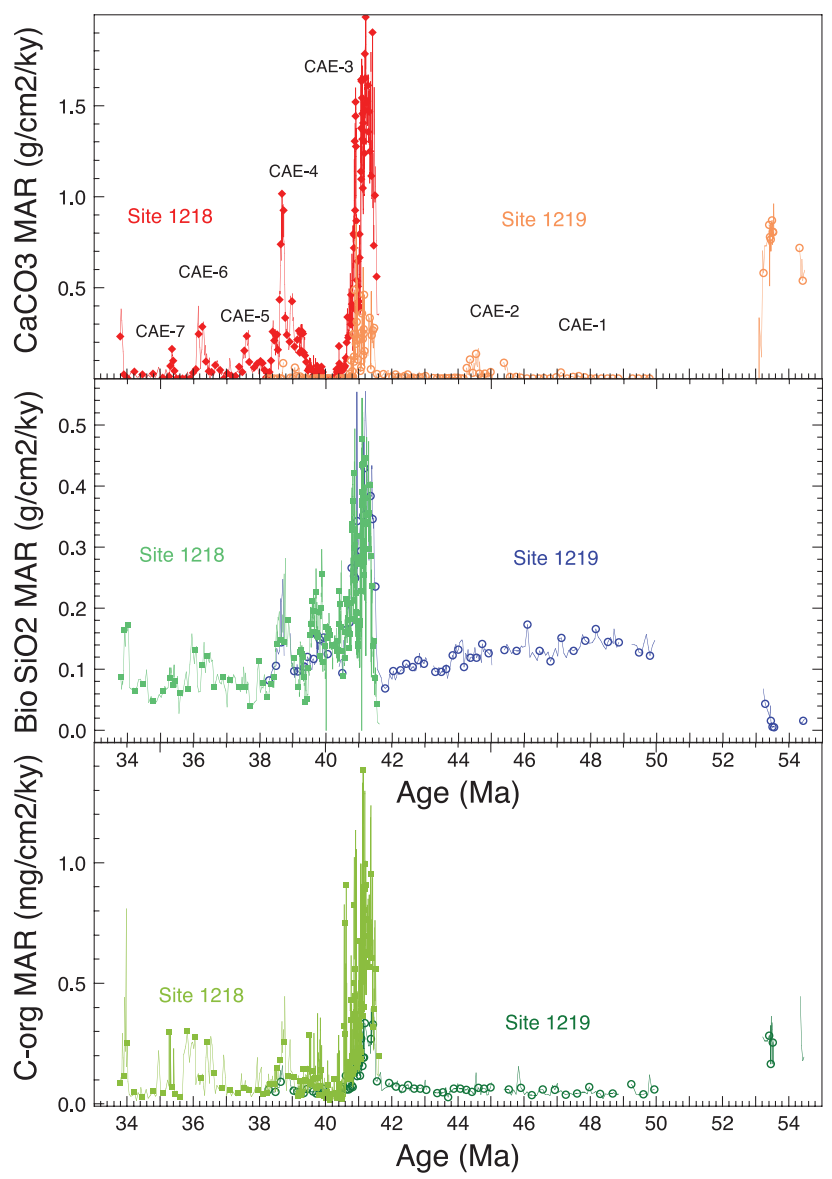

Figure 16. Eocene changes in carbonate, biogenic $\mathrm{SiO}_{2}$, and organic carbon mass accumulation rate, marking Eocene CCD excursions [from Lyle et al., 2005]. The carbonate accumulation events (CAEs) mark important changes in Eocene CCD. The largest of these events (CAE3 and CAE-4) also mark elevated productivity, as is shown by the increases in the other biogenic components. Site 1218 was about $700 \mathrm{~m}$ shallower than Site 1219, and the difference in carbonate MAR between them is a result of depth-dependent dissolution.

sedimentation as much as $10^{\circ}$ north of the equator at the time, about twice the distance from the equator that modern carbonates are deposited [Leg 199 Shipboard Scientific Party, 2002]. Carbonate burial then decreased by about $50 \%$ within $200 \mathrm{ka}$ after the Oi-1 event, but the CCD never returned to the shallow levels characteristic of the Eocene.

\subsection{Eocene CCD Record}

[115] The Eocene has been viewed as a warm and relatively stable climate regime, primarily because of the lack of continuous high-resolution sediment records that span this 21 million year interval. New records of the CCD indicate that the Eocene was punctuated by several transient but cool, high-carbonate deposition events lasting for 1-2 million years before dissipating [Lyle et al., 2005]. The seven events were first identified and termed "carbonate accumulation events" [Lyle et al., 2005] and are marked by high-carbonate burial, a relatively deep $\mathrm{CCD}$, and oxygen isotope evidence for cool global conditions. In the middle and late Eocene (between 42 and $38 \mathrm{Ma}$ ) the equatorial Pacific CCD twice oscillated by over $800 \mathrm{~m}$ water depth. There is also evidence that other smaller CCD deepenings occurred at around 45 and $47 \mathrm{Ma}$.

[116] The largest of the CAEs occurred in the late middle Eocene (CAE-3, between 42.2 and $40.3 \mathrm{Ma}$ ) and was clearly associated with increased productivity as well as cooling (Figure 16) [Moore et al., 2004; Lyle et al., 2005]. Oxygen isotopes measured in bulk carbonates increased by $1.2 \%$ between the beginning and the peak time of carbonate deposition. The change in oxygen isotopes indicates major cooling of tropical surface water and/or formation of ice sheets. Biogenic $\mathrm{Si}$ deposition rose to about 4 times its middle to late Eocene average [Olivarez Lyle and Lyle, 2005]. The end of the CAE-3 interval marks one of the fastest shoaling episodes of the CCD in the Cenozoic record, from a depth near $4400 \mathrm{~m}$ to less than $3250 \mathrm{~m}$, or more than $1 \mathrm{~km}$, and the maximum rate of change was more than $600 \mathrm{~m}$ in less than $100 \mathrm{ka}$, the limit of our current timescale resolution [Lyle et al., 2005].

[117] Deposition of both biogenic $\mathrm{Si}$ and carbonate dropped at the end of CAE-3 so that part of the shallowing of the CCD can be linked to a decrease in productivity. However, carbonate burial decreased much faster than biogenic Si burial in the equatorial Pacific, which implies that marine-dissolved inorganic carbon (DIC) content increased quickly relative to alkalinity. If the ratio of biogenic $\mathrm{Si}$ to carbonate did not change in the rain of plankton remains and only productivity dropped, the amount of change in both biogenic $\mathrm{Si}$ and carbonate would be in proportion to each other, and carbonate should still be present in the post-CAE-3 interval. Higher atmospheric $\mathrm{CO}_{2}$ concentration and concomitant greenhouse warming are thus implied by the changes. Future investigations are needed to determine the timing and magnitude of atmospheric $\mathrm{CO}_{2}$ oscillations relative to the carbonate burial events.

[118] The CCD excursions within the Eocene are large and rival the terminal E-O boundary deepening of $1200-$ $1500 \mathrm{~m}$. For comparison, note that throughout the Neogene (0-23 Ma), Pacific CCD variations are typically less than $200 \mathrm{~m}$, or less than $20 \%$ of the largest Eocene CCD fluctuations and Pleistocene variations associated with glacial conditions are about $100 \mathrm{~m}$. Despite the extreme CCD fluctuations within the Eocene the cool conditions and the CCD excursions always ended, and global climate returned to warm conditions until the E-O transition.

[119] The Eocene CCD oscillations are spaced roughly 2.5 million years apart between 47 and $40 \mathrm{Ma}$ and become more frequent after $40 \mathrm{Ma}$, about 1.2 million years apart. These same long-period variations are identified for Earth's orbital eccentricity around the Sun [Laskar et al., 2004; Pälike et al., 2004], suggesting, perhaps, that orbital insolation variations are a pacemaker for the carbonate events. If further work confirms this link, then orbital-induced insolation variability can be used to explore climate sensitivity in the Eocene. 
[120] Evidence suggests that the CAEs are linked to global cooling and perhaps to Antarctic glaciation [Lyle et al., 2005; Tripati et al., 2005]. Each CAE is marked by a significant increase in the oxygen isotope values of the bulk assemblage of carbonates, mostly composed of carbonatesecreting nanoplankton that lived in the euphotic zone [Lyle et al., 2005]. This oxygen isotope response reflects a combination of cooling tropical SST and/or an increase in ice volume. Benthic oxygen isotopes measured on bottomliving foraminifera also increase, a signal that combines high-latitude SST where the waters are sourced and ice volume [Tripati et al., 2005]. Bulk oxygen isotopes (the tropical surface water signal) changed by about $1.2 \%$, while benthic isotopes changed by about $0.8 \%$ over CAE-3, suggesting that tropical Pacific surface waters cooled with respect to the polar surface waters.

[121] Tripati et al. [2005] suggest that huge, Pleistocenesize ice caps at both the North and South poles formed during CAE-3, based on a comparison of $\mathrm{Mg} / \mathrm{Ca}$ temperature estimates with the oxygen isotope excursion. However, growth of such large ice sheets is equivalent to $120 \mathrm{~m}$ of sea level lowering and is unlikely to have occurred during the Eocene. First, the temperature signal that Tripati et al. [2005] report likely includes a preservation artifact with the $\mathrm{Mg} / \mathrm{Ca}$ data in this interval [Lear et al., 2004] rendering the data unreliable for temperature reconstructions. Second, independent evidence of sea level change during CAE-3 has been obtained from sequence stratigraphy of the New Jersey margin. These data support the idea of sea level falls during the middle Eocene but of a much smaller magnitude ( $30-$ 50 m [Browning et al., 1996; Miller et al., 1998, 2005]). Sequence stratigraphic data indicate a sea level fall for the E-O boundary of approximately 50 to $60 \mathrm{~m}$ [Miller et al., 2005]. An ice cap that accounts for 30-50 m of sea level lowering is about $40-70 \%$ of the total volume of ice present on Earth today.

[122] The CAE-3 event between 42.3 and 40.3 Ma might represent a significant but transient glaciation of Antarctica. It correlates with the first direct evidence of glaciation from Prydz Bay [Barron et al., 1991]. Assuming that an Antarctic ice sheet did form during CAE-3, the sudden termination of the event in two rapid steps, the second of which is about $200 \mathrm{ka}$ long, suggests that significant feedbacks existed in the middle Eocene to remove an ice cap even after it existed for more than a million years. If the ice cap appeared because of variations in Earth's orbital eccentricity, then the Eocene world had a significantly stronger sensitivity to insolation than the Holocene world.

\subsection{Implications of the Deep Oligocene CCD}

[123] An important outcome from the Eocene equatorial Pacific studies is the recognition of the apparent correlation between deepening of the $\mathrm{CCD}$, increased pelagic carbonate deposition, and global cooling. A similar correlation occurs for the Pleistocene as well: Higher carbonate deposition occurs in the glacial phase of glacial-interglacial cycles.

[124] Another correlation is that global warming is linked to a shallow oceanic CCD. The most dramatic evidence is associated with the Paleocene-Eocene thermal maximum warm transient event at $55 \mathrm{Ma}$. New ocean drilling reveals a very large and rapid rise of the CCD during this time as evidenced by enhanced dissolution of carbonate from shallow to deep waters in depth transects from both the Pacific and Atlantic oceans: the Shatsky Rise in the Pacific [Leg 198 Shipboard Scientific Party, 2002; Colosimo et al., 2006] and the Walvis Ridge in the South Atlantic [Leg 208 Shipboard Scientific Party, 2004]. The cause of the PETM warming is attributed to a large methane release at the Paleocene-Eocene boundary [Dickens et al., 1995], with equivalent additions of dissolved carbon from other sources [Zachos et al., 2005].

[125] From first principles we might predict from our knowledge of the carbon cycle and its control of atmospheric $\mathrm{CO}_{2}$ that global warming and cooling would be linked to the rise and fall of the $\mathrm{CCD}$ in the oceans. Extended periods of high atmospheric $\mathrm{CO}_{2}$ concentration require that the ocean not absorb all the excess $\mathrm{CO}_{2}$ and that ocean carbon chemistry remains in a basic steady state with the atmosphere. In other words, the relative proportion of DIC to alkalinity in seawater under the relatively high- $p \mathrm{CO}_{2}$ conditions of the Eocene must be significantly higher than the DIC to alkalinity ratio of the modern ocean in order for high atmospheric $\mathrm{CO}_{2}$ concentration to be maintained.

[126] The rapidity of the changes in the CCD challenges our understanding of how the carbon cycle behaves. Specifically, the alkalinity of the oceans is maintained by cations supplied by silicate weathering of the continents. Silicate weathering does not change dramatically on 10,000year timescales, as did the CCD. Furthermore, after the E-O boundary the CCD remained $1.2 \mathrm{~km}$ deeper than its average depth over the Eocene. We have yet to satisfactorily explain both the rapid change of the CCD (i.e., ocean chemistry) and the permanent offset at the E-O boundary relative to the older geologic record.

[127] Another problem made apparent by the E-O boundary event is the lack of negative feedbacks to stabilize the system. As discussed in section 8.4.1, a variety of positive feedbacks exist between sea level, temperature, and the carbon system. A set of negative feedbacks should exist to stabilize the carbon system, but the likely candidates are poorly understood. Berner et al. [1983] argued for a negative feedback through the weathering cycle and temperature; that is, higher temperatures cause higher weathering rates and elevated consumption of atmospheric $\mathrm{CO}_{2}$, which ultimately would act to lower the temperature. This negative feedback appears to be poorly coupled with climate itself in modern process studies [Raymo and Ruddiman, 1992; Edmond and Huh, 1997], but some negative feedback between atmospheric $\mathrm{CO}_{2}$ levels and weathering rates seems necessary to prevent huge swings in atmospheric $\mathrm{CO}_{2}$ content [Broecker and Sanyal, 1998; Kump et al., 2000].

\subsubsection{Rapid Reorganizations of the Carbon Cycle}

[128] A variety of mechanisms have been suggested to cause a relatively rapid change in the CCD in the oceans, linked to a climate change (thousands to tens of thousands of years). Rapid changes in sea level caused by the waxing 
and waning of ice sheets can change deep ocean carbon burial by two mechanisms, while changes in global temperature can also affect carbon burial rapidly.

[129] When ice caps grow and sea level falls, shallow shelf regions where marine carbonates are produced and buried become exposed, and an important carbonate reservoir is eliminated. This loss of the shallow carbonate reservoirs is ultimately balanced by higher rates of carbonate burial in the deep sea and depression of the CCD [Opdyke and Wilkinson, 1988; Betzler et al., 2000]. The effect should roughly scale with the change in low-latitude shallow marine surface area.

[130] Subaerial exposure of shallow marine carbonates should cause an additional weathering flux to the oceans, increase the calcium content of the oceans, and cause an increase in pelagic carbon burial [De La Rocha and DePaolo, 2000]. This mechanism changes ocean alkalinity and should cause a drop in atmospheric $\mathrm{CO}_{2}$, which is consumed when carbonates are weathered. This weathering should be transient, however, and the duration and magnitude of the effect should depend on the size of the shallow carbonate reservoir exposed to subaerial weathering.

[131] Temperature can also cause rapid changes in the CCD by altering organic carbon storage and burial. Metabolic effects link carbon utilization directly to temperature, caused by the universal rise of metabolic rates with temperature scaled to body size [Gillooly et al., 2001; Olivarez Lyle and Lyle, 2005, 2006]. Temperature can also cause less predictable changes when the climate is near the temperature tolerance of important organisms in an ecosystem [Dymond and Lyle, 1985; Archer and Maier-Reimer, 1994]. 8.4.2. Sea Level and Rapid Carbon Cycle Change at the E-O Boundary

[132] The sudden and permanent deepening of the global $\mathrm{CCD}$ at the E-O boundary could represent the removal and transfer of shallow water carbonate storage to the pelagic realm. However, on the basis of calculations of shelf area likely affected by the sea level fall, Rea and Lyle [2005] suggest that this mechanism was too small to explain all of the observed change in CCD at the E-O boundary. Figure 17 shows the hypsometry of the modern Earth along with estimated change in the area of pelagic carbonate burial resulting from a CCD deepening of $1300 \mathrm{~m}$, as observed in the equatorial Pacific. Assuming the hypsometry of the Eocene Earth was similar to the modern Earth and the latest Eocene sea level that was $50 \mathrm{~m}$ higher than Oligocene, Rea and Lyle [2005] estimate that only $\sim 3 \%$ of the Earth's surface previously covered by shallow seas was exposed by the sea level drop at the E-O transition.

[133] During the late Eocene, marine carbonate was deposited on only $20 \%$ of the Earth's surface because of the shallow CCD. After the CCD deepened at the E-O boundary, marine carbonates were deposited on $45 \%$ of the Earth's surface. A quarter of the globe was transformed into a carbonate depositional environment because of the deeper CCD. The removal of shallow carbonate environments will have a disproportionate effect upon the expansion of deep burial because the deposition rates of carbonate in the shallows is typically much higher than pelagic deposition rates. Nevertheless, a shelf-to-abyss carbonate transfer can only account for an expansion in pelagic carbonate depositional area of about $10 \%$ of the total surface area (i.e., from $20 \%$ to $30 \%$ of global surface area for marine carbonate burial but not $45 \%$ of the area) even assuming high rates of burial for shallow carbonates relative to pelagic carbonate burial. The remaining increase in marine carbonate burial area must relate to changes in the inorganic carbon cycle.

[134] Weathering of carbonates exposed by a drop in sea level helps to increase the net deepening of the CCD but also retards the attainment of maximum potential CCD scaled to the rate the exposed carbonate weathers and the volume of exposed carbonate. These rates slow as the surface becomes eroded back to the new sea level. Exposed high sea level carbonate terraces more than $100 \mathrm{ka}$ old [e.g., Ku et al., 1974] attest to the slowness of the weathering process relative to sea level changes.

\subsubsection{Temperature and Rapid Carbon Cycle Change at the E-O Boundary}

[135] Temperature has a strong effect on organic carbon production and burial, which might produce a positive feedback through variation in atmospheric $\mathrm{CO}_{2}$ and in the marine DIC pool. Gillooly et al. [2001] have proposed that all organisms have a common metabolic response to temperature when scaled for body mass. High temperatures require higher resting metabolic rates and a higher utilization of stores of $\mathrm{C}_{\mathrm{org}}$ to maintain life, causing roughly a doubling of respiration for each $10^{\circ} \mathrm{C}$ rise in temperature. How temperature affects carbon storage in shallowly buried $\mathrm{C}_{\text {org }}$ reservoirs is important for understanding impacts of anthropogenic global warming as well [Davidson and Janssens, 2006].

[136] Olivarez Lyle and Lyle [2005, 2006] have found evidence that temperature may have significantly affected Eocene pelagic $\mathrm{C}_{\text {org }}$ burial. High temperatures associated with the Eocene strongly limited the amount of $\mathrm{C}_{\text {org }}$ buried under a pelagic high-productivity regime. Olivarez Lyle and Lyle [2005, 2006] reached this conclusion by comparing a well-preserved indicator of $\mathrm{C}_{\text {org }}$ rain, biogenic barium, to actual $\mathrm{C}_{\text {org }}$ burial. From the very low amounts of $\mathrm{C}_{\text {org }}$ relative to biobarium it is clear that $\mathrm{C}_{\text {org }}$ is much more poorly preserved in the Eocene than in the Pleistocene (an order of magnitude change in $\mathrm{C}_{\text {org }}$ burial). In other words, particulate marine $\mathrm{C}_{\text {org }}$ was recycled at much higher rates in the warm Eocene compared to the Pleistocene, rendering it unavailable for burial. This imbalance, relative to carbonates, helps to retain DIC within the oceans and to maintain higher DIC/alkalinity as well as maintain higher atmospheric $\mathrm{CO}_{2}$ concentration. At any given point in geologic time the pelagic fraction of the total $\mathrm{C}_{\text {org }}$ burial flux is small and thus exerts relatively small leverage on the system. However, given sufficient time, a small leverage can cause a significant offset in the steady state conditions by a magnitude equal to the current anthropogenic increase in atmospheric $\mathrm{CO}_{2}$ in just 4000 years. Furthermore, similar changes in the metabolic use of carbon are expected for both the terrestrial soil carbon reservoirs and for shallow marine $\mathrm{C}_{\text {org }}$ reservoirs 


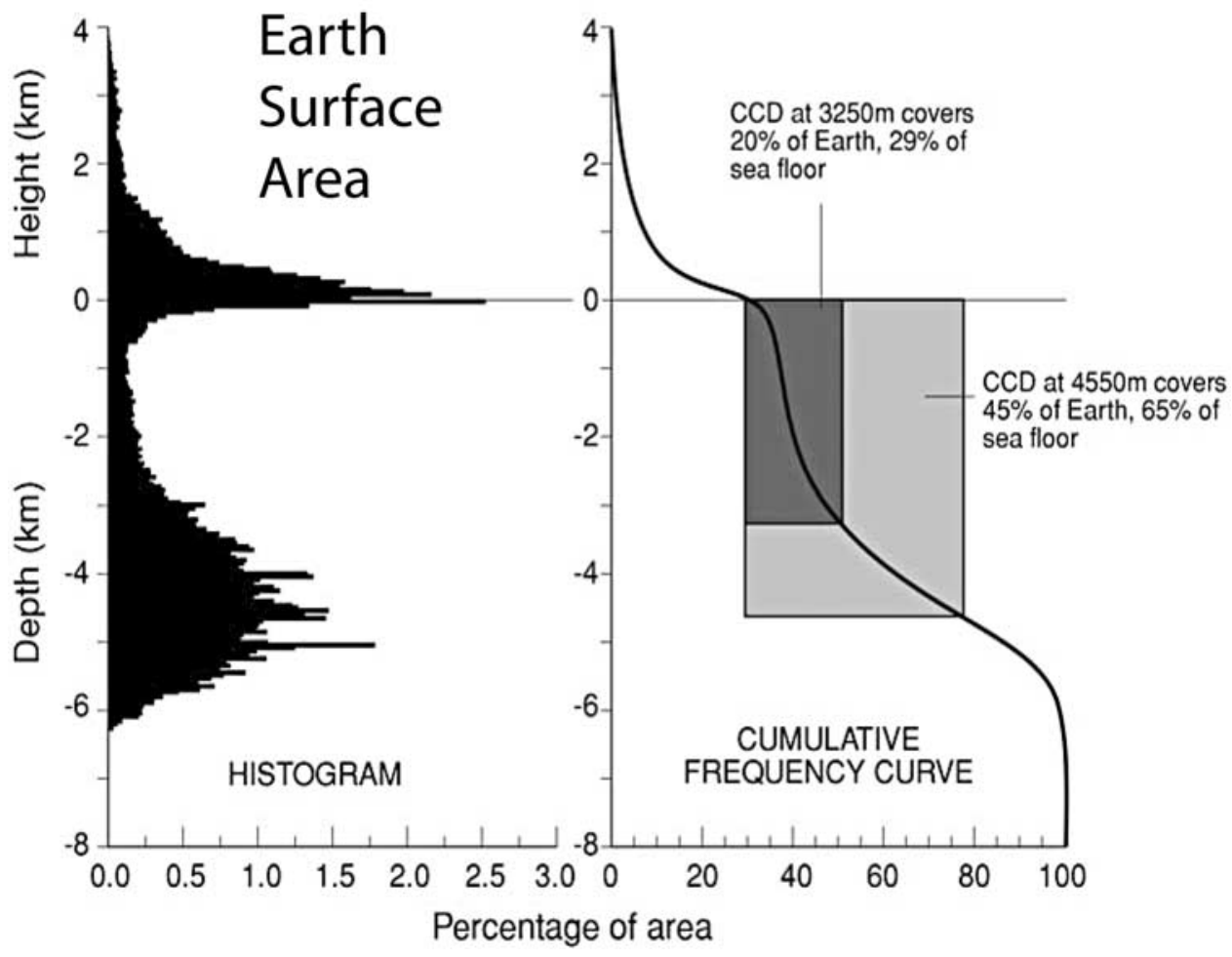

Figure 17. Hypsometry of the modern Earth, with superimposed change in CCD at Eocene-Oligocene boundary [from Rea and Lyle, 2005]. The 1200- to 1500-m CCD change increased the carbonate depositional environment by an area equivalent to one fourth of the entire Earth's surface area.

under warm conditions. Such feedbacks act to minimize the storage of $\mathrm{C}_{\text {org }}$ in shallow reservoirs during warm climates but expand these reservoirs when the Earth cools.

[137] Another temperature-related feedback could result from temperature tolerances of biogeochemically important plankton. Dymond and Lyle [1985], for example, suggested that the different optimum growth temperatures of diatoms versus coccolithophorids or other carbonate-producing phytoplankton could change surface ocean chemistry and atmospheric $\mathrm{CO}_{2}$, leading to a rapid positive feedback. For a large effect on atmospheric $\mathrm{CO}_{2}$, however, the increase in organic carbon burial must be greater than the carbon that is buried as calcium carbonates, a difficult task at the E-O boundary in the equatorial Pacific. An ecologicalbiogeochemical feedback through $\mathrm{C}_{\text {org }}$ burial should only be important in the high latitudes, given that silica-secreting diatoms were rare at the equator.

\subsection{Magnitude of the Carbon Cycle Change at the Eocene-Oligocene Boundary}

[138] An estimate can be made for the change in ocean chemistry if planktonic production of pelagic carbonate is assumed to remain constant, so that the deepening of the CCD reflects only the changes in marine carbon chemistry. For a $1200-\mathrm{m}$ deepening of the $\mathrm{CCD}$, either $[\mathrm{Ca}]$ or $\left[\mathrm{CO}_{3}\right]$ increased to offset the pressure effect on the calcite solubility product constant $\left(K_{\mathrm{sp}}\right)$ and to cause calcite saturation $1200 \mathrm{~m}$ deeper in the ocean. On the basis of Pytkowicz [1969] the change in $K_{\mathrm{sp}}$ of $\mathrm{CaCO}_{3}$ from 3300 to $4500 \mathrm{~m}$ is about $20 \%$, requiring some combination of either a $20 \%$ increase in marine [Ca] or $\left[\mathrm{CO}_{3}\right]$. Kerrick and Caldeira [1999] estimated that a $1-\mathrm{km}$ deepening of CCD requires a $15 \%$ increase of $\left[\mathrm{CO}_{3}\right]$, assuming constant $[\mathrm{Ca}]$, and that at constant $\mathrm{pH}$ this would also cause about a $15 \%$ decrease in atmospheric $\mathrm{CO}_{2}$.

[139] Two avenues lead to the CCD step at the E-O boundary: Either a large and permanent increase in $\mathrm{C}_{\text {org }}$ storage occurred at the boundary, or weathering increased significantly to deliver more dissolved $\mathrm{Ca}$ to the oceans. Development of shallow $\mathrm{C}_{\text {org }}$ reservoirs could cause a deepening of the $\mathrm{CCD}$ by removing $\mathrm{C}_{\text {org }}$ from the system rapidly and causing $\left[\mathrm{CO}_{3}\right]^{=}$to rise. The $\left[\mathrm{CO}_{3}\right]^{=}$content in seawater is approximately equal to the difference between total alkalinity and DIC, so that removing DIC relative to alkalinity from the oceans should deepen the CCD if the DIC removal is large enough. The shallow sedimentary carbon reservoirs hold about $5 \%$ of modern ocean DIC [Houghton et al., 2001]. Development of these reservoirs could thus cause about a third of the CCD drop observed. However, the effect would be transient unless the $\mathrm{C}_{\text {org }}$ was transferred from the shallow reservoirs into long-term geologic storage. Further work is needed to investigate this pathway.

[140] Ultimately, changes in the weathering cycle must be a major cause of the E-O CCD deepening and should cause ocean $\mathrm{Ca}$ content to increase by roughly $7 \%$, based on the following reasoning. First, $\mathrm{Ca}$ is not selectively weathered but is transported to the oceans with other cations and 
anions. Using the average composition of modern rivers [e.g., Livingstone, 1963; Martin and Meybeck, 1979] and assuming that Eocene rivers were similar, $\mathrm{Ca}$ makes up about $19 \%$ of the total cations and $27 \%$ of the total cation charge being weathered from the land. Only half the total cation charge is balanced by weathered anions like $\mathrm{Cl}$ and $\left[\mathrm{SO}_{4}\right]^{=}$. The remaining charge is balanced by the carbonate system through $\left[\mathrm{HCO}_{3}\right]^{-}$, which is formed directly from atmospheric $\mathrm{CO}_{2}$ during weathering. Weathering thus produces a flux of $\mathrm{Ca}$ to the oceans, an increase of ocean alkalinity through the addition of highly soluble cations, and a decrease in atmospheric $\mathrm{CO}_{2}$.

[141] The ocean $\left[\mathrm{CO}_{3}\right]^{=}$increases to balance the increase in total alkalinity of the oceans. The oceans become more saturated with respect to $\mathrm{CaCO}_{3}$, thus deepening the CCD in the oceans. Increased weathering will cause about a $13 \%$ increase in total alkalinity and $\left[\mathrm{CO}_{3}\right]^{=}$to balance the $7 \%$ increase of $\mathrm{Ca}$. We note that this estimate is lower than the estimated change in weathering flux relative to sedimentary flux estimated by De La Rocha and DePaolo [2000] based on changes in $\mathrm{Ca}$ isotopes.

[142] It is clear that a significant change in weathering could cause the CCD deepening, but it is not clear why weathering rates would suddenly cross an important threshold and then remain high. It is also unclear how the change in CCD is linked to the formation of the Antarctic ice sheet. Ravizza and Peucker-Ehrenbrink [2003] have suggested that glacial grinding of Antarctica and the production of fine aluminosilicate debris might cause an increase in weathering. However, the Os isotope weathering tracer does not rise concurrent with the Oi-1 glaciation but rises about $300 \mathrm{ka}$ after the peak glaciation. Further work is clearly needed to understand how weathering and the carbon cycle fit together to produce large climate changes and to define the sensitivity of the system's capability to reverse itself.

[143] Finally, it is worth reiterating that the E-O boundary represents a time of sudden change within a much more gradual decay of conditions. Atmospheric $\mathrm{CO}_{2}$ apparently took millions of years to drop after the boundary event, and the evolution of floral and shallow marine ecosystems in the Pacific Northwest was drawn out over about 6 million years between 35 and 29 Ma [Retallack et al., 2004]. An important lesson is that even after a climate trigger is passed, it may take millions of years to settle into a new quasi steady state, as evidenced, for example, by similar long-term evolution of the system that is characteristic of the Pliocene ice age developments [Ravelo et al., 2004].

\section{PACIFIC OCEAN, WESTERN U.S. WATER CYCLE, AND TERRESTRIAL ECOSYSTEMS: MIDDLE MIOCENE GLOBAL COOLING}

[144] The Eocene can be used to study how geosystems operated in the presence of high atmospheric $\mathrm{CO}_{2}$ concentration and how elevated levels of atmospheric $\mathrm{CO}_{2}$ can be maintained over tens of millions of years. In contrast, the middle Miocene "climatic optimum" at circa $15 \mathrm{Ma}$ is a time when warm global conditions were maintained without an obvious greenhouse gas driver. Atmospheric $\mathrm{CO}_{2}$ was near modern values [Pagani et al., 1999a, 1999b; Pearson and Palmer, 2000; Royer et al., 2001] suggesting that maintenance of global warmth over millions of years represents a unique dynamic balance of the other heattrapping components of the global climate system. Investigations of the middle Miocene and the decay of warm global temperatures leading to the Pleistocene ice ages are extremely important for understanding how the Earth regulates its temperature.

[145] At first appearance the beginning of the middle Miocene (circa $16 \mathrm{Ma}$ ) seems to represent either the culmination of a water vapor or methane greenhouse or a configuration of ocean and atmosphere that maximized Earth's heat retention and maintained warm high latitudes. The period between 16 and $14 \mathrm{Ma}$ coincides with the maximum eruption of the Columbia River flood basalts [Hooper, 1997; Hooper et al., 2002] suggesting that significant $\mathrm{CO}_{2}$ was introduced into the atmosphere at this time by volcanic outgassing. However, evidence that atmospheric $\mathrm{CO}_{2}$ was near modern levels (less than 100-200 ppm above preanthropogenic atmospheric $\mathrm{CO}_{2}$ ) during the middle Miocene is relatively good (Figure 10). Another hypothesis is that a prolonged, low-level greenhouse condition was created through feedbacks that involved increased atmospheric water vapor or methane to maintain warm global temperatures. Studies of the middle Miocene warm period and the decay from warm to cool and dry conditions by the beginning of the Pliocene (5.4 Ma) have been neglected for decades. The last major synthesis of Miocene paleoceanography [Kennett, 1985] to highlight important climate and carbon cycle changes is more than 20 years old. Development of a newer spatial array of information is straightforward but has yet to be done. Specifically, appropriate sediment sections are known to exist on land and in the ocean. Some have yet to be recovered, while others have already been drilled but not yet studied. Excellent new Miocene sediment records have been drilled and recovered in the Pacific, most recently from the Shatsky Rise in the North Pacific during ODP Leg 198 [Bralower et al., 2006], from the southeast Pacific near the Nazca Ridge, and in the eastern equatorial Pacific on the Cocos Ridge (both from Leg 202 [Mix et al., 2003]). Numerous ODP drilling legs of the last decade have also recovered good Miocene sections that have not been studied to their full potential.

\subsection{Miocene Water Cycle}

[146] One major difference between the Miocene and Pleistocene is the apparent strength of the water cycle. Here we explore the Miocene water cycle in the context of interactions between the North Pacific Ocean and western North America. Unlike its modern Mediterranean climate (dry summer and wet winter) the Miocene western United States experienced wet, humid summers. Between 15 and $5 \mathrm{Ma}$, wet summers disappeared, and deserts were formed in the interior. The drying of the western United States is part of a poorly understood global drying that profoundly affected vegetation and mammal evolution over much of 
the Earth [Cerling et al., 1997; Pagani et al., 1999a; Fortelius et al., 2002; Huang et al., 2007].

[147] During this climate transition the vegetation of the western United States switched from deciduous or mixed conifer-deciduous forests that flourished under wet summer conditions to evergreen forests, chaparral, and desert flora that could survive dry summers. Exploring the Miocene water cycle will ultimately produce a better understanding of the ocean sources of North American water and how the oceans and atmosphere interact to change the water cycle. Existing proxy records resolve some components of the Miocene climate system, yet the magnitude of the water cycle anomaly suggests that profound differences in many components relative to present would be found if this transition were studied in more detail.

[148] The drying of the American West has been linked to the development of the linear coastal mountain chain from Washington to California, but the evidence for this tectonic control is small. The development of a rain shadow eastward of these emerging mountains would cause reduced rainfall for the Great Basin region of the western United States. However, it has also been suggested that the cooling trend in the Pacific Ocean was another possible cause [Axelrod, 1977]. Two important lines of evidence refute the hypothesis that the Sierra/Cascade rain shadow was the dominant process that caused the drying of the American West. First, the gradual drying trend from at least 12 to $5 \mathrm{Ma}$ does not match the known tectonic histories of either the Cascades or the Sierra Nevada range but instead appears to be an expression of a global Miocene climate trend [Cerling et al., 1997; Zachos et al., 2001a; Fortelius et al., 2002; Huang et al., 2007]. The second line of evidence, and perhaps the strongest evidence so far, is that the disappearance of Miocene wet summer flora occurred along the coastal regions of California and Oregon as well as within the "rain shadow" region of the western interior. Aridification westward of the mountains (i.e., seaward) cannot be attributed to a developing rain shadow. The disappearance of flora on both the "wet" and "dry" side of the Cascades and Sierra Nevada suggests a loss of water vapor transport from the ocean source regions, especially in the summer. The drying of the West likely resulted from cooling of the North Pacific, which caused the gradual disappearance of a Miocene "Rocky Mountain" monsoon [Lyle et al., 2003] resulting in a gradual but drastic reduction of summer precipitation in California, Nevada, and the Pacific Northwest.

\subsection{Miocene North Pacific}

[149] The best summary to date of Miocene paleoceanographic development of the Pacific remains the Cenozoic Paleoceanography project compendium [Kennett, 1985.] However, the biostratigraphic ages in this work must first be adjusted to modern age models before comparing those data to recent studies. Ages of Miocene events quoted by Kennett [1985] can be 1 million years or more different than newer, better calibrated ages [Berggren et al., 1995; Shackleton et al., 1999, 2000; Zachos et al., 2001b]. For example, the "Monterey event," which records an early Miocene carbon isotope shift, was dated between 17.5 and $16.5 \mathrm{Ma}$ in 1985 based on the age of the CN2/CN3 nannofossil biostratigraphic boundary [Vincent et al., 1985; Vincent and Berger, 1985]. Newer, orbitally tuned biostratigraphy places the boundary age at $17.9 \mathrm{Ma}$.

[150] A pronounced shift in oxygen isotopes records a major expansion of Antarctic glaciation that occurred at about $14 \mathrm{Ma}$ in the middle Miocene [Kennett, 1977; Flower and Kennett, 1993]. However, the lack of evidence for a strong sea level change associated with the oxygen isotope shift suggests that a major cause of the isotope shift is the cooling of bottom waters, as well as buildup of ice [Miller et al., 2005]. After $14 \mathrm{Ma}$, benthic oxygen isotope contents continued to become heavier (toward colder, greater ice conditions [Zachos et al., 2001a]) until Northern Hemisphere glaciation intensified around $2.5 \mathrm{Ma}$.

[151] A major feature of the early and middle Miocene is the carbon isotope transient that developed between about 18 and $12.5 \mathrm{Ma}$ (the Monterey event [Vincent and Berger, 1985; Vincent et al., 1985]). The large magnitude of the transient (approximately 1.3\%o shift toward the heavier carbon isotope ${ }^{13} \mathrm{C}$ ) suggests that a significant drawdown of the surface organic carbon reservoirs occurred during this period, which, in turn, might have decreased atmospheric $\mathrm{CO}_{2}$. However, $p \mathrm{CO}_{2}$ proxies do not show much of a change in the interval [Pagani et al., 1999b; Royer et al., 2001; Pagani et al., 2005]. This period is also marked by a 200-m deepening of the tropical Pacific CCD by $15 \mathrm{Ma}$ [van Andel et al., 1975; Lyle, 2003] and the highest rates of biogenic sediment accumulation in the Neogene equatorial Pacific [Knappenberger, 2000; Mitchell et al., 2003], which clearly indicates that the carbon cycle was involved in the event. The early Miocene Pacific was also marked by a sharp increase in diatomaceous sedimentation in the north Pacific and eastern equatorial Pacific by about $16 \mathrm{Ma}$ [Keller and Barron, 1983].

[152] Pacific surface water circulation evolved, or at least sea surface temperature changed, during the Miocene. The early Miocene was marked by strong E-W temperature and faunal gradients in the equatorial Pacific (approximately $5^{\circ} \mathrm{C}$ as estimated by oxygen isotopes [Savin et al., 1985; Kennett et al., 1985]). The tropical E-W gradient disappeared by $7 \mathrm{Ma}$, and afterward the entire late Miocene tropical Pacific warmed with respect to early and middle Miocene times [Kennett et al., 1985; Romine and Lombari, 1985; Savin et al., 1985]. The pole-to-equator temperature gradient seems to have increased near that time as well, consistent with lowered ocean transport of heat out of the tropics.

[153] The North Pacific exhibited a reverse pattern, as shown by diatom flora [Barron, 1980, 1981, 2003]. Similar diatom floras in the early and middle Miocene indicate small east to west temperature differences between California and Japan, and the Alaska Gyre region appears to have been relatively warm. Conditions that indicate both cooling and separation of water masses started to occur in the early late Miocene [Barron, 2003]. Around 9.35 Ma, North 


\section{Annual Climatology (1971-2000)}

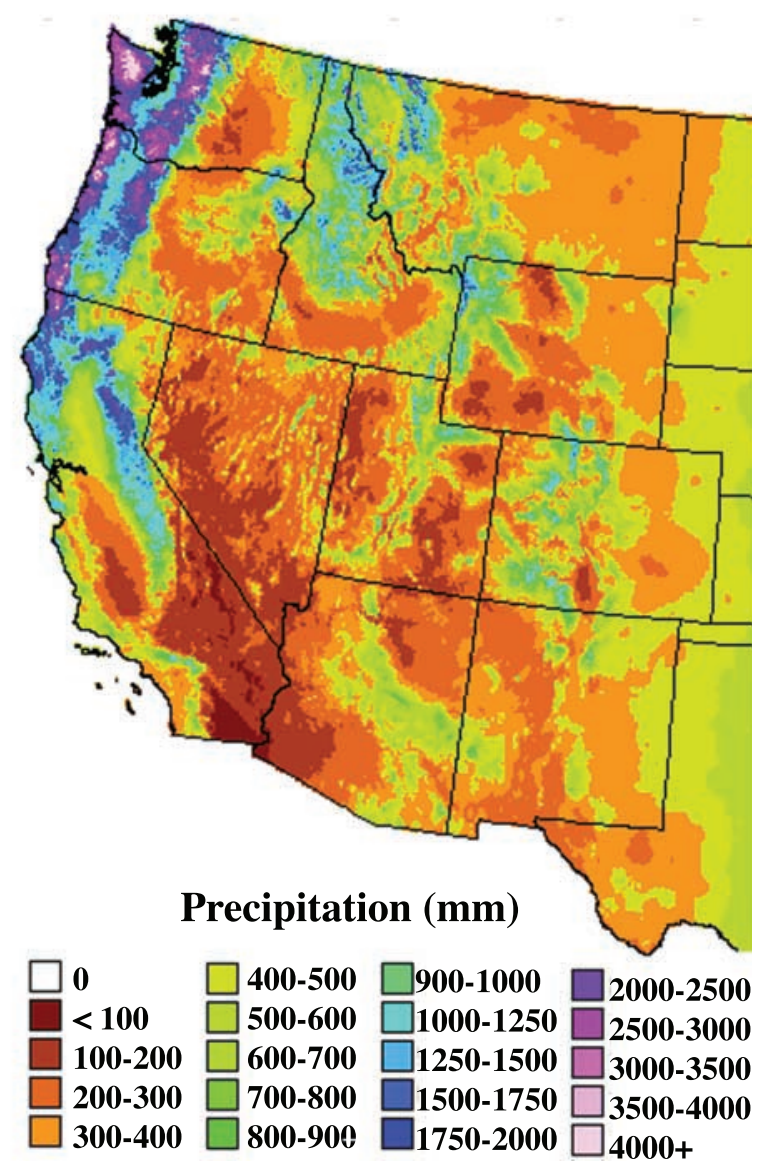

Figure 18. Average precipitation in the U.S. West for 1971-2000 from the Spatial Climate Analysis Service, Oregon Climate Service, used with permission. Green areas mark annual precipitation $>400 \mathrm{~mm}$ (16 inches). These areas also delineate the edges of modern forests. Copyright (C) 2004, Spatial Climate Analysis Service, Oregon State University, http://www.ocs.oregonstate.edu/prism/. Map created 28 Oct 2005 .

Pacific diatom species disappeared from the eastern equatorial Pacific, and by $9 \mathrm{Ma}$, diatom assemblages in the North Pacific, equatorial Pacific, and Southern Ocean became more provincial in character. By $8 \mathrm{Ma}$ the California margin developed a diatom flora indicative of much cooler conditions than those along Japan, consistent with the development of enhanced equator-to-pole temperature gradients and strong gyral circulation.

[154] Although there were major cooling trends in the North Pacific, late Miocene SST appears to have been distinctly warmer than modern conditions. Summer SST within the Alaska Gyre at $8 \mathrm{Ma}$ was about $5^{\circ} \mathrm{C}$ warmer than modern SST based upon quantitative estimates from radiolarian assemblages [Romine, 1985]. The Alaska Gyre continued to cool into the Pliocene. The first appearance of ice-rafted detrital sediment is dated at 6.5 Ma [Krissek, 1995], and the onset of Alaska tidewater glaciations began around 4.3 Ma [Rea and Snoeckx, 1995; Barron, 2003]. By 5.5 Ma, diatoms that only live in sea ice were widespread in the northern North Pacific.

[155] Evidence of the late Miocene cooling is also found in the Leg 198 sediments of the Shatsky Rise [Bralower et al., 2006]. Middle Miocene foraminiferal assemblages along a latitudinal gradient were uniform and characterized by subtropical affinities. Within the late Miocene a latitudinal gradient of temperature-sensitive foraminiferal fauna developed between the southern Shatsky Rise (south of $30^{\circ} \mathrm{N}$ paleolatitude) and the central and northern Shatsky Rise (roughly $34^{\circ} \mathrm{N}$ ).

[156] These cooling trends were not confined to the Pacific but reflect global trends [Cerling et al., 1997; Koch, 1998; Pagani et al., 1999a]. Cerling et al. [1997] note that herbivorous mammalian teeth record a carbon isotope shift between about 9 and $7 \mathrm{Ma}$, indicative of a change in diet from $\mathrm{C} 3$ plants (e.g., trees, shrubs, herbs, and many grasses) to plants that utilize the $\mathrm{C} 4$ metabolic pathway (e.g., grasses typical of tropical savannah, temperate prairies, and arid grasslands). $\mathrm{C} 4$ plants have the competitive advantage over C3 plants when $\mathrm{CO}_{2}$ is low and drought stress is high. Cerling et al. [1997] argued that the inferred transition from $\mathrm{C} 3$ to $\mathrm{C} 4$ plants was caused by a decrease in atmospheric $\mathrm{CO}_{2}$ that helped drive the late Miocene cooling, but the work of Pagani et al. [1999a] suggests the change is the result of global aridification. It is not clear why a global drying occurred in the late Miocene, but the parallel global cooling suggests the existence of potent positive feedbacks that reduced water vapor in the atmosphere and reduced global temperatures.

\subsection{Modern Climate of the Western United States}

[157] Modern precipitation in the western United States is generally confined to coastal regions north of $38^{\circ} \mathrm{N}$ and

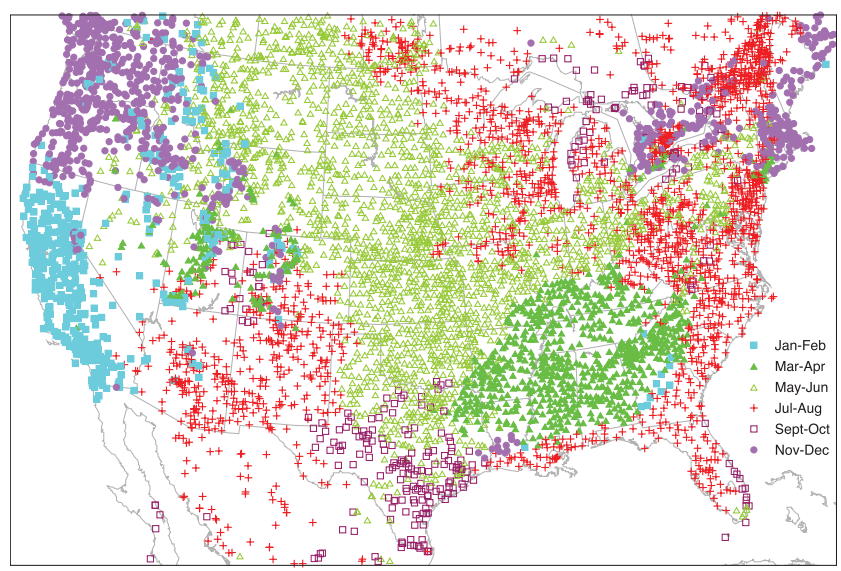

Distribution of the Seasonal Precipitation Maximum

Figure 19. Seasonality of precipitation maxima [from Mock, 1996]. The modern U.S. west coast and Pacific Northwest have winter season precipitation and dry summers. The U.S. Southwest has summer precipitation maxima caused by the North American monsoon. 


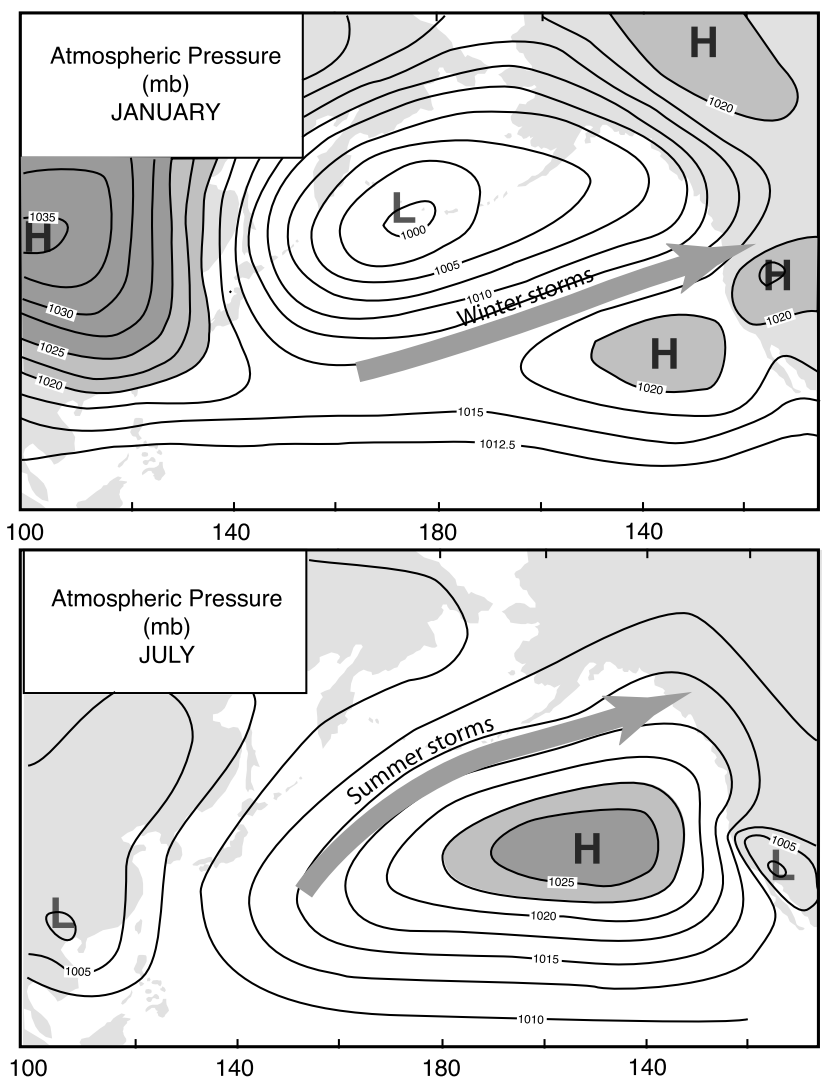

Figure 20. Seasonal pressure over the Pacific Ocean [after Huyer, 1983], reprinted with permission, copyright Elsevier, 1983. The NE Pacific high is just west of California and directs summer weather into Canada, but as it weakens in the winter, storms can track into the U.S. Pacific Northwest and California.

high elevations (Figure 18). Rain shadow caused by coastal mountains maintains true deserts in the interior basins. Precipitation is also highly seasonal [Mock, 1996] (Figure 19), with California, Nevada, and the Pacific Northwest experiencing wet winters and dry summers. The NE Pacific atmospheric high-pressure cell tends to block advection of moist air from the Pacific into the region during the summer. In contrast, the southwestern United States and eastern slope of the Rocky Mountains receive their highest precipitation in the summer months, associated with the development of the summer monsoon.

[158] Water sources to the western United States vary with the seasons. The major winter storms in the Pacific Northwest originate in the central Pacific and track into the region along the northern edge of the NE Pacific high when the high-pressure cell is in its southern configuration during the winter season (Figure 20). In contrast, significant summer precipitation brought into the southwestern part of the United States by the weak North American monsoon is sourced from the tropical Pacific or the Gulf of Mexico [Adams and Comrie, 1997; Friedman et al., 2002a, 2002b] and passes south of the highest part of the Sierra. In fact, much of the modern summer precipitation in the Great Basin all the way north to Oregon and Idaho has a tropical
Pacific source, and very little passes over the high Sierra [Friedman et al., 2002a, 2002b].

[159] There is now substantial evidence that the interannual and interdecadal variability of precipitation in the western United States is correlated with the variability of SST in the Pacific Ocean. Cayan et al. [1998] showed that precipitation in the southwestern United States was positively correlated with SSTs in the eastern equatorial Pacific and eastern Pacific subtropical gyre for the twentieth century. Warm SSTs in those oceanic regions are associated with anomalously heavy precipitation in the western United States in strong ENSO years (El Niño-Southern Oscillation event). More recently, McCabe et al. [2004] have demonstrated that $52 \%$ of the variance in multidecadal drought frequency in the contiguous United States is linked to the combined effects of two large-scale climate patterns, the Pacific Decadal Oscillation (PDO) and Atlantic Multidecadal Oscillation (AMO). Drought frequency in the Pacific Northwest is positively correlated with the PDO and drought frequency in the desert southwest and Rocky Mountain regions is negatively correlated with the PDO.

[160] Interactions between ENSO and the PDO are also important: ENSO teleconnections with western precipitation are generally strong when the PDO is negative and generally weak when the PDO is positive [McCabe and Dettinger, 1999]. Additionally, monsoon flow over the western United States is strong when El Niño conditions coincide with the positive PDO phase, and weak monsoonal flow occurs when La Niña conditions coincide with the negative PDO phase [Castro et al., 2001]. Connections between the Pacific and continental precipitation have been further defined by Lau et al. [2002], who included the North Pacific SST variability along with tropical SST variability to improve the seasonal predictability of the North American monsoon.

[161] The existence of linkages between precipitation in the western United States and the Pacific on decadal time frames suggests that larger-timescale reorganizations of Pacific SST associated with the Miocene cooling trend also had a large impact on precipitation patterns. As we develop better information about changing SST in the North Pacific, better models of climatic impacts on western water supplies will also be developed.

\subsection{Western North American Climate and Vegetation in the Miocene: Evidence for Drying}

[162] From a Cenozoic perspective the arid West of the last 5 million years is the anomaly not the norm [Axelrod, 1977; Wolfe, 1985; Retallack et al., 2002]. Middle to late Miocene time (i.e., 16-5 Ma) marks a western climate that is wetter than modern within a generally warmer Earth system. The entire Cenozoic prior to $6 \mathrm{Ma}$ was wetter than modern. The Miocene-Pliocene boundary is roughly defined by the disappearance of the Miocene deciduous "exotics" from coastal northern California [Heusser, 2000] and the beginning of the modern arid era. Similarly, drying east of the mountain barrier at 6-7 Ma [Retallack et al., 2002] is associated with the global drying at about this time [Cerling et al., 1997]. In contrast, the early to middle 
Miocene in eastern China had warm wet conditions similar to its modern climate, with perhaps less seasonality in precipitation [Sun et al., 2002]. Trends of vegetation change in Alaska and northwestern Canada are indicative of a cooling trend after peak warmth at about $15 \mathrm{Ma}$, with a major step at about $9 \mathrm{Ma}$.

[163] The evolution of the western North American water cycle has had a profound impact on ecosystems, and understanding this climate transition is an important aspect of understanding the long-term ecological change. Deciduous forests in SE China and the SE United States were part of a common forest biome that also extended to Europe in the early Miocene but were separated in the middle Miocene [Wen, 1999]. The warm, wet Miocene West along with a relatively warm Alaska and northeastern North America formed a critical link that joined Asian to American flora. The relationships between the deciduous forests of SE China and the SE United States provide important information about evolutionary genetics and ecosystem dispersal, and understanding how the forest ecosystems of the Miocene West were maintained and lost is critical to understanding modern biogeography.

[164] Large numbers of Miocene plant macrofossil localities throughout the U.S. West make this interval one of the best documented paleoclimate transitions in the Cenozoic [Axelrod, 1977; Graham, 1999]. The early Miocene wet and warm extreme (pre-15 Ma [Axelrod, 1968, 1977; Wolfe, 1985, 1994; Graham, 1999]) represents a fundamentally different water cycle in western North America, especially the U.S. West. The modern West is arid at all latitudes south of approximately $47^{\circ} \mathrm{N}$ except in the coastal regions (Figure 18). Forests in the western United States are confined to localities with annual precipitation levels above $400 \mathrm{~mm}$. Because the precipitation falls mainly in the winter months, western U.S. forests are mainly conifers. The modern Pacific Northwest, California, and Nevada experience Mediterranean conditions (dry summers and wet winters (Figure 19). A weak monsoon brings some summer precipitation to the Southwest, sufficient to support forests at higher elevations [Adams and Comrie, 1997], but the long winter dry season limits the types of trees that can survive.

[165] The Paleogene and Neogene West was covered with extensive deciduous and mixed deciduous-conifer forests that required extensive summer precipitation, probably greater than $400 \mathrm{~mm}$ in the summer months alone. Middle Miocene forests were distributed at all altitudes in the West and were not confined to high elevations, as are modern forests. Evidence for extensive wet summer conditions extends as far south as southern Nevada [Axelrod, 1992], and deciduous forests needing summer precipitation extended northward into Alaska during this time [Wolfe, 1985].

[166] There were still climate gradients in the middle Miocene: The region of the central Rockies experienced more seasonality of temperatures and less winter precipitation relative to other Miocene localities, while the Southwest was significantly warmer and moisture levels were lower than the Pacific Northwest at that time [Axelrod,
1977]. Floral paleotemperature estimates suggest that the mean annual temperature in the Pacific Northwest was about $4^{\circ} \mathrm{C}$ warmer than modern, primarily because of higher average winter temperatures [Wolfe, 1994].

\subsubsection{Aridification and Development of a Rain Shadow in the U.S. West}

[167] Subsequent to $15 \mathrm{Ma}$, the West began to aridify, and the forests gradually shifted coastward [Axelrod, 1977]. A few remnant species from the Miocene forests still remain in the modern coastal regions of California (e.g., the northern California sequoias), but they have been eliminated from inland regions. The Miocene deciduous forests did not disappear rapidly but slowly declined. A significant drop in warm season temperature occurred around $13 \mathrm{Ma}$, and the first signs of seasonal drought in the growing season appear in leaf assemblage analyses in the early late Miocene (circa 10-11 Ma [Wolfe, 1994]). By 7 Ma, grasslands had appeared in central Oregon, and the forests had disappeared [Retallack et al., 2002] in concert with grassland development throughout the world [Cerling et al., 1997; Retallack, 2001].

[168] Pollen from marine drill sites along the California margin (Deep Sea Drilling Project Site 467 [Ballog and Malloy, 1981] and Ocean Drilling Program Site 1022 [Heusser, 2000]) provides evidence for latitudinal precipitation gradients during the aridification and a continuous record of average terrestrial conditions of the nearby coastal region. Deciduous wet summer flora disappeared from Baja California at approximately $11 \mathrm{Ma}$ at a paleolatitude of $31^{\circ} \mathrm{N}$ [Ballog and Malloy, 1981] but persisted until $5 \mathrm{Ma}$ at a paleolatitude of about $38^{\circ} \mathrm{N}$ (Figure 21) [Heusser, 2000]. The pollen in both of these sites originated from west of the Sierra Nevada Mountains and is evidence of drying of the seaward side of this mountain range in concert with the Great Basin region.

[169] After $5 \mathrm{Ma}$, in the Pliocene and Pleistocene, the coastal flora types resembled those that exist today. However, the abundances and geographic extent of the floral assemblages waxed and waned with respect to the comparatively small climate variations of the last 5 million years, including the Pleistocene glacial-interglacial cycles [Heusser, 1998; Lyle et al., 2001; Pisias et al., 2001].

[170] Changes in boundary conditions undoubtedly were a major factor causing the disappearance of wet summer conditions. However, the nearby uplift of coastal mountain ranges was not a primary driver of the aridification of the West. As discussed in sections 5.2.2 and 9.1, a variety of evidence suggests that the Miocene West was already elevated, and the development of the coastal mountains did not occur at the same time as the aridification. The timing of aridification, instead, better matches the trends in global cooling.

[171] Furthermore, the wet summer floras disappeared from both sides of the uplifting Sierra Nevada [Heusser, 2000; Lyle et al., 2003] not just from the eastern flanks. If the rain shadow hypothesis was the primary cause of the aridification, the western slope of the Sierra should have become wetter not drier because any intercepted precipita- 

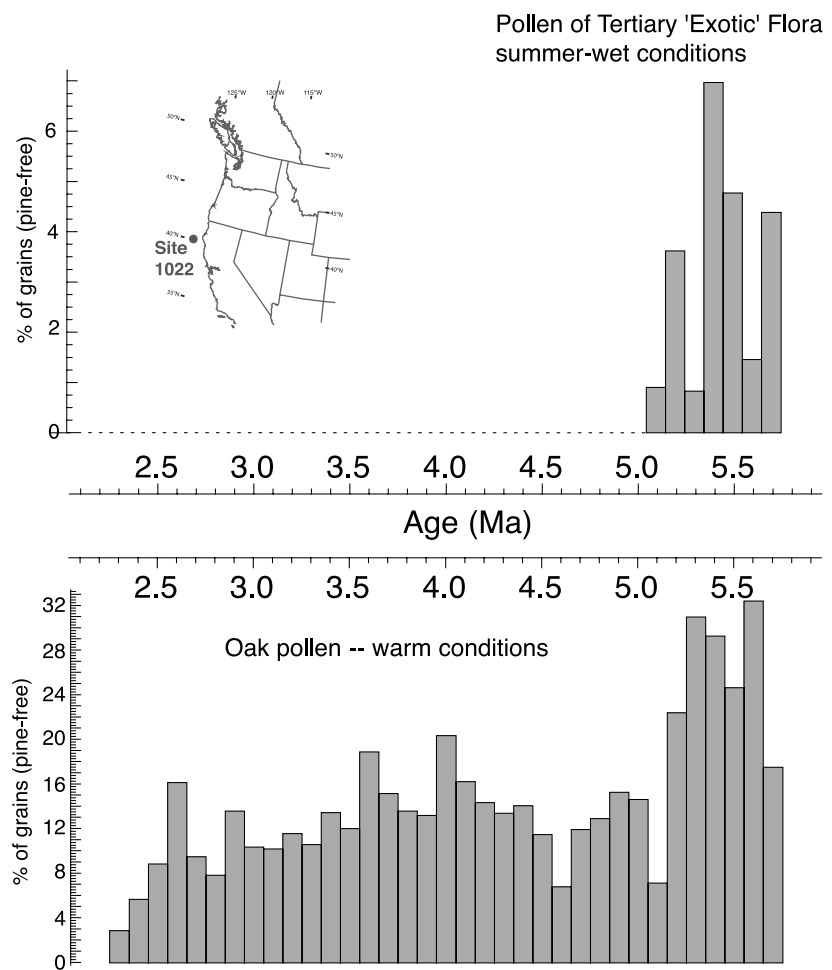

Figure 21. Loss of Miocene exotic flora at $5 \mathrm{Ma}$ (data from Heusser [2000]). Miocene exotic pollen are "wet summer" deciduous forms like sweet gum, hickory, and Chinese Wingnut. Lower oak percentages after $5 \mathrm{Ma}$ probably also reflect loss of more climate-sensitive species.

tion should have fallen on the western slope and not have been carried to the interior basins. Instead, the coastal sides of both the Cascade and Sierra Nevada mountains dried out concurrently with the intermountain region. While the rain shadow may not have been the cause of the aridification, its development did contribute strongly to modern regional patterns of very dry desert basins and wetter mountain ranges.

9.4.2. Linkages Between the Pacific and the Drying of the U.S. West

[172] The drying of western North America likely resulted from a cooling of the Pacific Ocean, which caused the gradual disappearance of a Miocene summer monsoon and a gradual but overall drastic reduction of summer precipitation. Pacific cooling is undoubtedly part of a larger and poorly understood global climate trend, and the Pacific certainly has been the primary atmospheric water source for western North America. In the Miocene some precipitation in the southwestern United States was undoubtedly derived from the Gulf of Mexico, as it is today [Friedman et al., 2002a]. However, the current geographic barriers to westward transport of atmospheric water from the Gulf of Mexico also existed in the Miocene, and it is hard to imagine that the Gulf of Mexico was a major source of precipitation to the western United States.

[173] The Miocene offers an opportunity to study how drying trends in the western United States can be linked to specific regional changes in SST. This will require the generation of regional SST records through the Miocene and modeling how changes in SST have affected water vapor transport to North America. These studies are just beginning, but there is evidence that the strongest cooling trends from 12 to $5 \mathrm{Ma}$ are within the Alaska Gyre and along the California margin. During that time period the western temperate north Pacific remained warm. Oddly, both the east and west equatorial Pacific warmed through the time period, but the eastern tropical Pacific warmed more than the west [Kennett et al., 1985; Savin et al., 1985].

\section{Western Precip Global TS Correlation}

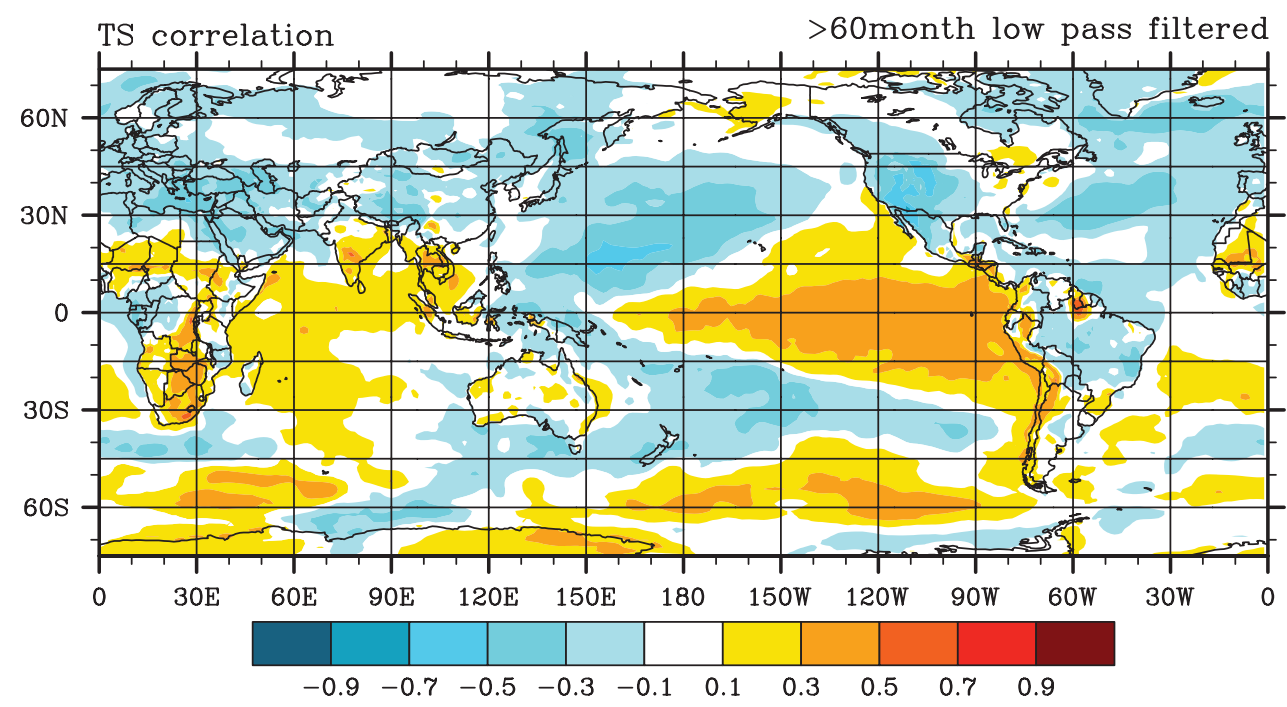

Figure 22. Correlation between modern global surface temperatures and precipitation in a $10^{\circ}$ square centered at $115^{\circ} \mathrm{W}, 40^{\circ} \mathrm{N}$. The data used were European Centre for Medium-Range Weather Forecasts (ECMWF) 40-year reanalysis project [Hagemann et al., 2005]. The data were subjected to a 60-month smoothing prior to correlation to search for interannual and decadal patterns. 


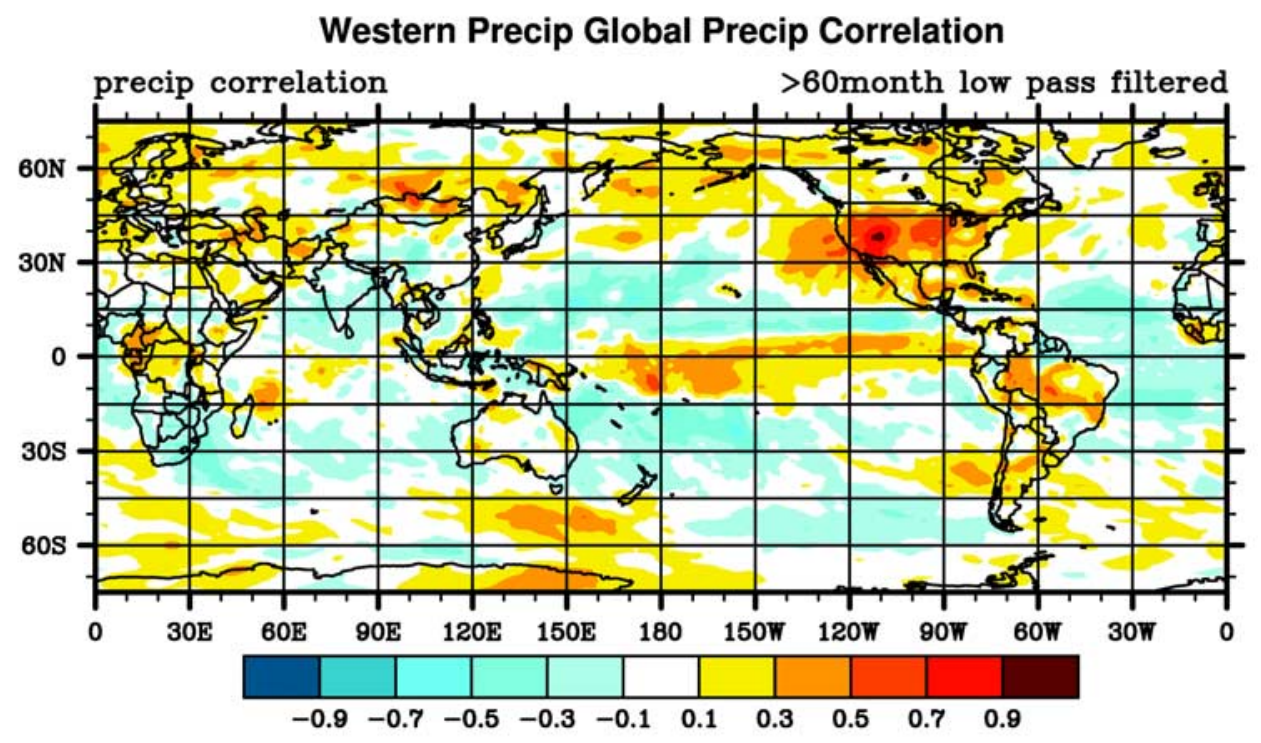

Figure 23. Correlation between modern global precipitation and precipitation in a $10^{\circ}$ square centered at $115^{\circ} \mathrm{W}, 40^{\circ} \mathrm{N}$. The data used were ECMWF 40 -year reanalysis project [Hagemann et al., 2005]. The data were subjected to a 60 -month smoothing prior to correlation to search for interannual and decadal patterns.

Up until about 1.7 Ma, SST in the east and west equatorial Pacific were nearly the same [Wara et al., 2005].

[174] Some insight can be gained about western water sources by studying modern correlations between precipitation and temperature regimes. Figure 22 illustrates the correlation between western U.S. precipitation in a $10^{\circ}$ square (centered at $115^{\circ} \mathrm{W}, 40^{\circ} \mathrm{N}$ ) and global surface temperature. The time series data have been subjected to a 60-month low-pass filter to extract only the interannual variability. Temperatures in the eastern tropical/subtropical Pacific and subantarctic Southern Ocean are positively correlated with western U.S. precipitation. The tropical/ subtropical Pacific correlation is reminiscent of an ENSO SST pattern. Higher temperatures in this ocean region strengthen the water vapor transport out of the tropics, either as strong subtropical winter storms or as a strengthened summer monsoon.

[175] When the low-pass-filtered western U.S. precipitation is correlated to global precipitation (Figure 23), it becomes clear that western U.S. precipitation is linked to weakened levels of precipitation around the normal summer position of the Intertropical Convergence Zone (roughly $10^{\circ} \mathrm{N}$ ), implying a less well developed Hadley circulation during times of high western precipitation. In addition, the positive correlation to precipitation in the Alaska Gyre and eastern temperate Pacific suggests a commonality of storms and storm tracks.

[176] During the modern summer the sources of water vapor into the western United States, as far north as southern Oregon, are primarily from regions south of $35^{\circ} \mathrm{N}$ [Friedman et al., 2002a]. This southern source for precipitation is not unexpected, because the NE Pacific high-pressure cell (Figure 20) typically redirects temperate summer air flow from the Pacific to Canada, but the summer development of a persistent low-pressure cell near the Mexico-U.S. border allows entry of air from the tropical eastern Pacific Ocean [Adams and Comrie, 1997]. The Miocene drying pattern is most strongly marked by a disappearance of summer rainfall and a drop in total precipitation that resembles a weakening of the monsoon. If this scenario is correct, then cooling of the eastern Pacific tropics and subtropics should be a critical part of the Miocene aridification process.

[177] Modern changes in SST in the eastern tropical Pacific are strongly linked to ENSO events and anomalous precipitation in the southwestern United States, demonstrating that Miocene climate changes could be linked to tropical SST. However, other factors can be important for long-term changes associated with the late Miocene aridification. For example, large-scale advection of cool sub-Arctic waters in the southward flowing California Current plays an important role in the heat balance of the surface ocean off southern California and Mexico [Hickey, 1979; Pares-Sierra and O'Brien, 1989; Roemmich and Mc Callister, 1989; Doose et al., 1997; Herbert et al., 2001; Di Lorenzo et al., 2005]. Hence the intensity of California Current flow and initial temperature of the water entering its northern terminus affects SST in the subtropics. Slower rates of flow of the California Current at the last glacial maximum are indicated by larger SST gradients along the California coast and relatively warm SST off Baja California during the Last Glacial Maximum [Doose et al., 1997; Herbert et al., 2001]. In contrast, cooling within the Alaska Gyre cools the subtropical eastern Pacific by lowering the SST of water transported within the California Current. Therefore subtropical NE Pacific SST is driven in part by factors affecting Alaska Gyre SST. 
[178] The Miocene history of the North Pacific and western North America is part of a larger story of cooling and drying that occurred globally between 12 and $5 \mathrm{Ma}$ after the formation of a full Antarctic ice cap and cooling of the Southern Ocean at $14 \mathrm{Ma}$ [Flower and Kennett, 1993; Shevenell et al., 2004]. Insufficient information exists about regional change to understand the dynamics of the global cooling, but these data can be developed by focused regional studies.

[179] The Himalayas were near-modern height during the Miocene aridification and cooling, indicating that their existence was probably necessary, but not sufficient, to cause the climate change. Without any evidence for high atmospheric $\mathrm{CO}_{2}$ concentration prior to the cooling we are left with reorganized heat transport as another mechanism that can support a warmer, wetter Earth. The slowly developed restriction of exchange of tropical surface waters, either between the Indian and Pacific oceans through the Indonesian passage or tropical exchange between the Pacific and Atlantic through the Panama Gateway, may have driven the cooling. Understanding how the reorganization of ocean circulation occurred will provide new insights into global climate processes.

\section{CLIMATE DRIFT AND OCEAN CIRCULATION: PLIOCENE COOLING}

[180] The more the Cenozoic is studied, the more that it becomes clear that global change can result from interactions between a variety of important processes rather than being dominated by any single factor. There is typically an association between a climate change and a change in physical boundary conditions, e.g., closing or opening ocean gateways. However, abrupt climate change can be a consequence of gradual change of water or air mass flow regulated by tectonics, strongly supporting nonlinear feedbacks as a major part of climate events. Furthermore, the largest climate changes may be driven by teleconnections to distant geographic regions.

[181] The Pliocene $(5.3-1.8 \mathrm{Ma})$ is data-rich relative to the earlier Cenozoic and represents the youngest example of when the Earth was significantly warmer than modern conditions [e.g., Dowsett et al., 1996; Sloan et al., 1996]. A strong desire to know why the Pleistocene ice ages began and intensified immediately after the end of the Pliocene has motivated studies of the Pliocene [Hays et al., 1976; Shackleton et al., 1984; Ruddiman and Raymo, 1988; Raymo, 1994]. The Pliocene is characterized by a transition from warm global temperature in the early part of this period (about $3{ }^{\circ} \mathrm{C}$ warmer than modern conditions [Sloan et al., 1996; Dowsett et al., 1996]) to the onset of the Northern Hemisphere cyclic glaciations by the end of the Pliocene [Shackleton et al., 1984; Ruddiman and Raymo, 1988; Maslin et al., 1995]. The Pliocene is fundamentally easier to study than the early Cenozoic. For example, accurate chronostratigraphy means that events can be dated well enough to examine teleconnections caused by orbitally forced insolation variability. In addition, tectonic recon- structions of the Pliocene are comparatively robust, providing good control on boundary, unlike the early Cenozoic.

\subsection{Onset of Northern Hemisphere Glaciation}

[182] Throughout the Cenozoic we observe sharp thresholds in the climate system only to find that the underlying forcing is much more gradual. The same is also true of Northern Hemisphere glaciation and is especially apparent in the North Pacific. The onset of glaciation is marked by an abrupt decline of diatoms in Alaska Gyre sediments [Haug et al., 1995; Rea et al., 1995], an abrupt increase in icerafted debris [Maslin et al., 1995; Krissek, 1995], vast volcanism [Prueher and Rea, 1998, 2001], and abrupt changes in SST that have been interpreted as higher seasonality of SST and density stratification [Haug et al., 2005]. The transition to a glacial-like North Pacific at 2.73 Ma took perhaps less than 1000 years [Haug et al., 2005] (Figure 24). In the North Atlantic the trend was less dramatic [Shackleton et al., 1984; Flesche Kleiven et al., 2002]. Ice-rafted detritus (IRD) strongly increases in the Greenland-Iceland-Norwegian seas at 3.2 Ma, although small but significant peaks can be found as early as 3.5 Ma. An order of magnitude increase in IRD deposition occurred at $2.72 \mathrm{Ma}$, signifying much higher and more extensive glacial discharge in the Greenland-IcelandNorwegian seas and into the North Atlantic as well.

[183] It is important to note that the abrupt intensification of Northern Hemisphere glaciation was foreshadowed by a series of long-term trends that originated near the beginning of the Pliocene, about 4.6 Ma, and that continue to the present [Billups et al., 1998; Haug and Tiedemann, 1998; Ravelo et al., 2004; Ravelo and Wara, 2004; Wara et al., 2005]. Even though these trends have been linked to tectonic events, i.e., the final closure of the Panama Gateway [Haug and Tiedemann, 1998] and restriction of the Indonesian Passage [Cane and Molnar, 2001], the critical issue to understand is how restricting a very small flow of tropical water in the early Pliocene could cause a rapid climate change in the high-latitude North Pacific. Furthermore, closer examination of the available records shows that key events in the transition were not coincident in time: The different regional responses spanned a range of at least 2 million years [Ravelo et al., 2004].

[184] Finally, we note that some researchers have characterized the problem in terms of assigning the "cause" of Northern Hemisphere glaciation to increased climate sensitivity to high-latitude drivers. However, the highest sensitivity to high-latitude forcing, measured by comparing the response of benthic oxygen isotopes to obliquity forcing (Figure 25) [Andreasen et al., 2001; Ravelo et al., 2004], contradicts this theory. The greatest sensitivity occurred between 1.9 and $0.6 \mathrm{Ma}$ in the early Pleistocene rather than closer to the onset of Northern Hemisphere glaciation at 2.7 Ma.

\subsection{Oceanographic Reorganizations Associated With Northern Hemisphere Glaciation}

[185] Ravelo and Wara [2004] present a good summary of oceanographic changes associated with Northern Hemi- 


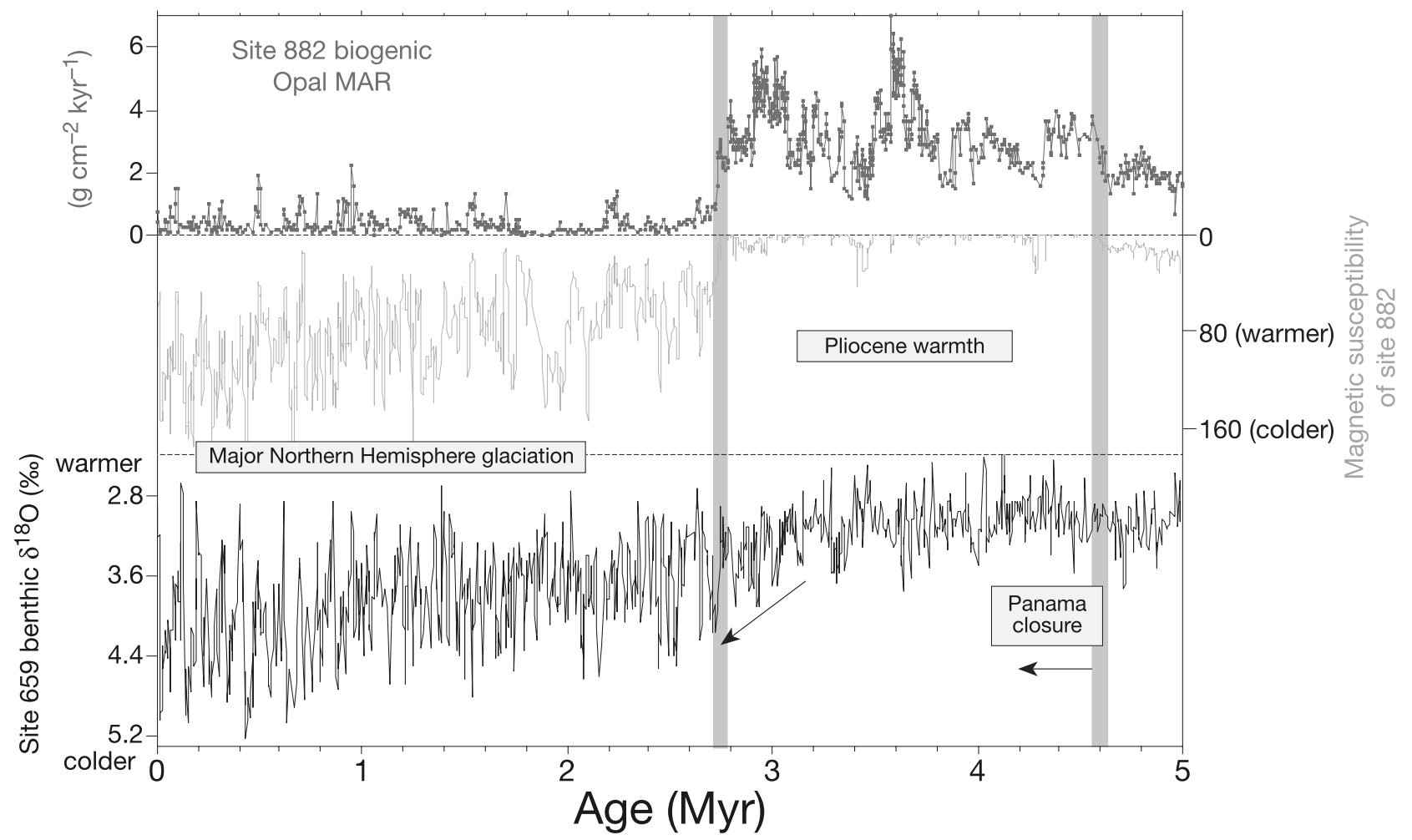

Figure 24. Onset of Northern Hemisphere glaciation in the Alaska Gyre [after Haug et al., 2005], reprinted by permission from Macmillan Publishers Ltd, copyright 2005, http://www.nature.com/nature/ index.html. Conditions changed in less than $20 \mathrm{ka}$ from high productivity to low and to conditions of higher seasonality. Ice-rafted debris, indicative of major sea ice, also appears abruptly at this time.

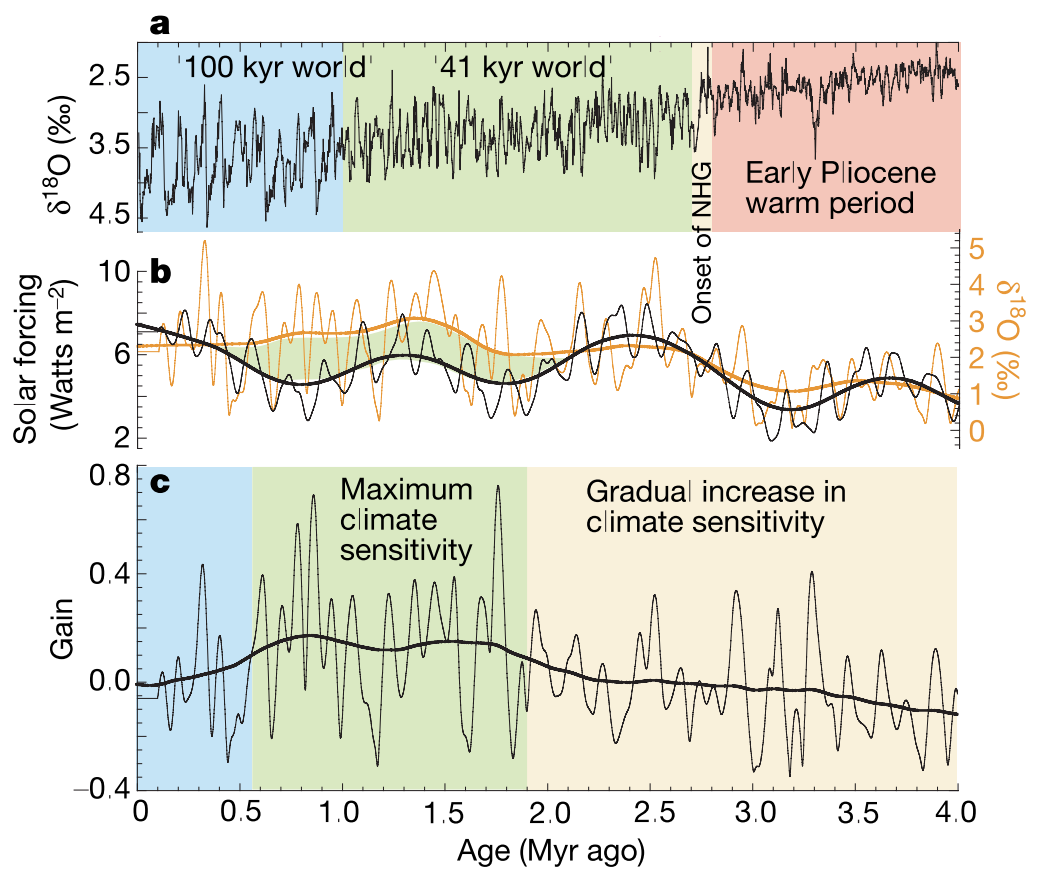

Figure 25. Change in sensitivity to obliquity forcing for the Pliocene [from Ravelo et al., 2004], reprinted by permission from Macmillan Publishers Ltd, copyright 2005, http://www.nature.com/nature/ index.html. (a) Change in benthic oxygen isotopes. (b) Time series of the deconvoluted oxygen isotope response to obliquity and of solar forcing. Obliquity affects high-latitude insolation balance the strongest and is a measure of high-latitude forcing. (c) Gain time series showing the ratio of obliquity forcing to oxygen isotope response. Note that the highest sensitivity to high-latitude forcing occurs long after the transition to Northern Hemisphere glaciations, indicating that the high-latitude albedo feedbacks are not the critical ones driving the transition. 
sphere glaciation. Two key events that are highlighted as important in the transition from warmth to the ice ages are (1) shallowing of the Panama Gateway to $<100 \mathrm{~m}$ depth at 4.6 Ma [Haug and Tiedemann, 1998; Driscoll and Haug, 1998] and (2) establishment of the modern salinity gradient between the Atlantic and Pacific at about 4.2 Ma. The salinity gradient could have resulted from the restriction of water exchange through the Panama Gateway [Haug et al., 2001] or the southward shift of the Intertropical Convergence Zone in the Atlantic [Billups et al., 1998]. Cane and Molnar [2001] have argued that the northward drift of Halmahara Island at the eastern entrance to the Indonesian Passage caused a change in thermocline source waters from a warm South Pacific source to a cold North Pacific source [Rodgers et al., 1999]. In turn, this could have resulted in a cooling of the Indian Ocean and a cooling of North America by teleconnection. The oxygen isotope evidence suggests that the major change between the Pacific Ocean and eastern Indian Ocean occurred between 3 and $1.5 \mathrm{Ma}$ [Ravelo and Wara, 2004], so this teleconnection may be a late part of the process of cooling. Similarly, 1.5 Ma marks the establishment of modern Walker circulation and the cool/warm partition of the equatorial Pacific [Wara et al., 2005]. All of these processes are proceeding in concert, and all ultimately lead to cooler conditions that can be roughly organized into two cooling steps: one between 3 and $2.5 \mathrm{Ma}$ and a second between 2 and 1.5 Ma [Ravelo et al., 2004]. The earlier period of cooling is linked to high-latitude circulation processes, but the later cooling is primarily caused by shifts in subtropical and tropical circulation processes.

[186] Understanding how the Earth cooled through the Pliocene remains controversial because the changes that occurred in underlying systems were not dramatic in themselves. Instead, the net cooling represents a combination of factors, each of which can be assigned roughly similar weight. At the present time we can conclude that the cooling cannot be ascribed primarily to positive ice-albedo feedbacks because there should also be a much stronger linkage between high-latitude insolation change and the waxing and waning of glaciations. We know that there may have been $30 \%$ higher greenhouse gas concentrations in the atmosphere of the warm early Pliocene relative to that of the interglacial (warmer) Pleistocene (roughly $400 \mathrm{ppm}$ or similar to A.D. 2007 concentrations [Van der Burgh et al., 1993; Raymo et al., 1996]). Certainly, the drop in $\mathrm{CO}_{2}$ could have been an important long-term forcing. However, the link between weathering and atmospheric $\mathrm{CO}_{2}$ concentrations is still poorly understood, and we currently lack evidence that weathering increased sufficiently over this interval to provide a mechanism to draw down atmospheric $\mathrm{CO}_{2}$. No atmospheric $\mathrm{CO}_{2}$ record yet exists over the crucial climate transitions to constrain the greenhouse influence. The tropical ocean gateways closed in the relevant time frame, but the disappearance of these small exchanges of water between Indian, Pacific, and Atlantic oceans in itself should not have been so important unless the exchanges regulated other equator-to-pole heat exchanges.
[187] In summary, the timing of long-term climate change in the Pliocene is becoming well established, but we have not yet deciphered the causes. Strong regional, nonlinear responses to slow forcing mechanisms (whether ocean circulation or greenhouse gas forcing) generated climate feedbacks that changed the "rules" of the system and eventually led to large glacial-interglacial swings of the Pleistocene.

\section{DISCUSSION AND CONCLUSIONS}

[188] Rich sedimentary records exist within the Cenozoic to study how geosystems have interacted to maintain, respond to, or change the Earth's climate. The study of these natural "experiments" is a fertile area for understanding how Earth processes interact and for improving our understanding of future climate change. The fundamental importance of paleoclimate studies does not hinge upon identifying analogous conditions to the current anthropogenic greenhouse. Instead, we should direct our efforts at observing geosystems under different baseline conditions in order to better understand the interactions among important climate parameters and to develop better theories to explain them.

[189] Pacific Ocean sediments are obvious targets for study because they have recorded important information about an ocean that has been a major part of the Earth's climate system throughout the Cenozoic. The Pacific Ocean has been an important reservoir for heat and nutrients and an important source of $\mathrm{CO}_{2}$ to the atmosphere. Most of the prominent changes in Cenozoic climate appear to be related to changes in Pacific Ocean circulation linked to changes in flow through ocean gateways. One of the important lessons we are learning is our need to understand how these oceanic gateways have affected the climate. The Pliocene sedimentary record has shown that a variety of large-scale global reorganizations have occurred that may have stemmed from small changes in flow through tropical gateways to the Pacific.

[190] Farther back in time, there existed climates that are not analogous to the modern Earth but obviously must have been maintained by natural Earth processes. The middle and late Miocene illustrate a time when the Earth had atmospheric $\mathrm{CO}_{2}$ near modern levels yet was significantly warmer than modern conditions. The ability of the Earth to maintain such warm conditions without any obvious forcing through elevated atmospheric $\mathrm{CO}_{2}$ suggests high sensitivity to minor differences in insolation, climate sensitivity to other greenhouse gases, or major reorganizations of "slow" systems that help to maintain warm conditions. The global cooling and drying within the late Miocene provides a unique opportunity to understand how a variety of systems are linked, including the oceans, atmosphere, water cycle, and biosphere.

[191] The early Cenozoic epochs of the Paleocene and Eocene provide opportunities to study global geosystems under conditions of high atmospheric $\mathrm{CO}_{2}$ concentration. It is clear from the geologic record that natural thermostats 
existed to maintain warm climates, as they must to maintain cold climates. In the Eocene the baseline global temperature was maintained at a much warmer average than is found in the modern world. The early Cenozoic is characterized by high-latitude mean annual temperatures near $10^{\circ} \mathrm{C}$ and tropical conditions that extended as far north as the Canada-U.S. border $\left(\sim 50^{\circ} \mathrm{N}\right)$. A series of transient events that occurred within the early Cenozoic provide an opportunity to understand these systems after they have received a strong, geologically rapid forcing. The PETM warm transient, for example, only lasted for 100-200 ka before returning to "cooler" baseline conditions. This transient represents the opportunity to study a major release of greenhouse gases under warm Earth conditions. Similarly, studying the recently discovered cool transients during the Eocene allows us to examine climate sensitivity under warm Earth conditions and to elucidate links between the carbon cycle and global temperature.

[192] Slowly, the barriers that previously have hampered study of the Cenozoic are falling. The critical key to all of our understanding has been the development of an accurate timescale for the entire Cenozoic. Fifteen years ago it was considered remarkable that one could compare 3-millionyear-old sedimentary records and determine with a precision of a few tens of thousands of years whether an event in one part of the globe was synchronous with an event in another part. Today that capability has been extended tenfold back into the Paleogene to at least to 35-40 Ma, with the timescale now better calibrated with absolute geochronology. One neglected area of study that remains is the tie between marine and terrestrial chronologies. Further stratigraphic work is needed in order that the timing of a terrestrial event can be compared with a marine event with the same confidence that applies to events in two marine records. If we are to understand the ocean-atmosphere-water cycle and interactions between the ocean, atmosphere, and biosphere, we need such accuracy.

[193] There also is a great need for further development of proxy measurements that accurately provide information about the Earth's past temperature, precipitation, ocean chemistry, and paleoproductivity. Many researchers have developed new proxies, and this work should be applauded. These new and older proxies must now be calibrated to work under the Cenozoic range of conditions.

[194] Finally, there is the basic need to collect and measure more sedimentary records. One common theme that has appeared from the earliest to latest parts of the Cenozoic is that geosystems operate on a regional scale but interact to change global conditions. We must measure both the global and regional changes to understand our Earth.

[195] ACKNOWLEDGMENTS. Our knowledge of the Cenozoic Pacific Ocean could not have been achieved without the tireless efforts of everyone associated with the Deep Sea Drilling Project, Ocean Drilling Program, and Integrated Ocean Drilling Program to collect, archive, and study these sedimentary records. This manuscript originated from a distinguished lectureship for ODP. We have been funded by the following sources while writing this manuscript: NSF grants OCE-0240906, OCE-
0451291, and EAR0450211 (M. Lyle and A. Olivarez Lyle) and OCE-0240924 (D. K. Rea).

[196] The Editor responsible for this paper was Henk Dijkstra. He thanks Deborah Thomas and an anonymous technical reviewer and one anonymous cross-disciplinary reviewer.

\section{REFERENCES}

Adams, D. K., and A. C. Comrie (1997), The North American monsoon, Bull. Am. Meteorol. Soc., 78, 2197-2213.

Alt, J. C. (1995), Sulfur isotopic profile through the oceanic crust: Sulfur mobility and seawater-crustal sulfur exchange during hydrothermal alteration, Geology, 23, 585-588.

Andreasen, D. H., et al. (2001), Remote forcing at the last glacial maximum in the tropical Pacific Ocean, J. Geophys. Res., 106, 879-897.

Archer, D., and E. Maier-Reimer (1994), Deep sea $\mathrm{CaCO}_{3}$ burial and atmospheric $p \mathrm{CO}_{2}$, Nature, 367, 260-264.

Axelrod, D. I. (1968), Tertiary floras and topographic history of the Snake River basin, Idaho, Geol. Soc. Am. Bull., 79, 713-734.

Axelrod, D. (1977), Outline history of California vegetation, in Terrestrial Vegetation of California, edited by M. Barbour and J. Major, pp. 139-193, John Wiley, New York.

Axelrod, D. I. (1992), Miocene floristic change at $15 \mathrm{Ma}$, Nevada to Washington, U.S.A., Palaeobotanist, 41, 234-239.

Baldauf, J. G. (1993), Middle Eocene through early Miocene diatom floral turnover, in Eocene-Oligocene Climatic and Biotic Evolution, edited by D. Prothero and W. A. Berggren, pp. 310-326, Princeton Univ. Press, Princeton, N. J.

Ballog, R. A., and R. E. Malloy (1981), Neogene palynology from the southern California continental borderland, Site 467, Deep Sea Drilling Project Leg 63, Initial Rep. Deep Sea Drill. Proj., 63, 565-577.

Barker, P. F. (2001), Scotia Sea regional tectonic evolution: Implications for mantle flow and palaeocirculation, Earth Sci. Rev., 55, 1-39.

Barker, P. F., and J. Burrell (1977), The opening of Drake Passage, Mar. Geol., 25, 15-34.

Barker, P. F., and E. Thomas (2004), Origin, signature and palaeoclimatic influence of the Antarctic Circumpolar Current, Earth Sci. Rev., 66, 143-162.

Barron, J. (1980), Lower Miocene to Quaternary diatom biostratigraphy of Leg 57, off northeastern Japan, Deep Sea Drilling Project, Initial Rep. Deep Sea Drill. Proj., 56/57, 641-693.

Barron, J. A. (1981), Late Cenozoic diatom biostratigraphy and paleoceanography of the middle-latitude eastern North Pacific, Deep Sea Drilling Leg 63, Initial Rep. Deep Sea Drill. Proj., 63, 565-577.

Barron, J. (2003), Appearance and extinction of planktonic diatoms during the past 18 m.y. in the Pacific and Southern oceans, Diatom Res., 128, 203-224.

Barron, J., and J. G. Baldauf (1989), Tertiary cooling steps and paleoproductivity as reflected by diatoms and biosiliceous sediments, in Productivity of the Ocean: Present and Past, edited by W. H. Berger et al., pp. 341-354, John Wiley, Hoboken, N. J.

Barron, J., et al. (1991), Evidence for late Eocene to early Oligocene Antarctic glaciation and observations on late Neogene glacial history of Antarctica: Results from Leg 119, Proc. Ocean Drill. Programs Sci. Results, 119, 869-891.

Basu, A. R., et al. (2001), Large groundwater strontium flux to the oceans from the Bengal Basin and the marine strontium isotope record, Science, 293, 1470-1473.

Berger, W. H. (1973), Cenozoic sedimentation in the eastern tropical Pacific, Geol. Soc. Am. Bull., 84, 1941-1954.

Berger, W. H. (1982), Deep-sea stratigraphy: Cenozoic climate steps and the search for chemo-climatic feedback, in Cyclic and Event Stratification, edited by G. Einsele and A. Seilacher, pp. 121-157, Springer, Berlin. 
Berger, W. H., et al. (1981), The deep-sea record: Major steps in Cenozoic ocean evolution, Spec. Publ. Soc. Econ. Paleontol. Mineral., 32, 489-504.

Berggren, W. A., and C. D. Hollister (1977), Plate tectonics and paleocirculation-Commotion in the ocean, Tectonophysics, 38 , $11-48$.

Berggren, W. A., et al. (1995), Geochronology, time scales and global stratigraphic correlation, Spec. Publ. Soc. SEPM Sediment. Geol., 54, 386 pp.

Berner, R. A., and K. Caldeira (1997), The need for mass balance and feedback in the geochemical carbon cycle, Geology, 25, 955-956.

Berner, R. A., et al. (1983), The carbonate-silicate geochemical cycle and its effect on atmospheric carbon dioxide over the past 100 million years, Am. J. Sci., 283, 641-683.

Betzler, C., et al. (2000), Synchroneity of major late Neogene sea level fluctuations and paleoceanographically controlled changes as recorded by two carbonate platforms, Paleoceanography, 15, $722-730$.

Bice, K. L., and J. Marotzke (2001), Numerical evidence against reversed thermohaline circulation in the warm Paleocene/Eocene ocean, J. Geophys. Res., 106, 11,529-11,542.

Bice, K. L., et al. (1997), Continental runoff and early Cenozoic bottom-water sources, Geology, 25, 951-954.

Billups, K., et al. (1998), Early Pliocene climate: A perspective from the western equatorial Atlantic warm pool, Paleoceanography, 13, 459-470.

Blum, J. D. (1998), The effect of late Cenozoic glaciation and tectonic uplift on silicate weathering rates and the marine ${ }^{87} \mathrm{Sr} /{ }^{86} \mathrm{Sr}$ record, in Tectonic Uplift and Climate Change, edited by W. F. Ruddiman, pp. 260-290, Plenum, New York.

Bralower, T. J., et al. (2002), Proceedings of the Ocean Drilling Program Initial Reports, vol. 198, Ocean Drill. Program, College Station, Tex.

Bralower, T. J., et al. (2006), Leg 198 synthesis: A remarkable $120-\mathrm{m}$. y. record of climate and oceanography from Shatsky Rise, northwest Pacific Ocean [online], Proc. Ocean Drill. Program, Sci. Results Leg 198, 47 pp. (Available at http://www-odp. tamu.edu/publications/198 SR/VOLUME/SYNTH/ SYNTH.PDF)

Brass, G. W., et al. (1982), Warm saline bottom water in the ancient ocean, Nature, 296, 620-623.

Brassell, S. C., et al. (1986), Molecular stratigraphy: A new tool for climatic assessment, Nature, 320, 129-133.

Brinkhuis, H., et al. (2006), Episodic fresh surface waters in the Eocene Arctic Ocean, Nature, 441, 606-609.

Broecker, W. S., and A. Sanyal (1998), Does atmospheric $\mathrm{CO}_{2}$ police the rate of chemical weathering?, Global Biogeochem. Cycles, 12, 403-408.

Browning, J. V., K. G. Miller, and D. K. Pak (1996), Global implications of lower to middle Eocene sequence boundaries on the New Jersey coastal plain: The icehouse cometh, Geology, 24, 639-642.

Cane, M. A., and P. Molnar (2001), Closing of the Indonesian seaway as a precursor to east African aridification around 3-4 million years ago, Nature, 411, 157-162.

Carter, L., R. M. Carter, and I. N. McCave (2004), Evolution of the sedimentary system beneath the deep Pacific inflow off eastern New Zealand, Mar. Geol., 205, 9-27.

Castro, C. L., et al. (2001), The relationship of the North American monsoon to tropical and north Pacific sea surface temperatures as revealed by observational analyses, J. Clim., 14, 4449-4473.

Cayan, D. R., et al. (1998), Decadal climate variability of precipitation over western North America, J. Clim., 11, 3148-3166.

Cecil, M. R., et al. (2006), Cenozoic exhumation of the northern Sierra Nevada, California, from (U-Th)/He thermochronology, Geol. Soc. Am. Bull., 118, 1481-1488.

Cerling, T. E., et al. (1997), Global vegetation change through the Miocene/Pliocene boundary, Nature, 389, 153-158.
Chamberlain, C. P., and M. A. Poage (2000), Reconstructing the paleotopography of mountain belts from the isotopic composition of authigenic minerals, Geology, 28, 115-118.

Chase, C. G., et al. (1998), Topographic history of the western cordillera of North America and controls on climate, in Tectonic Boundary Conditions for Climate Reconstruction, edited by T. J. Crowley and K. C. Burke, pp. 73-100, Oxford Univ. Press, New York.

Chavez, F. P., and R. T. Barber (1987), An estimate of new production in the equatorial Pacific, Deep Sea Res., Part A, 34, $1229-1243$

Christensen, M. N. (1966), Late Cenozoic crustal movements in the Sierra Nevada of California, Geol. Soc. Am. Bull., 77, 163182.

Clark, M. K., et al. (2005a), Late Cenozoic uplift of southeastern Tibet, Geology, 33, 525-528.

Clark, M. K., et al. (2005b), The non-equilibrium landscape of the southern Sierra Nevada, California, GSA Today, 15, 4-10.

Coates, A. G., and J. A. Obando (1996), The geologic evolution of the Central American isthmus, in Evolution and Environment in Tropical America, edited by J. B. C. Jackson et al., pp. 21-56, Univ. of Chicago Press, Chicago, Ill.

Colgan, J. P., et al. (2004), Diachroneity of Basin and Range extension and Yellowstone hotspot volcanism in northwestern Nevada, Geology, 32, 121-124.

Colosimo, A. B., et al. (2006), Evidence for lysocline shoaling at the Paleocene/Eocene thermal maximum on Shatsky Rise, northwest Pacific [online], Proc. Ocean Drill. Program Sci. Results, 198, 36 pp. (Available at http://www-odp.tamu.edu/publications/ 198 SR/VOLUME/CHAPTERS/112.PDF)

Copeland, P. (1997), The when and where of the growth of the Himalaya and the Tibetan Plateau, in Tectonic Uplift and Climate Change, edited by W. F. Ruddiman, pp. 19-40, Plenum Press, New York.

Coxall, H. K., et al. (2005), Rapid stepwise onset of Antarctic glaciation and deeper calcite compensation in the Pacific Ocean, Nature, 433, 53-57.

Crowley, T. J., , and K. C. Burke (Eds.) (1998), Tectonic Boundary Conditions for Climate Reconstructions, 285 pp., Oxford Univ. Press, New York.

Currie, B. S., et al. (2005), Middle Miocene paleoaltimetry of southern Tibet: Implications for the role of mantle thickening and delamination in the Himalayan orogen, Geology, 33, 181184.

Davidson, E. A., and I. A. Janssens (2006), Temperature sensitivity of soil carbon decomposition and feedbacks to climate change, Nature, 440, 165-173.

De Boer, A. M., and D. Nof (2004a), The Bering Strait's grip on the Northern Hemisphere climate, Deep Sea Res., Part I, 51, $1347-1366$

De Boer, A., and D. Nof (2004b), The exhaust valve of the North Atlantic, J. Clim., 17, 417-422.

DeConto, R. M., and D. Pollard (2003a), Coupled climate-ice sheet modeling approach to early Cenozoic history of the Antarctic ice sheet, Palaeogeogr. Palaecoclimatol. Palaeoecol., 198, 39-52.

DeConto, R. M., and D. Pollard (2003b), Rapid Cenozoic glaciation of Antarctica induced by declining atmospheric $\mathrm{CO}_{2}$, Nature, 421 , 245-249.

Delaney, M. L., and E. A. Boyle (1988), Tertiary Paleoceanic chemical variability: Unintended consequences of simple geochemical models, Paleoceanography, 3, 137-156.

De La Rocha, C. L., and D. J. DePaolo (2000), Isotopic evidence for variations in the marine calcium cycle over the Cenozoic, Science, 289, 1176-1178.

Demicco, R. V., et al. (2003), Atmospheric $p \mathrm{CO}_{2}$ since $60 \mathrm{Ma}$ from records of seawater $\mathrm{pH}$, calcium, and primary carbonate mineralogy, Geology, 31, 791-796.

Demicco, R. V., et al. (2005), Model of seawater composition for the Phanerozoic, Geology, 33, 877-880. 
DePaolo, D. J., and B. L. Ingram (1985), High-resolution stratigraphy with strontium isotopes, Science, 227, 938-941.

Derry, L. A., and C. France-Lanord (1996a), Neogene Himalayan weathering history and river ${ }^{87} \mathrm{Sr} /{ }^{86} \mathrm{Sr}$ : Impact on the marine Sr record, Earth Planet. Sci. Lett., 142, 59-74.

Derry, L. A., and C. France-Lanord (1996b), Neogene growth of the sedimentary organic carbon reservoir, Paleoceanography, 11, $267-275$.

Dettmann, D. L., and K. C. Lohmann (2000), Oxygen isotope evidence for high-altitude snow in the Laramide Rocky Mountains of North America during the late Cretaceous and Paleogene, Geology, 28, 243-246.

Dickens, G. R., et al. (1995), Dissociation of oceanic methane hydrate as a cause of the carbon isotope excursion at the ends of the Paleocene, Paleoceanography, 10, 965-971.

Dickens, G. R., et al. (1997), A blast of gas in the latest Paleocene: Simulating first-order effects of massive dissociation of oceanic methane hydrate, Geology, 25, 259-262.

Di Lorenzo, E., et al. (2005), The warming of the California Current system: Dynamics and ecosystem implications, J. Phys. Oceanogr., 35, 336-362.

Doose, H., et al. (1997), Biomarker temperature estimates for modern and last glacial surface waters of the California Current system between $33^{\circ}$ and $42^{\circ} \mathrm{N}$, Paleoceanography, 12, 615-622.

Dowsett, H., et al. (1996), Middle Pliocene sea surface temperatures: A global reconstruction, Mar. Micropaleontol., 27, 113125.

Driscoll, N. W., and G. H. Haug (1998), A short circuit in thermohaline circulation: A cause for Northern Hemisphere glaciation?, Science, 282, 436-438.

Droxler, A. W., et al. (1998), Caribbean constraints on circulation between Atlantic and Pacific oceans over the past 40 million years, in Tectonic Boundary Conditions for Climate Reconstructions, edited by T. J. Crowley and K. C. Burke, pp. 169-191, Oxford Univ. Press, New York.

Dugdale, R. C., and F. P. Wilkerson (1998), Silicate regulation of new production in the equatorial pacific upwelling, Nature, 391, $270-273$.

Dugdale, R. C., and F. P. Wilkerson (2001), Sources and fates of silicon in the ocean: The role of diatoms in the climate and glacial cycles, Sci. Mar., 65, 141-152.

Duplessy, J.-C., et al. (1988), Deepwater source variations during the last climatic cycle and their impact on the global deepwater circulation, Paleoceanography, 3, 343-360.

Duque-Caro, H. (1990), Neogene stratigraphy, paleoceanography and paleobiogeography in northwest South America and the evolution of the Panama Seaway, Palaeogeogr. Palaecoclimatol. Palaeoecol., 77, 203-234.

Dymond, J., and M. Lyle (1985), Flux comparisons between sediments and sediment traps in the eastern tropical Pacific: Implications for atmospheric $\mathrm{CO}_{2}$ variations during the Pleistocene, Limnol. Oceanogr., 30, 699-712.

Edmond, J. M., and Y. Huh (1997), Chemical weathering yields from basement and orogenic terrains in hot and cold climates, in Tectonic Uplift and Climate Change, edited by W. F. Ruddiman, pp. 330-353, Plenum Press, New York.

Egbert, G. D., and R. D. Ray (2000), Significant dissipation of tidal energy in the deep ocean inferred from satellite altimeter data, Nature, 405, 775-778.

Eldrett, J. S., I. C. Harding, P. A. Wilson, E. Butler, and A. P. Roberts (2007), Continental ice in Greenland during the Eocene and Oligocene, Nature, 446, 176-179.

Emiliani, C., and N. J. Shackleton (1974), The Bruhnes epoch: Isotopic paleotemperatures and geochronology, Science, 183, $511-514$.

Engebretson, D. C., et al. (1985), Relative motions between oceanic and continental plates in the Pacific Basin, Spec. Pap. Geol. Soc. Am., 206, 59 pp.

Ewing, J., M. Ewing, T. Aitken, and W. J. Ludwig (1968), North Pacific sediment layers measured by seismic profiling, in The
Crust and Upper Mantle of the Pacific Area, Geophys. Monogr. Ser., vol. 12, edited by L. Knopoff, C. L. Drake, and P. J. Hart, pp. 147-173, AGU, Washington, D. C.

Exon, N. F., J. P. Kennett, and M. J. Malone (2003), Leg 189 synthesis: Cretaceous-Holocene history of the Tasmanian Gateway (online), Proc. Ocean Drill. Program Sci. Results, 189, 37 pp. (Available at http://www-odp.tamu.edu/publications/189_SR/ synth/synth.htm)

Expedition 302 Scientists (2006), Expedition 302 summary, Proc. Integr. Ocean Drill. Program Initial Rep., 302, 22 pp., doi:10.2204/iodp.proc.302.101.2006.

Farrell, J. W., and W. L. Prell (1989), Climatic change and $\mathrm{CaCO}_{3}$ preservation: An 800,000 year bathymetric reconstruction from the central equatorial Pacific Ocean, Paleoceanography, 4, 447466.

Farrell, J. W., et al. (1995), Late Neogene sedimentation patterns in the eastern equatorial Pacific Ocean, Proc. Ocean Drill. Program Sci. Results, 138, 717-756.

Fawcett, P. J., and E. J. Barron (1998), The role of geography and atmospheric $\mathrm{CO}_{2}$ in long term climate change: Results from model simulations for the late Permian to the Present, in Tectonic Boundary Conditions for Climate Reconstructions, edited by T. J. Crowley and K. C. Burke, pp. 21-36, Oxford Univ. Press, New York.

Flesche Kleiven, H., et al. (2002), Intensification of Northern Hemisphere glaciations in the circum Atlantic region (3.5-2.4 Ma)-Ice-rafted detritus evidence, Palaeogeogr. Palaecoclimatol. Palaeoecol., 184, 213-223.

Flower, B. P., and J. P. Kennett (1993), Middle Miocene oceanclimate transition: High-resolution oxygen and carbon isotopic records from Deep Sea Drilling Project Site 588A, southwest Pacific, Paleoceanography, 8, 811-843.

Flower, B. P., and J. P. Kennett (1994), The middle Miocene climatic transition: East Antarctic ice sheet development, deep ocean circulation and global carbon cycling, Palaeogeogr. $\mathrm{Pa}$ laecoclimatol. Palaeoecol., 108, 537-555.

Forest, C. E., J. A. Wolfe, P. Molnar, and K. A. Emanuel (1999), Paleoaltimetry incorporating atmospheric physics and botanical estimates of paleoclimate, Geol. Soc. Am. Bull., 111, 497-511.

Fortelius, M., J. Eronen, J. Jernvall, L. Liu, D. Pushkina, J. Rinne, A. Tesakov, I. Vislobokova, Z. Zhang, and L. Zhou (2002), Fossil mammals resolve regional patterns of Eurasian climate change over 20 million years, Evol. Ecol. Res., 4, 1005-1016.

Fricke, H. C., and S. L. Wing (2004), Oxygen isotope and paleobotanical estimates of temperature and $\delta^{18} \mathrm{O}$-latitude gradients over North America during the early Eocene, Am. J. Sci., 304, 612-635.

Friedman, I., J. M. Harris, G. I. Smith, and C. A. Johnson (2002a), Stable isotope composition of waters in the Great Basin, United States 1. Air-mass trajectories, J. Geophys. Res., 107(D19), 4400, doi:10.1029/2001JD000565.

Friedman, I., G. I. Smith, C. A. Johnson, and R. J. Moscati (2002b), Stable isotope compositions of waters in the Great Basin, United States 2. Modern precipitation, J. Geophys. Res., 107(D19), 4401, doi:10.1029/2001JD000566.

Fulthorpe, C. S., R. M. Carter, K. G. Miller, and J. Wilson (1996), Marshall paraconformity: A mid-Oligocene record of inception of the Antarctic Circumpolar Current and coeval glacio-eustatic lowstand, Mar. Pet. Geol., 13, 61-77.

Funakawa, S., et al. (2006), Radiolarian faunal turnover and paleoceanographic change around Eocene/Oligocene boundary in the central equatorial Pacific, ODP Leg 199, Holes 1218A, 1219A, and 1220A, Palaeogeogr. Palaeoclimatol. Palaeoecol., $230,183-203$.

Ganachaud, A., and C. Wunsch (2000), Improved estimates of global ocean circulation, heat transport and mixing from hydrographic data, Nature, 408, 453-457.

Garzione, C. N., J. Quade, P. G. DeCelles, and N. B. English (2000), Predicting paleoelevation of Tibet and the Himalaya from 
delta ${ }^{18} \mathrm{O}$ vs. altitude gradients in meteoric water across the Nepal Himalaya, Earth Planet. Sci. Lett., 183, 215-229.

Gillooly, J. F., et al. (2001), Effects of size and temperature on metabolic rate, Science, 293, 2248-2251.

Gordon, A. L., and R. A. Fine (1996), Pathways of water between the Pacific and Indian oceans in the Indonesian Seas, Nature, $379,146-149$.

Gordon, A. L., et al. (2003), Cool Indonesian throughflow as a consequence of restricted surface layer flow, Nature, 425, 824828.

Graham, A. (1999), Late Cretaceous and Cenozoic History of North American Vegetation North of Mexico, 350 pp., Oxford Univ. Press, New York.

Gupta, A. K., et al. (2004), Indian Ocean high-productivity event (10-8 Ma): Linked to global cooling or to the initiation of the Indian monsoons?, Geology, 32, 753-756.

Hagemann, S., et al. (2005), Validation of the hydrological cycle of ERA40, Rep. Earth Syst. Sci. 10, Max Planck Inst. for Meteorol., Hamburg, Germany.

Hardie, L. A. (1996), Secular variation in seawater chemistry: An explanation for the coupled secular variation in the mineralogies of marine limestones and potash evaporites of the past 600 m.y., Geology, 24, 279-283.

Harrison, T. M., et al. (1998), Orographic evolution of the Himalaya and Tibetan Plateau, in Tectonic Boundary Conditions for Climate Reconstruction, edited by T. J. Crowley and K. C. Burke, pp. 39-73, Oxford Univ. Press, New York.

Hartley, A. J., G. May, G. Chong, P. Turner, S. J. Kape, and E. J. Jolley (2000), Development of a continental forearc: A Cenozoic example from the central Andes, northern Chile, Geology, 28, $331-334$.

Haug, G. H., and R. Tiedemann (1998), Effect of the formation of the Isthmus of Panama on Atlantic Ocean thermohaline circulation, Nature, 393, 673-676.

Haug, G. H., et al. (1995), Evolution of northwest Pacific sedimentation patterns since $6 \mathrm{Ma}$ (Site 882), Proc. Ocean Drill. Program Sci. Results, 145, 293-315.

Haug, G. H., et al. (2001), Role of Panama uplift on oceanic freshwater balance, Geology, 29, 207-210.

Haug, G. H., et al. (2005), North Pacific seasonality and the glaciation of North America 2.7 million years ago, Nature, 433, $821-825$.

Hay, W. W., et al. (2002), The late Cenozoic uplift-climate change paradox, Int. J. Earth Sci., 91, 746-774.

Hays, J. D., et al. (1969), Pliocene-Pleistocene sediments of the equatorial Pacific: Their paleomagnetic, biostratigraphic, and climatic record, Geol. Soc. Am. Bull., 80, 1481-1514.

Hays, J. D., et al. (1976), Variations in the Earth's orbit: Pacemaker of the ice ages, Science, 194, 1121-1131.

Herbert, T. D., et al. (2001), Collapse of the California Current during glacial maxima and associated terrestrial climatic changes, Science, 293, 71-76.

Hess, J., et al. (1986), Evolution of the ratio of strontium-87 to strontium-86 in seawater from Cretaceous to present, Science, $231,979-984$.

Heusser, L. E. (1998), Direct correlation of millennial-scale changes in western North American vegetation and climate with changes in the California Current system over the past $\sim 60 \mathrm{kyr}$, Paleoceanography, 13, 252-262.

Heusser, L. E. (2000), Initial results of pollen analyses from ODP sites 1018, 1020, 1021, and 1022, Proc. Ocean Drill. Program Sci. Results, 167, 239-249.

Hickey, B. M. (1979), The California Current System: Hypotheses and facts, Prog. Oceanogr., 8, 191-279.

Honjo, S., et al. (1995), Export production of particles to the interior of the equatorial Pacific Ocean during the 1992 EqPac experiment, Deep Sea Res., Part II, 42, 831-870.

Hooper, P. R. (1997), The Columbia River flood basalt province: Current status, in Large Igneous Provinces: Continental, Oceanic, and Planetary Flood Volcanism, Geophys. Monogr. Ser., vol. 100, edited by J. J. Mahoney and M. F. Coffin, pp. 1-28, AGU, Washington, D. C.

Hooper, P. R., et al. (2002), Ages of the Steens and Columbia River flood basalts and their relationship to extension-related calcalkalic volcanism in eastern Oregon, Geol. Soc. Am. Bull., $114,43-50$.

Hoorn, C., et al. (1995), Andean tectonics as a cause for changing drainage patterns in Miocene northern South America, Geology, $23,237-240$

Horita, J., et al. (2002), Chemical evolution of seawater during the Phanerozoic: implications from the record of marine evaporites, Geochem. Cosmochim. Acta, 66, 3733-3756.

Horton, T. W., et al. (2004), Spatial and temporal variation of Cenozoic surface elevation in the Great Basin and Sierra Nevada, Am. J. Sci., 304, 862-888.

Houghton, J. T., et al. (2001), Climate Change 2001: The Scientific Basis, 881 pp., Cambridge Univ. Press, Cambridge, U. K.

Huang, Y., S. C. Clemens, W. Liu, Y. Wang, and W. L. Prell (2007), Large-scale hydrological change drove the late Miocene C4 plant expansion in the Himalayan foreland and Arabian Peninsula, Geology, 35, 531-534, doi:10.1130/G23666A.1.

Huber, M. (2002), Straw man 1: A preliminary view of the tropical Pacific from a global coupled climate model simulation of the early Paleogene, Proc. Ocean Drill. Program Initial Rep., 199, $1-30$.

Huber, M., and R. Caballero (2003), Eocene El Niño: Evidence for robust tropical dynamics in the "Hothouse," Science, 299, 877881.

Huber, M., and D. Nof (2006), The ocean circulation in the Southern Hemisphere and its climatic impacts in the Eocene, Palaeogeogr. Palaecoclimatol. Palaeoecol., 231, 9-28.

Huber, M., and L. C. Sloan (1999), Warm climate transitions: A general circulation modeling study of the late Paleocene thermal maximum, J. Geophys. Res., 104, 16,633-16,655.

Huber, M., and L. C. Sloan (2001), Heat transport, deep waters, and thermal gradients: Coupled simulation of an Eocene greenhouse climate, Geophys. Res. Lett., 28, 3481-3484.

Huber, M., et al. (2003), Early Paleogene oceans and climate: A fully coupled modeling approach using the NCAR CCSM, in Causes and Consequences of Globally Warm Climates in the Early Paleogene, edited by S. L. Wing et al., pp. 25-47, Spec. Pap. Geol. Soc. of Am., 369, 25-48.

Huber, M., H. Brinkhuis, C. E. Stickley, K. Döös, A. Sluijs, J. Warnaar, S. A. Schellenberg, and G. L. Williams (2004), Eocene circulation of the Southern Ocean: Was Antarctica kept warm by subtropical waters?, Paleoceanography, 19, PA4026, doi:10.1029/2004PA001014.

Huber, N. K. (1981), Amount and timing of late Cenozoic uplift and tilt of the central Sierra Nevada, California-Evidence from the upper San Joaquin river basin, 28 pp., U.S. Geol. Surv. Prof. Pap., 1197, 28 pp.

Huyer, A. (1983), Coastal upwelling in the California Current system, Prog. Oceanogr., 12, 259-284.

Isacks, B. L. (1988), Uplift of the central Andean Plateau and bending of the Bolivian orocline, J. Geophys. Res., 93, 32113231 .

Jenkyns, H. C., et al. (2004), High temperatures in the Late Cretaceous Arctic Ocean, Nature, 432, 888-892.

Jordan, T. E., et al. (1997), Variability in age of initial shortening and uplift in the central Andes, $16-33^{\circ} 30^{\prime} \mathrm{S}$, in Tectonic Uplift and Climate Change, edited by W. F. Ruddiman, pp. 42-63, Plenum Press, New York.

Keigwin, L. (1982), Isotopic paleoceanography of the Caribbean and east Pacific: Role of Panama uplift in late Neogene time, Science, 217, 350-353.

Keller, G. (1985), Depth stratification of planktonic foraminifers in the Miocene ocean, in The Miocene Ocean: Paleoceanography and Biogeography, edited by J. P. Kennett, Mem. Geol. Soc. Am., 163, 177-186. 
Keller, G., and J. Barron (1983), Paleoceanographic implications of Miocene deep-sea hiatuses, Geol. Soc. Am. Bull., 94, 590-613.

Kennett, J. P. (1977), Cenozoic evolution of Antarctic glaciation, the circum-Antarctic Ocean, and their impact on global paleoclimate, J. Geophys. Res., 82, 3843-3860.

Kennett, J. P. (1982), Marine Geology, 813 pp., Prentice-Hall, Englewood Cliffs, N. J.

Kennett, J. P. (1985), The Miocene Ocean: Paleoceanography and Biogeography, Mem. Geol. Soc. Am., 163, 344 pp.

Kennett, J. P., and L. D. Stott (1991), Abrupt deep-sea warming, palaeoceanographic changes and benthic extinctions at the end of the palaeocene, Nature, 353, 225-229.

Kennett, J. P., et al. (1985), Miocene planktonic foraminiferal biogeography and paleoceanographic development of the Indo-Pacific region, in The Miocene Ocean: Paleoceanography and Biogeography, edited by J. P. Kennett, Mem. Geol. Soc. Am., 163, 197-237.

Kerrick, D. M., and K. Caldeira (1999), Was the Himalayan orogen a climatically significant coupled source and sink for atmospheric $\mathrm{CO}_{2}$ during the Cenozoic?, Earth Planet. Sci. Lett., $173,195-203$.

Knappenberger, M. B. (2000), Sedimentation rates and Pacific plate motion calculated using seismic cross sections of the Neogene equatorial sediment bulge, M.S. thesis, 95 pp., Boise State Univ., Boise, Idaho.

Koch, P. L. (1998), Isotopic reconstruction of past continental environments, Annu. Rev. Earth Planet. Sci., 26, 573-613.

Kohn, M. J., et al. (2002), Oxygen isotope evidence for progressive uplift of the Cascade Range, Oregon, Earth Planet. Sci. Lett., $204,151-165$.

Kominz, M., and S. F. Pekar (2001), Oligocene eustasy from twodimensional sequence stratigraphic backstripping, Geol. Soc. Am. Bull., 113, 291-304.

Krissek, L. A. (1995), Late Cenozoic ice-rafting records from Leg 145 sites in the North Pacific: Late Miocene onset, late Pliocene intensification, and Pliocene-Pleistocene events, Proc. Ocean Drill. Program Sci. Results, 145, 179-195.

Kroopnick, P. M. (1985), The distribution of ${ }^{13} \mathrm{C}$ of $\sum \mathrm{CO}_{2}$ in the work oceans, Deep Sea Res., Part A, 32, 57-84.

$\mathrm{Ku}$, T.-L., et al. (1974), Eustatic sea level 120,000 years ago on Oahu, Hawaii, Science, 183, 959-962.

Kump, L. R., et al. (2000), Chemical weathering, atmospheric $\mathrm{CO}_{2}$, and climate, Annu. Rev. Earth Planet. Sci., 28, 611-667.

Kurtz, A. C., L. R. Kump, M. A. Arthur, J. C. Zachos, and A. Paytan (2003), Early Cenozoic decoupling of the global carbon and sulfur cycles, Paleoceanography, 18(4), 1090, doi:10.1029/2003PA000908.

Laskar, J., et al. (2004), A long-term numerical solution for the insolation quantities of the Earth, Astron. Astrophys., 428, $261-$ 285.

Latimer, J. C., and G. M. Fillipelli (2002), Eocene to Miocene terrigenous inputs and export production: Geochemical evidence from ODP Leg 166, Site 1090, Palaeogeogr. Palaecoclimatol. Palaeoecol., 182, 151-164.

Lau, K.-M., K. Kim, and S. S. P. Shen (2002), Potential predictability of seasonal precipitation over the United States from canonical ensemble correlation predictions, Geophys. Res. Lett., 29(7), 1097, doi:10.1029/2001GL014263.

Lawver, L. A., and L. M. Gahagan (1998), Opening of Drake Passage and its impact on Cenozoic ocean circulation, in Tectonic Boundary Conditions for Climate Reconstructions, edited by T. J. Crowley and K. C. Burke, pp. 212-223, Oxford Univ. Press, New York.

Lawver, L. A., and L. M. Gahagan (2003), Evolution of Cenozoic seaways in the circum-Antarctic region, Palaeogeogr. Palaecoclimatol. Palaeoecol., 198, 11-37.

Lea, D. W., et al. (2000), Climate impact of late Quaternary equatorial Pacific sea surface temperature variations, Science, 289 , $1719-1724$
Lear, C. H., et al. (2000), Cenozoic deep-sea temperatures and global ice volumes from $\mathrm{Mg} / \mathrm{Ca}$ in benthic foraminiferal calcite, Science, 287, 269-272.

Lear, C. H., Y. Rosenthal, H. K. Coxall, and P. A. Wilson (2004), Late Eocene to early Miocene ice sheet dynamics and the global carbon cycle, Paleoceanography, 19, PA4015, doi:10.1029/ 2004PA001039.

Lee, T., et al. (2002), Effects of the Indonesian Throughflow on the Pacific and Indian oceans, J. Phys. Oceanogr., 32, 1404-1429.

Leg 119 Shipboard Scientific Party (1989), Site 737, Proc. Ocean Drill. Program Initial Rep., 119, 159-227.

Leg 198 Shipboard Scientific Party (2002), Leg 198 summary, Proc. Ocean Drill. Program Initial Rep., 198, 1-148, doi:110.2973/odp.proc.ir.2198.2101.2002.

Leg 199 Shipboard Scientific Party (2002), Leg 199 summary, Proc. Ocean Drill. Program Initial Rep., 199, 1-87, doi:10.2973/odp.proc.ir.2199.2101.2002.

Leg 208 Shipboard Scientific Party (2004), Leg 208 summary, Proc. Ocean Drill. Program Initial Rep., 208, 1-112. doi:110.2973/odp.proc.ir.2208.2101.2004.

Leinen, M. (1979), Biogenic silica accumulation in the central equatorial Pacific and its implications for Cenozoic paleoceanography: Summary, Geol. Soc. Am. Bull., Part 1, 90, 801-803.

Linthout, K., et al. (1997), Late Miocene obduction and microplate migration around the southern Banda Sea and the closure of the Indonesian Seaway, Tectonophysics, 281, 17-30.

Livermore, R., et al. (2005), Paleogene opening of Drake Passage, Earth Planet. Sci. Lett., 236, 459-470.

Livingstone, D. A. (1963), Chemical composition of rivers and lakes: Data of geochemistry, U.S. Geol. Surv. Prof. Pap., 440$G, \mathrm{G} 1-\mathrm{G} 64$

Lourens, L. J., et al. (2005), Astronomical pacing of late Palaeocene to early Eocene global warming events, Nature, 435, 1083 1087.

Lowenstein, T. K., et al. (2001), Oscillations in Phanerozoic seawater chemistry: Evidence from fluid inclusions, Science, 294, 1086-1088.

Lowenstein, T. K., et al. (2003), Secular variation in seawater chemistry and the origin of calcium choloride basinal brines, Geology, 31, 857-860.

Lyle, M. (1997), Could early Cenozoic thermohaline circulation have warmed the poles?, Paleoceanography, 12, 161-167.

Lyle, M. (2003), Neogene carbonate burial in the Pacific Ocean, Paleoceanography, 18(3), 1059, doi:10.1029/2002PA000777.

Lyle, M., et al. (1995), The Late Miocene (11-8 Ma) eastern Pacific carbonate crash: Evidence for reorganization of deep water circulation by the closure of the Panama Gateway, Proc. Ocean Drill. Program Sci. Results, 138, 821-837.

Lyle, M., et al. (2001), Interglacial theme and variations: 500 k.y. of orbital forcing and associated responses from the terrestrial and marine biosphere, U.S. Pacific Northwest, Geology, 29, $1115-1118$.

Lyle, M., et al. (2002), Proceedings of the Ocean Drilling Program Initial Reports, vol. 199, Ocean Drill. Program, College Station, Tex. (Available at http://www-odp.tamu.edu/publications/ 199 IR/199ir.htm)

Lyle, M., et al. (2003), North Pacific sea surface temperature, western U.S. vegetation, and the demise of the Miocene Rocky Mountain monsoon, Eos Trans. AGU, 84(46), Fall Meet. Suppl., Abstract PP21C-1185.

Lyle, M. W., A. Olivarez Lyle, J. Backman, and A. Tripati (2005), Biogenic sedimentation in the Eocene equatorial Pacific: The stuttering greenhouse and Eocene carbonate compensation depth [online], Proc. Ocean Drill. Program Sci. Results, 199, 1-35. (Available at http://www-odp.tamu.edu/publications/199_SR/ VOLUME/CHAPTERS/219.PDF)

Lyle, M., S. Gibbs, T. C. Moore Jr., and D. K. Rea (2007), Late Oligocene initiation of the Antarctic Circumpolar Current: Evidence from the South Pacific, Geology, 35, 691-694. 
Marincovich, L., Jr., and A. Y. Gladenkov (1999), Evidence for an early opening of the Bering Strait, Nature, 397, 149-151.

Marlowe, I. T., et al. (1990), Long-chain alkenones and alkyl alkenoates and the fossil coccolith record of marine sediments, Chem. Geol., 88, 349-375.

Martin, J.-M., and M. Meybeck (1979), Elemental mass-balance of material carried by major world rivers, Mar. Chem., 7, 173-206.

Maslin, M. A., et al. (1995), Northwest Pacific site 882: The initiation of Northern Hemisphere glaciation, Proc. Ocean Drill. Program Sci. Results, 145, 315-325.

Mayer, L. A., et al. (1992), Proceedings of the Ocean Drilling Program Initial Reports, vol. 138, Ocean Drill. Program, College Station, Tex.

McArthur, J. M., et al. (2001), Strontium isotope stratigraphy: Lowess version 3: Best fit to the marine Sr-isotope curve for 0-509 Ma and accompanying look-up table for deriving numerical age, J. Geol., 109, 155-170.

McCabe, G. J., and M. D. Dettinger (1999), Decadal variability in the strength of ENSO teleconnections with precipitation in the western United States, Int. J. Climatol., 19, 1399-1410.

McCabe, G. J., et al. (2004), Pacific and Atlantic Ocean influences on multidecadal drought frequency in the United States, Proc. Natl. Acad. Sci., 101, 4136-4141.

Mikolajewicz, U., and T. J. Crowley (1997), Response of a coupled ocean/energy balance model to restricted flow through the Central American isthmus, Paleoceanography, 12, 429-441.

Mikolajewicz, U., et al. (1993), Effect of Drake Passage and Panamanian gateways on the circulation of an ocean model, Paleoceanography, 8, 409-426.

Miller, K. G., et al. (1987), Tertiary oxygen isotope synthesis, sea level history, and continental margin erosion, Paleoceanography, $2,1-21$.

Miller, K. G., et al. (1991), Unlocking the ice house: OligoceneMiocene oxygen isotopes, eustasy and margin erosion, J. Geophys. Res., 96, 6829-6848.

Miller, K. G., G. S. Mountain, J. V. Browning, M. Kominz, P. J. Sugarman, N. Christie-Blick, M. E. Katz, and J. D. Wright (1998), Cenozoic global sea level, sequences, and the New Jersey transect: Results from coastal plain and continental slope drilling, Rev. Geophys., 36, 569-602.

Miller, K. G., et al. (2005), The Phanerozoic record of global sealevel change, Science, 310, 1293-1298.

Mitchell, N. C. (1998), Modeling Cenozoic sedimentation in the central equatorial Pacific and implications for true polar wander, J. Geophys. Res., 103, 17,749-17,766.

Mitchell, N. C., M. W. Lyle, M. B. Knappenberger, and L. M. Liberty (2003), Lower Miocene to present stratigraphy of the equatorial Pacific sediment bulge and carbonate dissolution anomalies, Paleoceanography, 18(2), 1038, doi:10.1029/ 2002PA000828.

Mix, A. C., et al. (2003), Proceedings of the Ocean Drilling Program Initial Reports, vol. 202, Ocean Drill. Program, College Station, Tex.

Mock, C. J. (1996), Climatic controls and spatial variations of precipitation in the western United States, J. Clim., 9, 11111125.

Molnar, P., and P. C. England (1990), Late Cenozoic uplift of mountain ranges and global climate change: Chicken or egg?, Nature, 346, 29-34.

Molnar, P., et al. (1993), Mantle dynamics, uplift of the Tibetan Plateau, and the Indian monsoon, Rev. Geophys., 31, 357-396.

Moore, T. C. (1969), Radiolaria: Change in skeletal weight and resistance to solution, Geol. Soc. Am. Bull., 80, 2103-2108.

Moore, T. C., Jr., J. Backman, I. Raffi, C. Nigrini, A. Sanfilippo, H. Pälike, and M. Lyle (2004), Paleogene tropical Pacific: Clues to circulation, productivity, and plate motion, Paleoceanography, 19, PA3013, doi:10.1029/2003PA000998.

Moran, K., et al. (2006), The Cenozoic palaeoenvironment of the Arctic Ocean, Nature, 441, 601-605.
Mulch, A., et al. (2004), Reconstructing paleoelevaton in eroded orogens, Geology, 32, 525-528.

Munk, W., and C. Wunsch (1998), Abyssal recipes II: Energetics of tidal and wind mixing, Deep Sea Res., Part I, 45, 1977-2010.

Murphy, M. A., et al. (1997), Did the Indo-Asian collision alone create the Tibetan Plateau, Geology, 25, 719-722.

Murray, R. W., et al. (1993), Biogenic flux of Al to sediment in the central equatorial Pacific Ocean: Evidence for increased productivity during glacial periods, Paleoceanography, 8, 651-671.

Murray, S. P., and D. Arief (1988), Throughflow into the Indian Ocean through the Lombok Strait, January 1985-January 1986, Nature, 333, 444-447.

Myhre, A. M., and J. Thiede (1995), North Atlantic-Arctic gateways, Proc. Ocean Drill. Program Initial Rep., 151, 5-27.

Myhre, A. M., et al. (1995), Proceedings of the Ocean Drilling Program, Initial Reports, vol. 151, Ocean Drill. Program, College Station, Tex.

Nilsson, J., et al. (2003), The thermohaline circulation and vertical mixing: Does weaker density stratification give stronger overturning?, J. Phys. Oceanogr., 33, 2781-2795.

Nishimura, S., and S. Suparka (1997), Tectonic approach to the Neogene evolution of Pacific-Indian Ocean seaways, Tectonophysics, 281, 1-16.

Nong, G. T., R. G. Najjar, D. Seidov, and W. H. Peterson (2000), Simulation of ocean temperature change due to the opening of Drake Passage, Geophys. Res. Lett., 27, 2689-2692.

Norris, R. D., and U. Röhl (1999), Carbon cycling and chronology of climate warming during the Palaeocene/Eocene transition, Nature, 401, 775-778.

Norris, R. D., et al. (1996), Skiing in the Eocene Uinta Mountains? Isotopic evidence in the Green River formation for snow melt and large mountains, Geology, 24, 403-406.

Nuñes, F., and R. D. Norris (2006), Abrupt reversal in ocean overturning during the Palaeocene/Eocene warm period, Nature, 439, $60-63$

O'Connell, S., et al. (1996), Implications for the creation of warm saline deep water: Late Paleocene reconstructions and global climate model simulations, Geol. Soc. Am. Bull., 108, 270-284.

Olivarez Lyle, A., and M. Lyle (2005), Organic carbon and barium in Eocene sediments: Possible controls on nutrient recycling in the Eocene equatorial Pacific Ocean [online], Proc. Ocean Drill. Program Sci. Results, 199, 1-33. (Available at http://www-odp.tamu.edu/publications/199_SR/222/222_.htm)

Olivarez Lyle, A., and M. W. Lyle (2006), Missing organic carbon in Eocene marine sediments: Is metabolism the biological feedback that maintains end-member climates?, Paleoceanography, 21, PA2007, doi:10.1029/2005PA001230.

Omta, A. W., and H. A. Dijkstra (2003), A physical mechanism for the Atlantic-Pacific flow reversal in the early Miocene, Global Planet. Change, 36, 265-276.

Opdyke, B. N., and B. H. Wilkinson (1988), Surface area control of shallow cratonic to deep marine carbonate accumulation, Paleoceanography, 3, 685-703.

Pagani, M., et al. (1999a), Late Miocene atmospheric $\mathrm{CO}_{2}$ concentrations and the expansion of C4 grasses, Science, 285, 876-878.

Pagani, M., M. A. Arthur, and K. H. Freeman (1999b), Miocene evolution of atmospheric carbon dioxide, Paleoceanography, 14, 273-292.

Pagani, M., et al. (2005), Marked decline in atmospheric carbon dioxide concentrations during the Paleogene, Science, 309, 600603.

Pälike, H., et al. (2004), Geologic constraints on the chaotic diffusion of the solar system, Geology, 32, 929-932.

Pälike, H., et al. (2005), Integrated stratigraphic correlation and improved composite depth scales for ODP Sites 1218 and 1219, Proc. Ocean Drill. Program Sci. Results, 199, 1-41.

Pälike, H., et al. (2006), The heartbeat of the Oligocene climate system, Science, 314, 1894-1898.

Palmer, M. R., and J. M. Edmond (1989), The strontium isotope budget of the modern ocean, Earth Planet. Sci. Lett., 92, 11-26. 
Palmer, M. R., and H. Elderfield (1985), Sr isotope composition of sea water over the past $75 \mathrm{Myr}$, Nature, 314, 526-528.

Pares, J. M., and T. C. Moore (2005), New evidence for the Hawaiian hotspot plume motion since the Eocene, Earth Planet. Sci. Lett., 237, 951-959.

Pares-Sierra, A., and J. J. O'Brien (1989), The seasonal and interannual variability of the California Current system: A numerical model, J. Geophys. Res., 94, 3159-3180.

Paytan, A., et al. (1998), Sulfur isotopic composition of Cenozoic seawater sulfate, Science, 282, 1459-1462.

Pearson, P. N., and M. R. Palmer (2000), Atmospheric carbon dioxide over the past 60 million years, Nature, 406, 695-699.

Pekar, S. F., et al. (2002), Calibration between eustatic estimates from backstripping and oxygen isotopic records for the Oligocene, Geology, 30, 903-906.

Peterson, L. C., et al. (1992), Cenozoic carbonate accumulation and compensation depth changes in the Indian Ocean, in Synthesis of Results From Scientific Drilling in the Indian Ocean, Geophys. Monogr. Ser., vol. 70, edited by R. A. Duncan and D. Rea, pp. 311-333, AGU, Washington, D. C.

Pfuhl, H. A., and I. N. McCave (2005), Evidence for late Oligocene establishment of the Antarctic Circumpolar Current, Earth Planet. Sci. Lett., 235, 715-728.

Pisias, N. G., et al. (2001), Millennial-scale climate variability of the northeast Pacific Ocean and northwest North America based on radiolaria and pollen, Quat. Sci. Rev., 20, 1561-1576.

Poage, M. A., and C. P. Chamberlain (2001), Empirical relationships between elevation and the stable isotope composition of precipitation and surface waters: Considerations for studies of paleoelevation change, Am. J. Sci., 301, 1-15.

Prahl, F. G., and S. G. Wakeham (1987), Calibration of unsaturation patterns in long-chain ketone compositions for palaeotemperature assessment, Nature, 330, 367-369.

Prahl, F., T. Herbert, S. C. Brassell, N. Ohkouchi, M. Pagani, D. Repeta, A. Rosell-Melé, and E. Sikes (2000), Status of alkenone paleothermometer calibration: Report from Working Group 3, Geochem. Geophys. Geosyst., 1(11), doi:10.1029/ 2000GC000058.

Prell, W. L., and J. E. Kutzbach (1992), Sensitivity of the Indian monsoon to forcing parameters and implications for its evolution, Nature, 360, 647-652.

Prell, W. L., and J. E. Kutzbach (1997), The impact of TibetHimalayan elevation on the sensitivity of the monsoon climate system to changes in solar radiation, in Tectonic Uplift and Climate Change, edited by W. F. Ruddiman, pp. 172-203, Plenum Press, New York.

Prell, W. L., D. W. Murray, S. C. Clemens, and D. M. Anderson (1992), Evolution and variability of the Indian Ocean summer monsoon: Evidence from the western Arabian Sea drilling program, in Synthesis of Results from Scientific Drilling in the Indian Ocean, Geophys. Monogr. Ser., vol. 70, edited by R. A. Duncan and D. Rea, pp. 447-469, AGU, Washington, D. C.

Prueher, L. M., and D. K. Rea (1998), Rapid onset of glacial conditions in the subarctic North Pacific region at 2.67 Ma: Clues to causality, Geology, 26, 1027-1030.

Prueher, L. M., and D. K. Rea (2001), Volcanic triggering of late Pliocene glaciation: Evidence from the flux of volcanic glass and ice rafted debris to the North Pacific Ocean, Palaeogeogr. Palaeoclimatol., Palaeoecol., 173, 215-230.

Pytkowicz, R. M. (1969), Chemical solution of calcium carbonate in sea water, Am. Zool., 9, 673-679.

Quade, J., L. Roe, P. G. DeCelles, and T. P. Ojha (1997), The late Neogene ${ }^{87} \mathrm{Sr} /{ }^{86} \mathrm{Sr}$ record of lowland Himalayan rivers, Science, $278,1828-1831$.

Ravelo, A. C., and M. W. Wara (2004), The role of the tropical oceans on global climate during a warm period and a major climate transition, Oceanography, 17, 32-41.

Ravelo, A. C., et al. (2004), Regional climate shifts caused by gradual global cooling in the Pliocene epoch, Nature, 429, $263-267$.
Ravizza, G., and B. Peucker-Ehrenbrink (2003), The marine ${ }^{187} \mathrm{Os} /{ }^{188} \mathrm{Os}$ record of the Eocene-Oligocene transition: The interplay of weathering and glaciation, Earth Planet. Sci. Lett., 210, $151-165$.

Raymo, M. E. (1994), The initiation of Northern Hemisphere glaciation, Annu. Rev. Earth Planet. Sci., 22, 353-383.

Raymo, M. E., and W. F. Ruddiman (1992), Tectonic forcing of late Cenozoic climate, Nature, 359, 117-122.

Raymo, M. E., et al. (1988), Influence of late Cenozoic mountain building on ocean geochemical cycles, Geology, 16, 649-653.

Raymo, M. E., et al. (1996), Mid-Pliocene warmth: Stronger greenhouse and stronger conveyer, Mar. Micropaleontol., 27, 313326.

Rea, D. K. (1994), The paleoclimatic record provided by eolian deposition in the deep sea: The geologic history of wind, Rev. Geophys., 32, 159-195.

Rea, D. K., and M. W. Lyle (2005), Paleogene calcite compensation depth in the eastern subtropical Pacific: Answers and questions, Paleoceanography, 20, PA1012, doi:10.1029/ 2004PA001064.

Rea, D. K., and H. Snoeckx (1995), Sediment fluxes in the Gulf of Alaska: Paleoceanographic record from Site 887 on the PattonMurray Seamount Platform, Proc. Ocean Drill. Program Sci. Results, 145, 247-256.

Rea, D. K., et al. (1995), Scientific results of drilling the North Pacific transect, Proc. Ocean Drill. Program Sci. Results, 145, 577-595.

Retallack, G. J. (2001), Cenozoic expansion of grasslands and climatic cooling, J. Geol., 109, 407-426.

Retallack, G. J., et al. (2002), Late Miocene advent of tall grassland paleosols in Oregon, Palaeogeogr. Palaecoclimatol. Palaeoecol., 183, 329-354.

Retallack, G. J., et al. (2004), Eocene-Oligocene extinction and paleoclimatic change near Eugene, Oregon, Geol. Soc. Am. Bull., $116,817-839$.

Rind, D., et al. (1997), The effects of uplift on ocean-atmosphere circulation, in Tectonic Uplift and Climate Change, edited by W. F. Ruddiman, pp. 124-149, Plenum, New York.

Rodgers, K. B., M. A. Cane, N. H. Naik, and D. P. Schrag (1999), The role of the Indonesian Throughflow in equatorial Pacific thermocline ventilation, J. Geophys. Res., 104, 20,551-20,570.

Roemmich, D., and T. McCallister (1989), Large scale circulation of the North Pacific Ocean, Prog. Oceanogr., 22, 171-204.

Romine, K. (1985), Radiolarian biogeography and paleoceanography of the North Pacific at $8 \mathrm{Ma}$, in The Miocene Ocean: Paleoceanography and Biogeography, edited by J. P. Kennett, pp. 237-273, Geol. Soc. of Am., Boulder, Colo.

Romine, K., and G. Lombari (1985), Evolution of Pacific circulation in the Miocene: Radiolarian evidence from DSDP Site 289, in The Miocene Ocean: Paleoceanography and Biogeography, edited by J. P. Kennett, pp. 273-291, Geol. Soc. of Am., Boulder, Colo.

Rosell-Melé, A., et al. (2001), Precision of the current methods to measure the alkenone $\mathrm{U}_{37}^{\mathrm{K}^{\prime}}$ and absolute alkenone abundance in sediments: Results of an interlaboratory comparison study, Geochem. Geophys. Geosyst., 2(7), doi:10.1029/2000GC000141.

Rowley, D. B., et al. (2001), A new approach to stable isotopebased paleoaltimetry: Implications for paleoaltimetry and paleohypsometry of the high Himalaya since the late Miocene, Earth Planet. Sci. Lett., 188, 253-268.

Royer, D. L. (2002), Estimating latest Cretaceous and Tertiary atmospheric $\mathrm{CO}_{2}$ concentration from stomatal indices, Ph.D. thesis, 163 pp., Yale Univ., New Haven, Conn.

Royer, D. L. (2006), $\mathrm{CO}_{2}$-forced climate thresholds during the Phanerozoic, Geochim. Cosmochim. Acta, 70, 5665-5675.

Royer, D. L., et al. (2001), Paleobotanical evidence for near present-day levels of atmospheric $\mathrm{CO}_{2}$ during part of the Tertiary, Science, 292, 2310-2313.

Royer, D. L., et al. (2004), $\mathrm{CO}_{2}$ as a primary driver of Phanerozoic climate, GSA Today, 14, 4-10. 
Ruddiman, W. F., and J. E. Kutzbach (1989), Forcing of late Cenozoic Northern Hemisphere climate by plateau uplift in southern Asia and the American West, J. Geophys. Res., 94, $18,409-18,427$.

Ruddiman, W. F., and W. L. Prell (1997), Introduction to the upliftclimate connection, in Tectonic Uplift and Climate Change, edited by W. F. Ruddiman, pp. 3-15, Plenum, New York.

Ruddiman, W. F., and M. E. Raymo (1988), Northern Hemisphere climate regimes during the past $3 \mathrm{Ma}$ : Possible tectonic connections, Philos. Trans. R. Soc. London, Ser. B, 318, 411-430.

Savin, S. M., et al. (1985), The evolution of Miocene surface and near-surface marine temperatures: Oxygen isotope evidence, in The Miocene Ocean: Paleoceanography and Biogeography, edited by J. P. Kennett, pp. 49-83, Geol. Soc. of Am., Boulder, Colo.

Scher, H. D., and E. E. Martin (2006), Timing and climatic consequences of the opening of Drake Passage, Science, 312, 428430.

Schouten, S., et al. (2002), Distributional variations in marine crenarchaeotal membrane lipids: A new tool for reconstructing ancient sea water temperatures?, Earth Planet. Sci. Lett., 204, $265-274$.

Seager, R., et al. (2002), Is the Gulf Stream responsible for Europe's mild winters?, Q. J. R. Meteorol. Soc., 128, 2563-2586.

Shackleton, N. J. (1985), Oceanic carbon isotope constraints on oxygen and carbon dioxide in the Cenozoic atmosphere, in The Carbon Cycle and Atmospheric $\mathrm{CO}_{2}$ : Natural Variations Archaean to Present, edited by E. T. Sundquist and W. S. Broecker, Geophys. Monogr. Ser., vol. 32, AGU, Washington, D. C.

Shackleton, N. J., et al. (1984), Oxygen isotope calibration of the onset of ice-rafting and history of glaciation in the North Atlantic region, Nature, 307, 620-623.

Shackleton, N. J., et al. (1999), Astronomical calibration of Oligocene-Miocene time, Philos. Trans. R. Soc. London, Ser. A, 357, 1907-1929.

Shackleton, N. J., et al. (2000), Astronomical calibration age for the Oligocene-Miocene boundary, Geology, 28, 447-450.

Shaffer, G., and J. Bendtsen (1994), Role of the Bering Strait in controlling North Atlantic Ocean circulation and climate, Nature, $367,354-357$.

Shevenell, A. E., et al. (2004), Middle Miocene Southern Ocean cooling and Antarctic cryosphere expansion, Science, 305, $1766-1770$.

Sijp, W. P., and M. H. England (2004), Effect of the Drake Passage throughflow on global climate, J. Phys. Oceanogr., 34, 12541266.

Sloan, L. C., and M. Huber (2001), Eocene oceanic responses to orbital forcing on precessional time scales, Paleoceanography, 16, 101-111.

Sloan, L. C., et al. (1996), Modeling of middle Pliocene climate with the NCAR GENESIS general circulation model, Mar. Micropaleontol., 27, 15-61.

Sluijs, A., et al. (2006), Subtropical Arctic Ocean temperatures during the Palaeocene/Eocene thermal maximum, Nature, 441, $610-613$.

Smetacek, V. S. (1985), Role of sinking in diatom life-history cycles: Ecological, evolutionary and geological significance, Mar. Biol., 84, 239-251.

Spicer, R. A., et al. (2003), Constant elevation of southern Tibet over the past 15 million years, Nature, 421, 622-624.

Stickley, C. E., H. Brinkhuis, S. A. Schellenberg, A. Sluijs, U. Röhl, M. Fuller, M. Grauert, M. Huber, J. Warnaar, and G. L. Williams (2004), Timing and nature of the deepening of the Tasmanian Gateway, Paleoceanography, 19, PA4027, doi:10.1029/ 2004PA001022.

Stock, G. M., R. S. Anderson, and R. C. Finkel (2004), Pace of landscape evolution in the Sierra Nevada, California, revealed by cosmogenic dating of cave sediments, Geology, 32, 193-196.
Sun, Q.-G., et al. (2002), Quantitative reconstruction of palaeoclimate from the middle Miocene Shanwang flora, eastern China, Palaeogeogr. Palaeoclimatol. Palaeoecol., 180, 315-329.

Sun, J., et al. (2005), Tectonic uplift in the northern Tibetan Plateau since 13.7 Ma ago inferred from molasse deposits along the Altyn Tagh Fault, Earth Planet. Sci. Lett., 235, 641-653.

Takeuchi, A., and P. B. Larson (2005), Oxygen isotope evidence for the late Cenozoic development of an orographic rain shadow in eastern Washington, USA, Geology, 33, 313-316.

Thiede, J., et al. (1996), Proceedings of the Ocean Drilling Program Scientific Results, vol. 151, Ocean Drill. Program, College Station, Tex.

Thomas, D. J., et al. (2002), Warming the fuel for the fire: Evidence for the thermal dissociation of methane hydrate during the Paleocene-Eocene thermal maximum, Geology, 30, 1067-1070.

Thomas, E. (2003), Extinction and food at the seafloor: A high resolution benthic foraminiferal record across the initial Eocene thermal maximum, Southern Ocean site 690, Spec. Pap. Geol. Soc. Am., 369, 319-333.

Thomas, D. J. (2004), Evidence for deep-water production in the North Pacific Ocean during the early Cenozoic warm interval, Nature, 430, 65-68.

Thomas, D. J. (2005), Reconstructing ancient deep-sea circulation patterns using the $\mathrm{Nd}$ isotopic composition of fossil fish debris, in Isotopic and Elemental Tracers of Cenozoic Climate Change, Spec. Pap. Geol. Soc. Am., 395, 1-11.

Thomas, D. J., and R. K. Via (2007), Neogene evolution of Atlantic thermohaline circulation: Perspective from Walvis Ridge, southeastern Atlantic Ocean, Paleoceanography, 22, PA2212, doi:10.1029/2006PA001297.

Toggweiler, J. R., and H. Bjornsson (2000), Drake Passage and palaeoclimate, J. Quat. Sci., 15, 319-328.

Tracey, J. I., and Leg 8 Shipboard Scientific Party (1971), Initial Reports of the Deep Sea Drilling Project, vol. 8, U.S. Gov. Print. Office, Washington, D. C.

Tripati, A., et al. (2005), Eocene bipolar glaciation associated with global carbon cycle changes, Nature, 436, 341-345.

Uddin, A., and N. Lundberg (1998), Cenozoic history of the Himalayan-Bengal system; sand composition in the Bengal basin, Bangladesh, Geol. Soc. Am. Bull., 110, 497-511.

van Andel, T. H. (1974), Cenozoic migration of the Pacific plate, northward shift of the axis of deposition and paleobathymetry of the central equatorial Pacific, Geology, 2, 507-510.

van Andel, T. H., and T. C. Moore Jr. (1974), Cenozoic calcium carbonate distribution and calcite compensation depth in the central equatorial Pacific Ocean, Geology, 2, 87-92.

van Andel, T. H., G. R. Heath, R. H. Bennett, J. D. Bukry, S. Charleston, D. S. Cronan, M. G. Dinkelman, A. Kaneps, K. S. Rodolfo, and R. S. Yeats (1973), Initial Reports of the Deep Sea Drilling Project, vol. 16, 949 pp., Ocean Drill. Program, College Station, Tex.

van Andel, T. H., et al. (1975), Cenozoic history and paleoceanography of the central equatorial Pacific Ocean, Mem. Geol. Soc. Am., 143, 133 pp.

van de Flierdt, T., M. Frank, A. N. Halliday, J. R. Hein, B. Hattendorf, D. Günther, and P. W. Kubik (2004), Deep and bottom water export from the Southern Ocean to the Pacific over the past 38 million years, Paleoceanography, 19, PA1020, doi:10.1029/2003PA000923.

Vanden Berg, M. D., and R. D. Jarrard (2004), Cenozoic mass accumulation rates in the equatorial Pacific based on high-resolution mineralogy of Ocean Drilling Program Leg 199, Paleoceanography, 19, PA2021, doi:10.1029/2003PA000928.

Van der Burgh, J., et al. (1993), Paleoatmospheric signatures in Neogene fossil leaves, Science, 260, 1788-1790.

Veizer, J. (1989), Strontium isotopes in seawater through time, Annu. Rev. Earth Planet. Sci., 17, 141-167.

Verplanck, E. P., and R. A. Duncan (1987), Temporal variations in plate convergence and eruption rates in the western Cascades, Oregon, Tectonics, 6, 197-211. 
Via, R. K., and D. J. Thomas (2006), Evolution of Atlantic thermohaline circulation: Early Oligocene onset of deep-water production in the North Atlantic, Geology, 34, 441-444.

Vincent, E., and W. H. Berger (1985), Carbon dioxide and polar cooling in the Miocene: The Monterey hypothesis, in The Carbon Cycle and Atmospheric $\mathrm{CO}_{2}$ : Natural Variations Archaean to Present, Geophys. Monogr. Ser., vol. 32, edited by E. T. Sundquist and W. S. Broecker, pp. 455-469, AGU, Washington, D. C.

Vincent, E., et al. (1985), Miocene oxygen and carbon isotope stratigraphy of the tropical Indian Ocean, in The Miocene Ocean: Paleoceanography and Biogeography, edited by J. P. Kennett, pp. 103-131, Geol. Soc. of Am., Boulder, Colo.

von der Heydt, A., and H. A. Dijkstra (2006), Effect of ocean gateways on the global ocean circulation in the late Oligocene and early Miocene, Paleoceanography, 21, PA1011, doi:10.1029/2005PA001149.

Wade, B. S., and H. Pälike (2004), Oligocene climate dynamics, Paleoceanography, 19, PA4019, doi:10.1029/2004PA001042.

Wakabayashi, J., and T. L. Sawyer (2001), Stream incision, tectonics, uplift, and evolution of topography of the Sierra Nevada, California, J. Geol., 109, 539-562.

Wara, M. W., A. C. Ravelo, and Margaret L. Delaney (2005), Permanent El Niño-like conditions during the Pliocene warm period, Science, 309, 758-761.

Wells, M. L., et al. (1999), Tectonic processes in Papua New Guinea and past productivity in the eastern equatorial Pacific Ocean, Nature, 398, 601-604.

Wen, J. (1999), Evolution of eastern Asian and eastern North American disjunct distributions in flowering plants, Annu. Rev. Ecol. Syst., 30, 421-455.

Wilkinson, B. H., and T. J. Algeo (1989), Sedimentary carbonate record of calcium-magnesium cycling, Am. J. Sci., 289, 11581194.

Wolfe, J. A. (1985), Distribution of major vegetational types during the tertiary, in The Carbon Cycle and Atmospheric $\mathrm{CO}_{2}$ : Natural Variations Archean to Present, Geophys. Monogr. Ser., vol. 32, edited by E. T. Sundquist and W. S. Broecker, pp. 357375, AGU, Washington, D. C.

Wolfe, J. A. (1994), Tertiary climatic changes at middle latitudes of western North America, Palaeogeogr. Palaeoclimatol. Palaeoecol., 108, 195-205.
Wolfe, J. A., et al. (1997), Paleobotanical evidence for high altitudes in Nevada during the Miocene, Science, 276, 1672-1675. Wolfe, J. A., et al. (1998), Paleobotanical evidence of Eocene and Oligocene paleoaltitudes in midlatitude western North America, Geol. Soc. Am. Bull., 110, 664-678.

Wright, J. D., and K. G. Miller (1996), Control of North Atlantic Deep Water circulation by the Greenland-Scotland Ridge, Paleoceanography, 11, 157-170.

Zachos, J. C., L. D. Stott, and K. C. Lohmann (1994), Evolution of early Cenozoic marine temperatures, Paleoceanography, 9, 353387.

Zachos, J., et al. (2001a), Trends, rhythms, and aberrations in global climate $65 \mathrm{Ma}$ to Present, Science, 292, 686-693.

Zachos, J. C., et al. (2001b), Climate response to orbital forcing across the Oligocene-Miocene boundary, Science, 292, 274-277.

Zachos, J. C., et al. (2003), Transient rise in tropical sea surface temperature during the Paleocene-Eocene thermal maximum, Science, 302, 1551-1554

Zachos, J. C., et al. (2005), Rapid acidification of the ocean during the Paleocene-Eocene thermal maximum, Science, 308, 16111615.

Ziegler, A. M., and D. B. Rowley (1998), The vanishing record of epeiric seas, with emphasis on the late Cretaceous "Hudson Seaway", in Tectonic Boundary Conditions for Climate Reconstructions, edited by T. J. Crowley and K. C. Burke, pp. 147-165, Oxford Univ. Press, New York.

M. Lyle and A. Olivarez Lyle, Department of Oceanography, Texas A \& M University, College Station, TX 77843-3146, USA. (mlyle@ocean. tamu.edu)

J. Barron, U.S. Geological Survey, 345 Middlefield Road, Menlo Park, CA 94025, USA.

T. J. Bralower, Department of Geosciences, Pennsylvania State University, College Park, PA 16802, USA.

M. Huber, Department of Earth and Atmospheric Sciences, Purdue University, West Lafayette, IN 47907, USA.

A. C. Ravelo, Department of Ocean Sciences, University of California, Santa Cruz, Santa Cruz, CA 95064, USA.

D. K. Rea, Department of Geological Sciences, University of Michigan, Ann Arbor, MI 48109, USA.

P. A. Wilson, Southampton Oceanography Centre, Southampton SO14 3ZH, UK. 